Research Report

\title{
IMPACT OF COVID-19 PANDEMIC ON CIVIL SOCIETY ORGANISATIONS IN NIGERIA
}

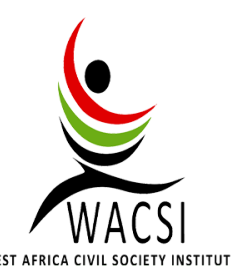

WEST AFRICA CIVIL SOCIETY INSTITUTE 


\section{Impact of COVID-19 Pandemic on Civil Society Organisations in Nigeria}

\section{Researcher:}

Dr. Gbemisola Abdul-Jelil Animasawun

\section{Editorial Team:}

Nana Asantewa Afadzinu

Emmanuel Kumi (Ph.D)

Nancy Kankam Kusi

Charles Kojo VanDyck

Lisa Emefa Sengretsi

Jimm Chick Fomunjong

Designed by: Michael Kumordzi Tetteh

\section{Copyright WACSI 2021}

All rights reserved. No part of this publication may be used or reproduced in any manner without written permission of the Institute except in the case of brief quotations embodied in critical articles and reviews.

\section{Disclaimer:}

WACSI accepts no responsibility for suitability of any materials submitted by the contributors of this publication. WACSI assumes no responsibility or liability for errors or inaccuracies. The author accepts all responsibility for opinions expressed. Use of this research report constitutes acceptance and understanding of these disclaimers.

For more information, write to:

West Africa Civil Society Institute (WACSI)

P.O. Box AT1956 Achimota

Accra, Ghana

Email: info@wacsi.org

Tel: (+233) 303937264

Cite as: WACSI (2021). Impact of COVID-19 Pandemic on Civil Society Organisations in Nigeria, West Africa Civil Society Institute, Accra, Ghana. 


\section{ABOUT PARTNERS}

\section{West Africa Civil Society Institute}

The West Africa Civil Society Institute (WACSI) was set up by the Open Society Initiative for West Africa (OSIWA) in 2005 to strengthen the institutional and operational capacities of civil society in in the West Africa based on critical needs assessments and consultations with key civil society constituents and policy makers.

WACSI's institutional strengthening approach has evolved and integrates the varying experiences of working with civil society organisations (CSOs) and development agencies. It is designed to assist an organisation and institution to engage in a process of assessments, reflection, and improvement, which is aimed at enhancing performance and the achievement of set targets.

\section{www.wacsi.org}

\section{Vision}

A peaceful and prosperous West Africa where development is driven by its people.

\section{Mission}

We strengthen civil society in West Africa to be responsive, collaborative, representative, resilient, and influential through knowledge sharing, learning, connecting and influencing.

\section{Wilde Ganzen Foundation}

The Wilde Ganzen Foundation is a Dutch NGO, founded in 1957 with a mission to reduce poverty and inequality through community-led initiatives. It supports community-based organisations in the Global South and their Dutch fundraising partners in joint efforts to achieve a better future because it believes communities should have control over their own development.

The Wilde Ganzen Foundation utilises more than 60 years of operational experience in international development to promote responsible philanthropy. The Wilde Ganzen Foundation supports social changemakers that are taking on initiatives to fight inequality. They do this through grantmaking, in-depth technical assistance, expertise and their onthe-ground networks. 


\section{ACKNOWLEDGEMENT}

This study was commissioned by the West Africa Civil Society Institute (WACSI) with support from Wilde Ganzen Foundation. It sought to understand the extent to which COVID-19 has impacted civil society organisations (CSOs) and provide knowledgebased findings to inform strategies for addressing the ruinous impact of COVID-19 on CSOs in Nigeria.

The Institute extends sincere gratitude to Dr. Gbemisola Abdul-Jelil Animasawun Centre for Peace \& Strategic Studies, University of Ilorin, Nigeria for leading on this research in Nigeria.

We also want to commend the Institute's team led by Jimm Chick Fomunjong, Christian Cedric Elongue, Charles Kojo VanDyck, Nancy Kusi Kankam, Sunday Jean Claude Kadi, Yse Auque-Pallez and Leandre Banon for the dedicated efforts that have been put in to ensure that this research is completed. For his suggestions and inputs in reviewing the report, the Institute extends its appreciation to Dr. Emmanuel Kumi.

This research would not have been possible without the participation of the eighty CSOs leaders who completed the questionnaire, the participants at the focus group discussion and those who granted interviews to the researcher; interviews with Mr. Hasheem Salahudeen, Senator Iroegbu, Adedamola Ogunsesan, Mary Job and Nathaniel Awuapila provided in-depth practitioner experiences and perceptions on the impact of the pandemic on CSOs in the country.

The Institute further extends gratitude to the team that worked closely with the researcher to ensure that such a comprehensive research is done. Special thanks to Fisayo Ajala and Olawale Gbadeyan who proved dependable and resourceful. 


\section{TABLE OF CONTENTS}

\section{ACKNOWLEDGEMENTS}

LIST OF FIGURES

LIST OF ABBREVIATIONS

1.0 INTRODUCTION

1.1

1.2

1.3

1.4

2.0

2.1

2.2 .

2.3 .

2.4 .

2.5 .

Background of the Study

Research Aims

Research Methodology

Outline of the Report

\section{LITERATURE REVIEW: CONTEXTUAL INFORMATION}

$\begin{array}{ll}\text { Overview of the Civil Society Sector in Nigeria } & 7\end{array}$

Brief Overview of the COVID-19 Pandemic 9

CSOs' Roles and Contributions in the Fight Against the COVID-19 Pandemic in Nigeria $\quad 10$ Impact of COVID-19 on Civil Society Organisations

\section{RESEARCH METHODOLOGY}

Research Design

Population and Sampling Frame

Data Collection Instruments

Data Analysis

\section{KEY FINDINGS}

Over CSOs Surveyed

Years of Existence of Organisations

Geographic Location of Organisations 17

Level of Operation 17

Thematic Areas 18

Impact of COVID-19 on Funding, Domestic Resources Mobilisation and Sustainability 19 Impact of COVID-19 on the Operations and Programmes of CSOs 19 Impact of COVID-19 on Funding, Resources Mobilisation and Sustainability 22 Impact of COVID-19 on CSOs' Role and Relationship with Stakeholders 27 Organisations' Active Cooperation with other CSOs and Beneficiaries to Mitigate the Effects of the COVID-19 Pandemic Specific Initiatives Implemented to Support Beneficiaries and Communities during COVID-19 


\section{LIST OF FIGURES}

Figure 1: $\quad$ Types of organisations 16

Figure 2: $\quad$ Year of establishment $\quad 17$

Figure 3: $\quad$ Geographic location of CSOs 17

Figure 4: $\quad$ Level of CSOs' operation 18

Figure 5: $\quad$ Thematic focus of CSOs 18

Figure 6: $\quad$ Donors informing CSOs about the impact of COVID-19 on funding 19

Figure 7: $\quad$ Closure of office due to COVID-19 20

Figure 8: $\quad$ Short-term impact of COVID-19 on CSOs 20

Figure 9: $\quad$ Long-term impact of COVID-19 on CSOs' operation in 6-12 months. 21

Figure 10: $\quad$ Extent of CSOs' ability to provide services to beneficiaries during the COVID-19 pandemic. $\quad 21$

Figure 11: Dismissal of staff by CSOs due to COVID-19 22

Figure 12: Impact of COVID-19 on organisational funding 22

Figure 13: COVID-19 and organisational funding in the next 3-6 months 23

Figure 14: $\quad$ Survival of CSOs in the next 6-12 months 23

Figure 15: Availability of organisational reserves 23

Figure 16: Mobilisation of domestic resources by CSOs during the COVID-19 pandemic 23

Figure 17: $\quad$ Sources of domestic resources for CSOs during the pandemic 24

Figure 18: COVID-19 and opportunities for mobilising domestic resources $\quad 24$

Figure 19: Domestic resources mitigating against the impact of COVID-19 25

Figure 20: The capacity (technical, personnel and material) to mobilise domestic resources to support their activities during the COVID-19 pandemic

$\begin{array}{lll}\text { Figure 21: } & \text { Ability of CSOs to sustain their activities with existing resources } & 26 \\ \text { Figure 22: } & \text { CSOs' perception of feeling distressed about their sustainability } & 26\end{array}$

Figure 23: To what extent will COVID-19 affect the overall sustainability of the CSO sector in your country?

Figure 24: $\quad$ Are you certain that your project activities can be sustained by intended beneficiaries after COVID-19 pandemic

Figure 25: Is your organisation actively involved in working with other CSOs and beneficiaries to mitigate the effects of the COVID-19 pandemic

Figure 26: What specific activities/initiatives have you undertaken as an organisation to support beneficiaries and communities during the covid-19 pandemic

Figure 27: What specific response activities have you undertaken as an organisation to support beneficiaries and communities during the COVID-19 pandemic?

Figure 28: Do you think your funders/donors will change their priorities after the COVID-19 pandemic?

Figure 29: In mitigating the effects of COVID-19, which of the following issues have you discussed with your donors?

Figure 30: How would you rank the flexibility of your donors with regards to the needs of your organisation during the COVID-19 pandemic?

Figure 31: What do you think are your top needs requiring assistance from donors and stakeholders to mitigate the impact of COVID-19 on your organisation? 


\section{LIST OF ABBREVIATIONS}

BRICSOS
CBOs
CIDA
CSOs
FGDs
GHRP
GOCSOs
IDI
IOCSOs
LEAs
NCDC
NGOs
NNNGO
PTF
UN
WACSI
WHO

\author{
Brief-Case Civil Society Organisations \\ Community-Based Organisations \\ Control of Infectious Diseases Act \\ Civil Society Organisations \\ Focus Group Discussions \\ Global Humanitarian Response Plan \\ Government owned Civil Society Organisations \\ In-Depth Interviews \\ Individual Owned Civil Society Organisations \\ Law Enforcement Agents \\ Nigerian Centre for Disease Control \\ Non-Governmental Organisations \\ National Network of Non-Governmental Organisation \\ Presidential Task Force \\ United Nations \\ West Africa Civil Society Institute \\ World Health Organization
}

\section{PHOTO CREDITS}

Page 1: photo from Shutterstock

Page 3: photo from https://english.alarabiya.net/

Page 4: photo by Jesuit Refugee Service International on flickr.com

Page 5: photo by Jesuit Refugee Service International on flickr.com

Page 7: photo by Ebun Akinbo via IMF on flickr.com

Page 8: photo by Nur via Getty Images

Page 9: photo by Afolabi Sotunde via REUTERS

Page 10: photo from Federal Ministry of Health, Nigeris

Page 12: photo from http://sandbox.fmnplc.com/

Page 14: photo by Kunle Ogunfuyi on flickr.com

Page 16: photo by https://www.naijaloaded.com.ng/

Page 19: photo by https://nairametrics.com/

Page 24: photo by Ebun Akinbo via IMF on flickr.com

Page 32: photo by Ebun Akinbo via IMF on flickr.com

Page 33: photo by Ebun Akinbo via IMF on flickr.com

Page 35: photo by Grace Ekpu via The Guardian

Page 37: photo by Awwal Bissala on flickr.com

Page 38: photo by Ebun Akinbo via IMF on flickr.com

Page 2,13,34: $\quad$ photo by Jakayla Toney on Unsplash

Page 5,15,36: photo from pixabay 


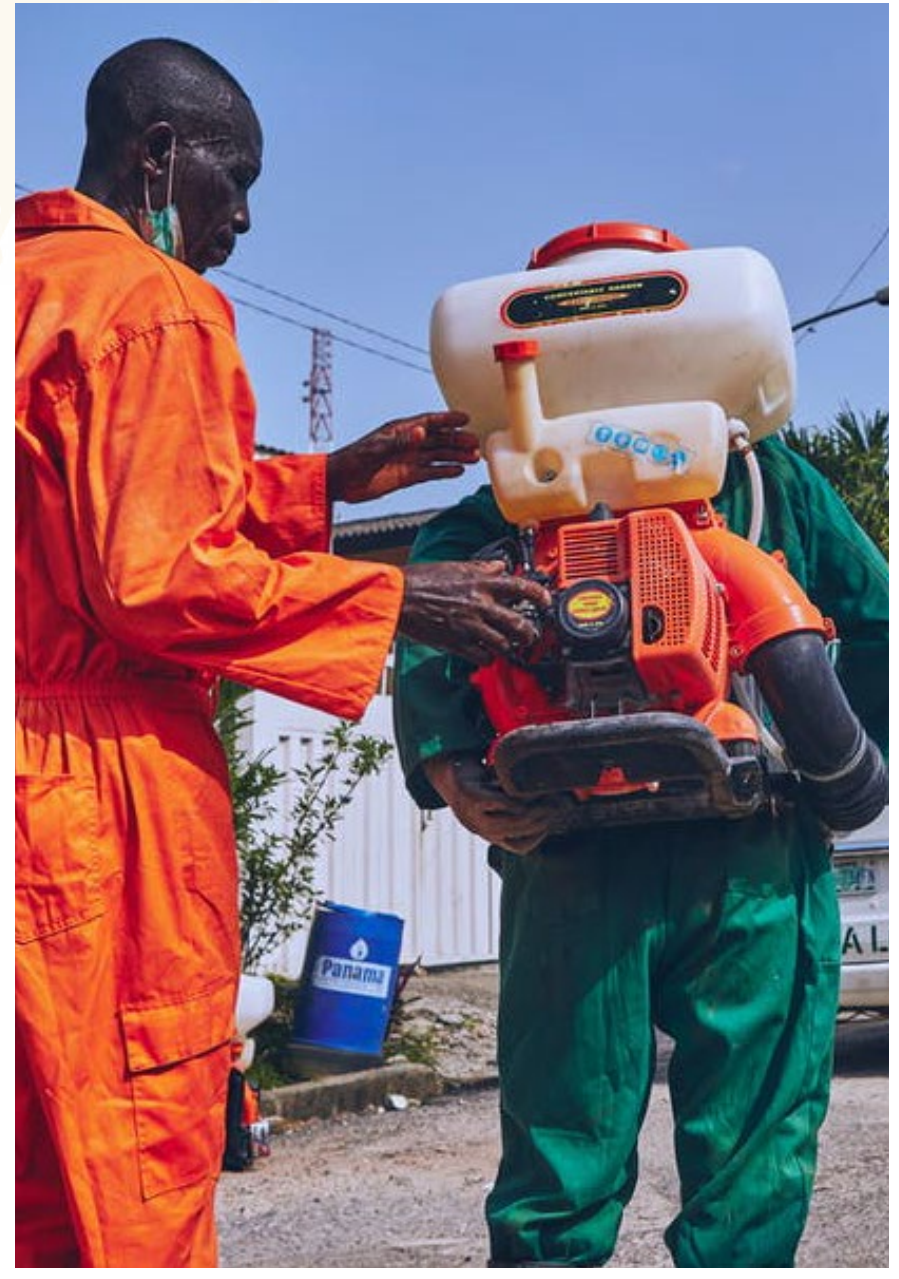

\section{EXECUTIVE SUMMARY}

The outbreak and protraction of the coronavirus disease (COVID-19), now a global pandemic, has crippled the activities of many civil society organisations (CSOs) across Africa, including Nigeria. In order to ameliorate the effects, facilitate their recovery and guarantee survival in post-pandemic Nigeria, responses must reflect empirical realities; which justifies the timeliness and relevance of this study.

Informed by the preceding, the aim of this study was to document the impact of the COVID-19 pandemic on CSOs' operations. It further sought to identify areas where CSOs need to shore up their capacities and how to go about it. Also, the study explores how WACSI can facilitate support to CSOs as well as specific areas where CSOs themselves need to internally reform.

The study used the sequential explanatory mixed methods approach as its design. This entailed the generation of quantitative data from eighty (80) CSOs that voluntarily participated in the study through an electronically administered questionnaire in compliance with COVID-19 regulations. This was complemented with qualitative data garnered from a focus group discussion (FGD), which was attended by four out of the six invited participants representing CSOs working on peacebuilding, the environment and use of technology for delivering educational services. Also, five in-depth interviews (IDI) were conducted with purposively selected respondents. All of these went on alongside reviews of literature on resilience, civic space and COVID-19 in Nigeria.

Findings revealed that state responses like lockdowns, border closures, physical and social distancing protocols and bans on public gatherings, placed unimaginable strains on CSOs and their beneficiaries. This was expressed by more than $88 \%$ of the CSOs who had to completely close their offices and suspend their operations and programmes. Furthermore, $72 \%$ of CSOs experienced restrictions of staff movements with $70 \%$ of CSOs cancelling meetings, conferences and local and international travels. COVID-19 also exposed their overdependence on donors, shrunken reserves and weak technological infrastructure which were direly needed to stay afloat during the pandemic. In addition, over $55 \%$ of the CSOs lacked the capacity to mobilise domestic resources while $79 \%$ of the CSOs had no financial reserves at all. In coping and adapting to the uncertainty caused by the pandemic, most CSOs leveraged on technology and cooperation with networks.

In ensuring the survival of CSOs in the country, leading actors like the West Africa Civil Society Institute (WACSI) must provide leadership, support and coordination in expanding resources and upscaling CSOs' capacities with more in-country and regional networks of CSOs through which organisations can share experiences, learn from one another and support each other. Just as the government is providing relief and stimulus packages for other sectors, CSOs too should be supported through aid and grants to preserve their existence. Furthermore, this study posits that the unsavoury experiences faced by the CSOs and the public during the pandemic which exposed the draconian and obsolete nature of certain laws, spike and bestiality in domestic violence, unwarranted loss of lives and reported brutalisation of citizens by security and law enforcement agents (LEAs) while enforcing restrictions, should be used to develop areas of thematic collaboration, agenda setting for researches and advocacy by CSOs, policy makers and researchers in driving post-Covid-19 recovery. 


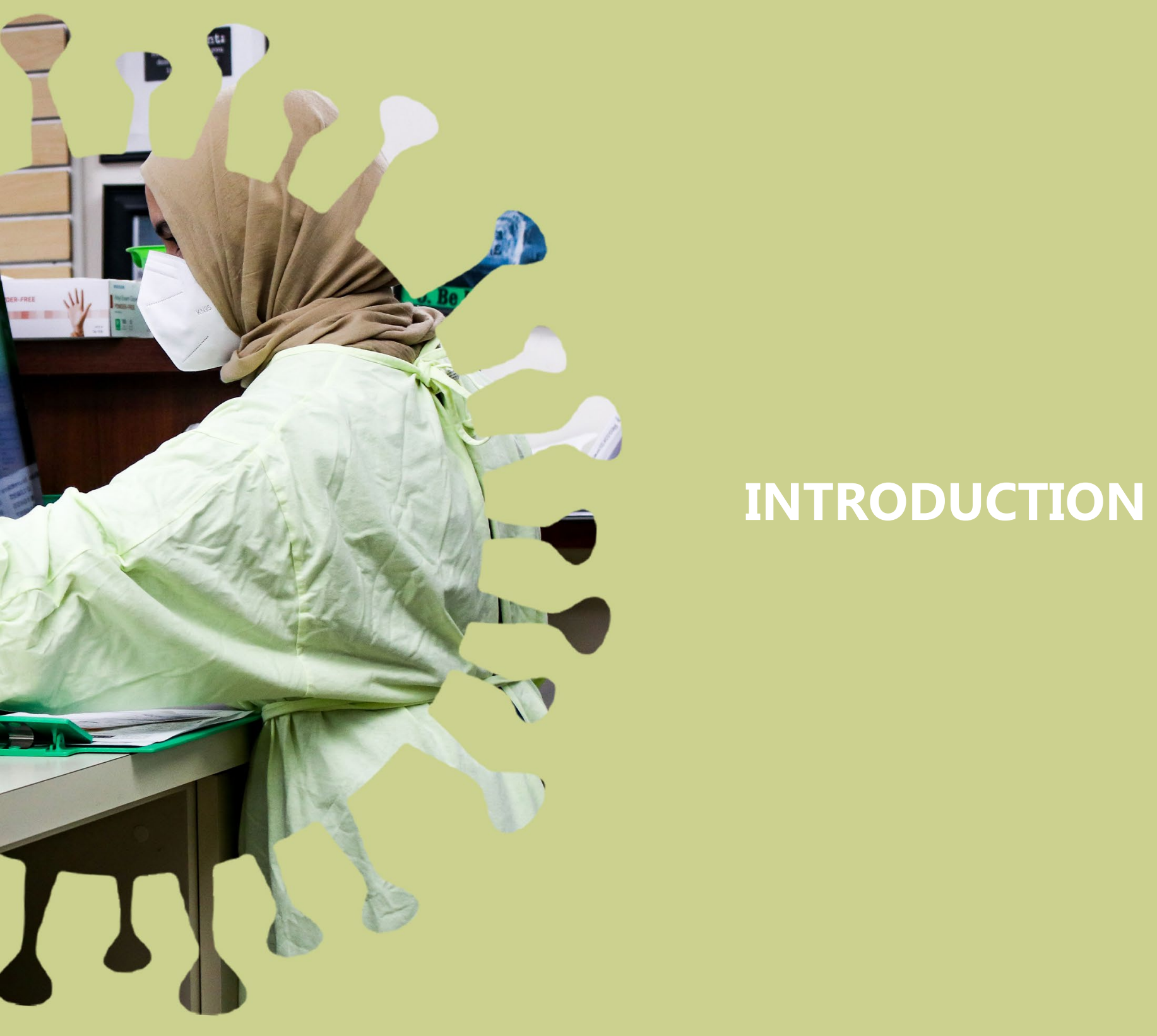

3 


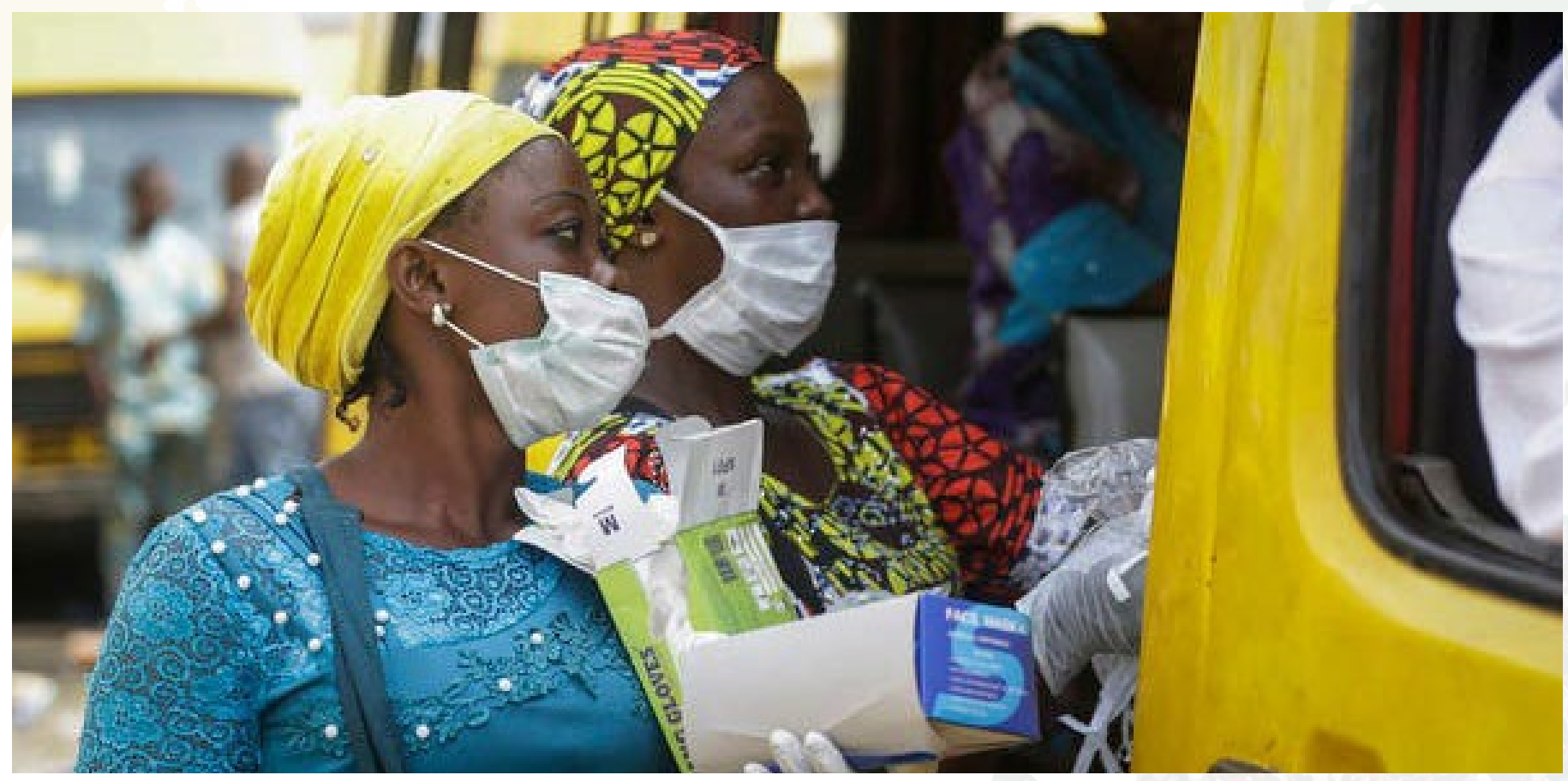

\subsection{Background of the Study}

"Major crises have major consequences, usually unforeseen. The more that is learned about COVID-19, the disease caused by the novel coronavirus, the more it seems the crisis will be protracted, measured in years rather than quarters. Poor countries with crowded cities and weak public health systems will be hit hard" (Fukuyama, 2020:1).

The contemporary generation of civil society organisations (CSOs) collectively called non-governmental organisations (NGOs) stands out in its commitment to 'restrict the state, democratise it, and/or take over its functions' (Kew, 2004:101). Practically, this has placed civil society in a strategic position to complement the developmental efforts of the state in addition to playing the role of a watchdog and ensuring the accessibility, quality and affordability of services to people.

As a country, Nigeria can be described as politically stable but physically insecure due to the spate and spread of insecurity arising from insurgency, militancy and communal conflicts, that have configured inhabited spaces in the country into three broad types. In the first category are communities where the authority of the Nigerian state is being contested. Examples of such are places where Boko Haram have seized some local government areas within the state especially in the northeastern part of the country. In the other grouping are states where the government has lost the capacity to impose order and has been compelled to negotiate or even pay outlaws to have a semblance of order across the north-west geo-political zone. In the third category are communities where inter-group violence has caused widespread militarisation as can be seen in many parts of the country from north to south (Animasawun, 2020).

As people living in fear and coping with low level of state presence, many residents in most of Nigeria's rural communities have had to rely on the CSOs providing a broad array of support and services for them to make life worth living. This is because CSOs have been actively filling the gaps created as a result of state incapacity and absence in both fragile and stable contexts across Nigeria. Therefore, the disruption in activities of CSOs as a result of COVID-19 have meant a direct blow on millions of Nigerians whose livelihood, support system and hope depended on these CSOs.

As indicated in the quotation above (Fukuyama, 2020), poor countries like Nigeria face the severest realities as a result of COVID-19. This is because of their teeming population, parlous state of their infrastructure, frailty of governments' capacity to provide public goods and the fact that for most of their population, living is striving (See Chabal, 2009). Although, Nigeria's containment of the Ebola virus outbreak in 2014 and current score on the Epidemic Preparedness Index (38.9\%) places her higher than African and global averages, the outbreak of the pandemic complicates an already precarious condition. In this context, what the outbreak of COVID-19 meant for Nigeria was captured succinctly by the Chatham House thus: 
"But the outbreak is compounding Nigeria's numerous pre-existing crises. It was already grappling with a Lassa fever outbreak that has claimed more than one hundred lives in 2020, the aftermath of recession, and conflict and insecurity within its borders".

CSOs have not been spared from this pandemic that has affected every facet of individual, corporate and international life. Also, across informal and formal trading spaces as well as learning and worship places, COVID-19 has imposed new ways of governance, resistance, and the provision of services. Therefore, commensurate with their diverse contexts, networks, and scope of engagements, CSOs' needs and responses to the impacts of COVID-19 differ from one context to another even within the same country.

Therefore, enhancing the capacity of CSOs to sustain their supportive role despite COVID-19 becomes paramount. This is pertinent not only for the purpose of cushioning the effects of COVID-19 on the vulnerable, but also in order to prevent negative outcomes especially in the contexts of state-society relations, worsening fragile inter-group relations and preservation of the sanctity of the civic space. This is because perilous times are often exploited to pervert civil society by military despots and kleptomaniacs such as how Nigeria under Babangida and Abacha saw the 'manufacturing of civil society' (Obadare, 2004:139), whereby the regime covertly created and funded CSOs with sinister anti-democratic agenda to masquerade as democratic voices in the public sphere.

Since its outbreak in Nigeria, the strain, fear and anxiety placed on relationships in formal, informal and even intimate contexts by COVID-19 has been causally linked to an unprecedented rise in cases of domestic violence and breakdown of public order which became a shadow pandemic in Nigeria (UN Women, 2020). The need to complement the efforts of health workers and to respond to breaches of law and order, led the police in Nigeria to issue an "NPF COVID-19 Guidance Booklet" spelling out how its personnel should relate with the public while enforcing Covid-19 restrictions in order to ensure civility in their conduct.

So, as a pandemic that became an emergency for both state and non-state actors, the central research question underpinning this research is: How are CSOs, especially

1 Examples are the emergence of the Association for Better Nigeria (ABN) led by Senator Arthur Nzeribe that secured a late night injunction on June 10, 1993 to stop the June 12, 1993 Presidential election. Also, Daniel Kanu's group known as Youths Earnestly Ask for Abacha (YEAA) was one of the many that came to beg Abacha to transmute from a military head of state to a civilian president

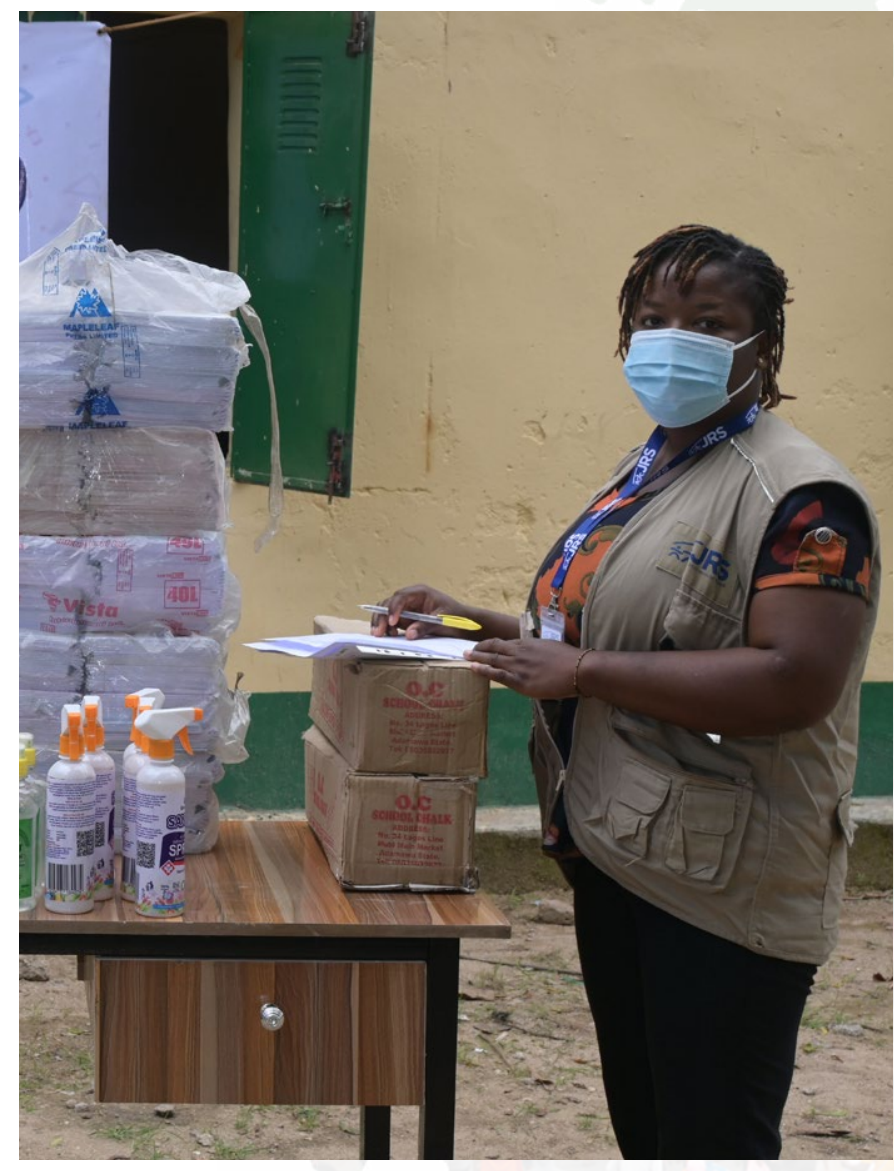

community-based organisations (CBOs) in Nigeria adapting and responding to the COVID-19 situation?

This study contributes towards enriching learning opportunities through comparing and sharing experiences on the factors that have influenced civil society's responsiveness, resilience, and adaptability across West African countries. With this clear and contextual understanding of CSOs' needs and responses to the COVID-19 pandemic, it will be possible to design and implement the appropriate and context-relevant civil society strengthening programme that would help CSOs to be more effective and resilient in their operations and interventions during and or post COVID-19.

\subsection{Research Aims}

\section{The specific aims of this study are outlined below:}

1. To document the impact of the COVID-19 pandemic on CSOs' operations.

2. To support selected CBOs with capacity building and provision of technological resources enabling them to continue their work.

3. To help CSOs identify the kind of support they require as a result of the pandemic.

4. To help CSOs ascertain the support WACSI can provide consequent upon the vagaries of COVID-19.

5. To help CSOs to know specific areas they must internally reform. 


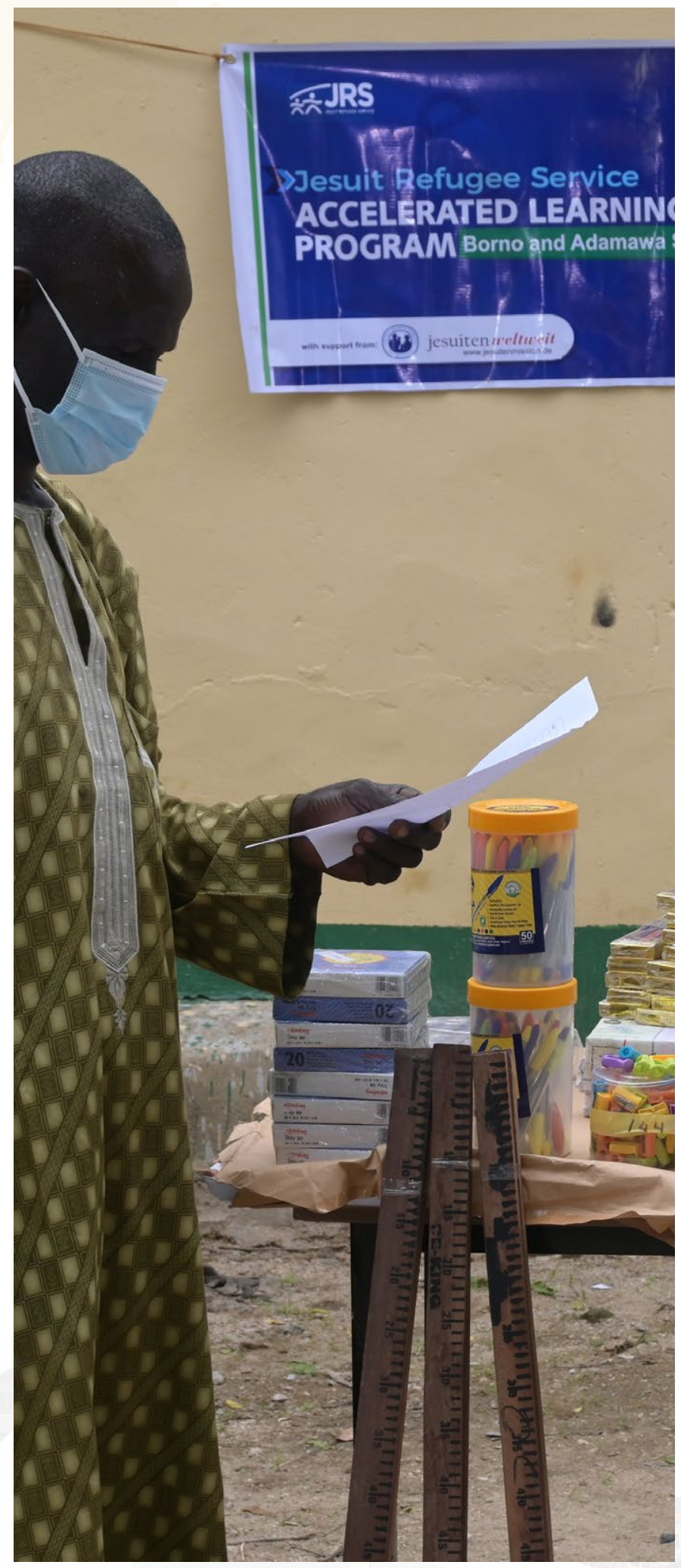

\subsection{Research Methodology}

This study employed the sequential explanatory mixed methods design whereby the qualitative data were generated to deepen the analyses of previously generated quantitative data from eighty (80) CSOs that freely participated in the study. A focus group discussion (FGD) was organised and attended by four out of the six invited participants representing CSOs working to promote peace, environment issues and use of technology for delivering educational services.

Also, five in-depth interviews (IDI) sessions were conducted with purposively selected respondents. All of these went on alongside reviews of literature on resilience, civic space and COVID-19. Also, a mapping of the actors and critical stakeholders to intimate them about the research and enlist their cooperation to be part of it at every stage by being available for interviews and FGDs was done.

\subsection{Outline of the Report}

Following this introduction, the next section presents a review of the literature contextually focused on overview of the civil society universe in Nigeria, an overview of the COVID-19 situation in the country, the roles of CSOs and their input to the resistance and mitigation of the impact of the pandemic. The succeeding section concentrates on the impact of COVID-19 on civil society organisations and their strategies for coping and self-preservation. The challenges that accompany surviving during the pandemic concludes the section on literature review.

Next, is the section on methodology wherein the research design, population and frame of sampling, instruments used for generating data, and analysis of data are detailed. Thereafter comes the presentation and analysis of data, summary, conclusion and recommendations and lastly, the teasing out of the implications of the research findings for policy and practice. 


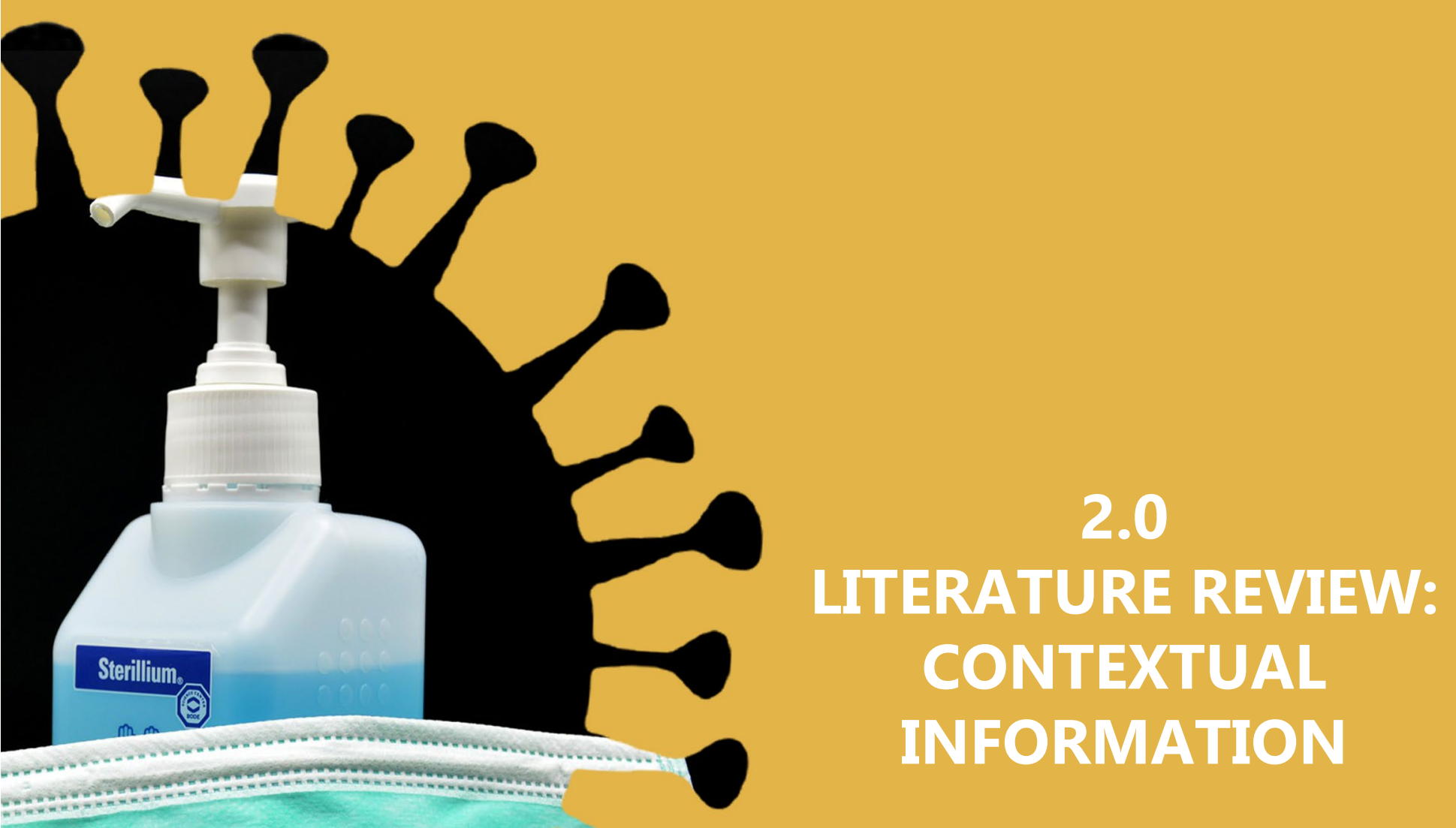

\section{CONTEXTUAL INFORMATION}

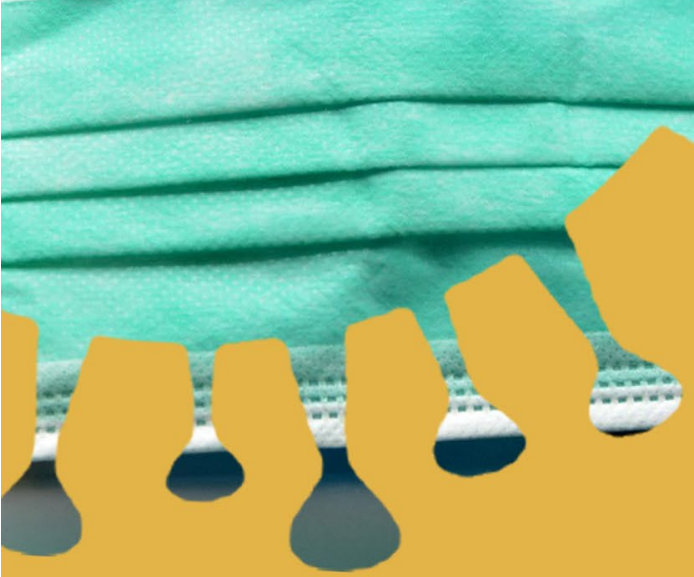



The present crop of CSOs are donor driven, and have their projects tied to donor requests (Obadare, 2014). They leverage on the use of social media and its fast users for their online and offline campaigns. Through this, they have carried out several advocacy campaigns, aimed at both political office holders, law enforcement agents, and the government. One of the most audacious in recent times was, \#OccupyNigeria, in response to the fuel subsidy removal by the Goodluck Jonathan administration in 2012 (Egbunike and Olorunnisola, 2015). It was a protest led by civil rights and labour activists, opposition politicians, student associations, socially conscious artistes and musicians, professional associations and other categories of the Nigerian public, with support from organised labour groups, who occupied public spaces in defiance of the subsidy removal (Obadare and Adebanwi, 2013). The subsidy removal protests championed by the \#OccupyNigeria group gave further impetus for other social-media conceived, and offline birthed advocacy campaigns, such as the Bring Back Our Girls Campaign (BBOG), \#OccupyNASS, \#OpenBudget, \#NotTooYoungtoRun, \#EndSARS, etc.

While they have mostly proliferated in the past two decades, several are being described in non-placatory terms such as government owned CSOs (GOCSOs), individual owned CSOs (IOCSOs), and briefcase CSOs (BRICSOS) (Smith, 2010). The present crop of CSOs are mostly funded and driven by donor funds and demands, which exposes them to public criticism and dependence on donors. Their reliance on Western funding, among other reasons, has instigated a barrage of legislative proposals aimed at whittling down their capacity in Nigeria. These proposals, which have been challenged by different nongovernmental organisation (NGO) coalitions on social media and other public fora, are incidentally spurred by global demands to protect the NGO sector from being used for sinister purposes. However, the legislative approaches adopted by Nigerian lawmakers and the government have been described and criticised as aimed at systematically undermining the legitimacy of CSOs in the country. For instance, the calls for the establishment of an NGO regulatory commission, despite the existence of existing legislative frameworks and agencies that overlook the activities of CSOs in the country has been roundly rejected because it is seen as a veiled attempt at suppressing CSOs (Ibezim-Ohaeri, 2017).
It is important to note that the political brick walls mounted against civil society is not limited to Nigeria alone. According to a 2019 Freedom House Report, not less than 12 African countries have adopted different forms of anti-NGO framework legislations that seek to restrict civil society's work within the last 15 years. These measures include the:

"establishment of onerous registration
requirements that are subject to broad bureaucratic
discretion, the limiting, capping, or excluding
foreign funding and staff hires, improper state
interference in the internal affairs and operations
of civil society organisations, and the exclusion of
organisations from material areas of activity that
are deemed political"(Musila, 2019: 3).

These measures are especially targeted at CSOs working in the areas of human rights and civic engagement, and the overall objective has been to "delegitimise civil society and civic engagement as legitimate space for citizens and cast doubt on the credibility of autonomous civic spheres that can activate and channel citizens' interests and demands" (Musila, 2019:4).

Despite these challenges, the civil society sector in Nigeria has recorded unprecedented growth and expansion in the past two decades. It has served as an effective watchdog in keeping politicians and public office holders accountable in their electoral duties and political promises. They have also performed creditably well in the areas of political mobilisation and sensitisation, legislative advocacy, law enforcement reforms, social rights and economic justice, transparency and anti-corruption. As of 2020, the actual number of CSOs in Nigeria is imprecise although it keeps soaring as analysed by Mohammed et al. (2018: 169):

"The CSO sector in Nigeria ... includes more than 500,000 organisations, ranging from communitybased groups to professional and national organisations. In 2018, more than 92,000 CSOs (an increase from 90,000 in 2017) were registered at the national level with the Corporate Affairs Commission (CAC). It is difficult to estimate the total number of CSOs at the state and local levels, because CSOs register with various agencies or not at all."

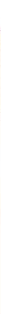




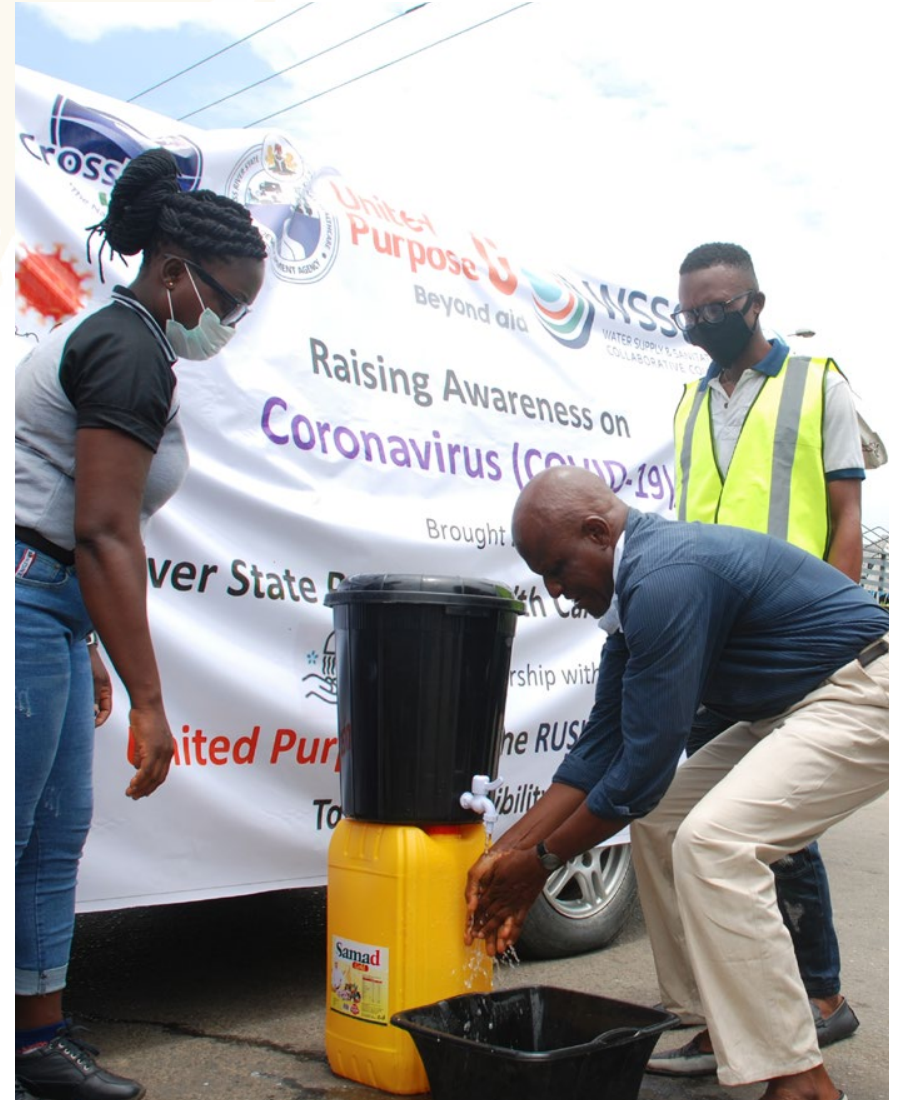

2.2. Brief Overview of the COVID-19 Pandemic

The novel coronavirus disease (COVD-19), which originated in the Wuhan city of China in December 2019 has emerged as the most pressing public health concern in recent times. It was caused by severe acute respiratory syndrome corona virus 2 (SARS-Cov-2) and is present in all continents. It was declared a global pandemic by the World Health Organization (WHO) on 11 March 2020 (WHO, 2020). Its rate of spread and transmission revealed a high level of unpreparedness at all levels (global, regional, and national) of human governance and security across the world. As of August 2020, over 18 million deaths and 600 thousand recoveries had been recorded from the COVID-19 pandemic globally. Likewise, the total statistics (deaths, recoveries, and infected) of COVID-19 in Nigeria within the same period was over 88,000 (Global Covid-19 NCDC Update, 2020).

Nigeria recorded its index COVID-19 case on 27 February 2020 in Lagos, its economic capital city. Between February and August 2020, more than 287,000 samples were tested across the country, with Lagos state and the Federal Capital Territory (FCT), Abuja, recording the most cases within the period (NCDC, 2020). The Nigerian Centre for Disease Control (NCDC) is the government's health agency in charge of managing COVID-19 emergencies. As part of its first efforts in managing the crisis, the Nigerian government in January 2020, established a multi-sectoral
Coronavirus Preparedness Group with representatives from the Federal Ministry of Health, Office of the National Security Adviser, World Health Organization and other international health agencies (NCDC, 2020). Subsequently, a Presidential Task Force on COVID-19 was constituted on March 9, 2020. The taskforce was mandated with the task of coordinating and overseeing the inter-governmental efforts of relevant government agencies, departments to contain the spread and mitigate the impact of the COVID -19 pandemic in the country (PTF, 2020).

Like its counterparts in Africa and other continents, the Nigerian government undertook various actions to prevent, contain and mitigate the spread of the COVID-19 virus in the country. These include travel bans, lockdowns and movement restrictions, social and physical distancing measures, self-isolation and quarantine and other public health actions. In mid-March 2020, the Nigerian government rolled out its first set of directives on containing and managing COVID-19; which was the issuance of a travel ban on commercial flights from high risk countries; with the exception of emergency and essential flights for medical and humanitarian purposes. This was also followed by compulsory health screenings at airports and border ports, 14 days of self-quarantine for arriving travellers who are not showing symptoms, and isolation measures for travellers showing COVID-19 symptoms (Adebowale, 2020).

By the end of March 2020, the Federal Government placed Lagos, Ogun and the FCT on lockdown for an initial period of two weeks. Schools, businesses, and organisations operating in these areas were suspended during the period. These lockdown measures were scaled up across various states of the country as each state adopted its lockdown measures. The lockdown was extended for another two weeks from April 13, 2020 up till April 28 when a gradual ease of lockdown measures was implemented. This phased easing of the lockdown was supported by regulations on enforceable actions on social and physical distancing protocols, religious and social mass gathering, use of facemasks, inter and intra-state travel, schools, businesses and organisations. There have been continuous updates and revisions to the ongoing phase 2 lockdown restrictions up to the time of writing. 
The Nigerian government embarked on different socioeconomic interventions to mitigate the impact of COVID-19 on its citizens. These included a moratorium for government funded loans, conditional cash transfer programme, distribution of food to poor and vulnerable households, and the delivery of dry food rations to households of pupils enrolled in the National Home Grown School Feeding Programme. ${ }^{2}$ Fiscal measures like the reduction of the benchmark crude oil price from USD 57 to USD 30, the promise of injecting NGN 1.1 trillion (USD 3 billion) into critical sectors of the economy by the Central Bank. In the same vein, there was a moratorium on all Federal Government funded loans issued by the Bank of Industry, Bank of Agriculture and the Nigeria ExportImport Bank. Furthermore, on April 1st, the Nigerian Electricity Regulatory Commission (NERC) put on hold, implementation of the payment of new electricity tariffs owing to poor electricity supply, wide metering gap and the impact of the COVID-19 pandemic. Subsequently, the National Assembly postponed the effective date of the new tariff to the first quarter of 2021. On October 11 just as the NERC suspended the Multi Year Tariff Order (MYTO) 2020 for the Electricity Distribution Licensees for 2 weeks.

However, there have been various controversies and corruption allegations surrounding the payment and disbursement of funds for COVID-19 palliatives in Nigeria (Haruna, 2020). It is unclear the impact of the various responses of the government to mitigate the effect of COVID-19, especially those who trade in the informal sector. Already, Nigeria's informal sector accounts for $65 \%$ percent of the working population (BoI, 2018). What is however known is that, the uncontrollability of the spread of the disease was due to a number of structural factors, notably, the lack of a public health infrastructure that could adequately respond to health emergencies, and absence of a robust social welfare system that caters for a significant number of the working, underemployed and unemployed population.

The multifarious social challenges arising from people's failure to comply with government's containment measures, and the relative unpreparedness of Nigerian security agencies in policing health emergencies led to extra-judicial killings and different categories of human right abuses and violations. There were 105 cases of human right violations, which led to 18 deaths by security forces. In addition to this, there have also been cases of gender and sexual based violence, as well as domestic

2 See www.statehouse.ng violence that has occurred within the context of the pandemic (NHRC, 2020). All of these have contributed to the precarious situation of COVID-19 in the country.

\subsection{CSOs' Roles and Contributions in the Fight Against the COVID-19 Pandemic in Nigeria}

Since the outbreak of the pandemic, the Nigerian civil society community, like their counterparts in other countries, have played very important roles in the fight against the COVID-19 pandemic. They have embarked on sensitisation campaigns, provided humanitarian aid, engaged poor and under-served communities, called for accountability and transparency on management and disbursement of COVID-19 palliatives, undertaken digital/ remote advocacy for victims of human rights abuses, challenged authoritarian policies and campaigned against legislative proposals that have far-reaching impacts on the current health crisis and beyond.

They have been able to achieve this through collaborative partnerships and active pulling of legal, human and financial resources to contribute maximally to ensuring justice for victims of human right abuses by security forces. For instance, a coalition of CSOs under the banner of the Action Group on Free Civic Space launched legal helplines to report incidents of COVID-19 human rights violations in Nigeria. Within a spate of four weeks, the Action group coalition handled 103 cases of human rights violations involving unlawful detention, extortion, assault, domestic violence, stigmatisation, and murder. They also granted free legal representation, secured police bails, and campaigned against using public health emergencies as pretext for continued closure of the civic spaces (Spaces for Change, 2020).

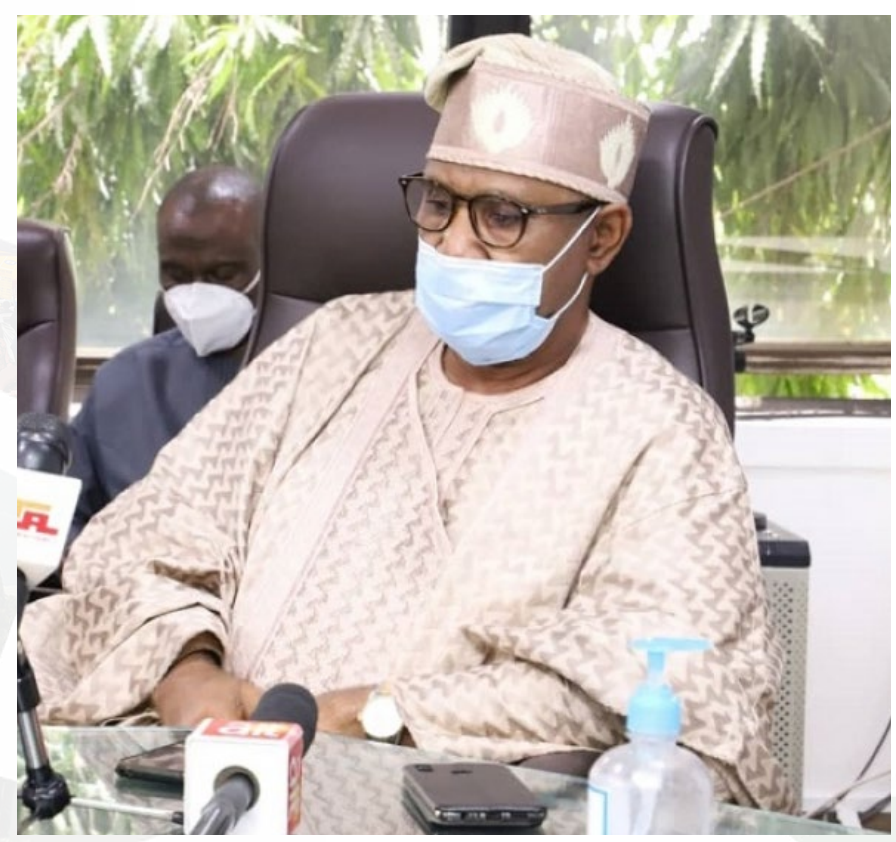


Perhaps the most recognisable contribution of CSOs to the fight against the COVID-19 pandemic is the campaign against the Infectious Diseases Bill that was hurriedly and perhaps stealthily passed by the National Assembly in early May 2020. The bill sought to repeal the outdated National Quarantine Act 2004, and replace it with a new law titled, Control of Infectious Diseases Act (CIDA) Bill 2020. The bill was criticised and rejected by CSOs because it gave uncircumscribed powers to the Nigeria Centre for Disease and Control (NCDC), Director General and the Minister of Health which would translate into a direct breach of the fundamental human rights and medial confidentiality of Nigerians in performing their functions of preventing, managing and controlling outbreak of infectious diseases in Nigeria. It also empowered police and health officers to carry out arbitrary arrest without warrant, confiscate and demolish properties, and obtain information from any person or organisation without any restraint. The Nigerian civil society coalition mobilised against the continued deliberation of the proposed legislation at a public hearing, forcing the national lawmakers to suspend the consideration of the diseases bill (Adebowale, 2020).

\subsection{Impact of COVID-19 on Civil Society Organisations}

Nigerian CSOs, like their global counterparts, have been gravely impacted by the COVID-19 pandemic. This impact has been felt regardless of the sectors in which they function in, whether it is security, education, health, gender, housing, environment, human rights, legislative and policy advocacy. According to the Nigeria Network of NGOs (NNNGO), loss of funding has been one of the ways in which the NGO sector has been affected by the COVID-19 pandemic (NNNGO, 2020).

There have been losses of revenue from grants, cancellation of fundraising events, as well as loss of jobs and unpaid salaries. The COVID-19 pandemic has also put CSOs at risk of being abused for the purposes of money laundering in the name of donations and support to combat COVID-19. Fraudulent entities and sham CSOs may want to take advantage of the COVID-19 pandemic and exploit NGO vulnerabilities by carrying out digital fundraising activities and online donations at this precarious time (NNNGO 2020).

The outbreak and continued spread of the pandemic have created operational disruptions for several CSOs. The restriction on movement prevented them from holding programmes that require physical contact. This has impacted on their watchdog role, as some of these projects and interventions require engaging local communities to come together to participate in initiatives. This has created paucity of materials for the media especially in instances where CSOs rely on the media to broadcast some of their activities on matters revealing the abuse of power and other ills in the society. This has further limited the space for civic work in the time of COVID-19.

CSOs whose operations require physical interaction have suffered seriously since the outbreak of the virus because it has put a temporary stop to most of their activities. Bigger CSOs, with robust donor support, solid organisational structure, and working environment, have slowly transitioned to remote work. They have leveraged the importance of technology to organise webinars, meetings and other work-related activities. However, this has not been without its own challenges given the under-developed state of Nigeria's digital economy as such CSOs have incurred huge internet tariff and other operational costs during the period. Accordingly, CSOs in Nigeria as revealed in this study's survey, have indicated different areas in which they would like to be supported to mitigate the impact of the COVID-19 pandemic. These areas include, and are not limited to, long-term grants, capacity building for staff, volunteers and resource persons, and broad based financial, technical and technological support.

Perhaps learning from business entities, CSOs need to diversify and create avenues for sustainability beyond reliance on donor support. Given that only few CSOs in Nigeria are in the top percentile of entities that have strong organisational structures that can outlast their founders (Mohammed et al., 2018), helping them to develop strategic plans for sustainability becomes crucial. When asked in the course of this study, about the ways in which the West Africa Civil Society Institute (WACSI), and other international CSOs can help them to become resilient in the post-COVID-19 era, the dominant preference was for help in building capacity in the areas of resource mobilisation, funding for overhead and personnel costs, assistance in the development of contingency plans, and projects that can ensure resilience and continued operations.

2.5. Civil Society Organisations' Strategies for Managing Sustainability Challenges Amidst COVID-19

Disrupted by the sudden outbreak and protracted nature of the COVID-19 pandemic, CSOs in Nigeria and globally 


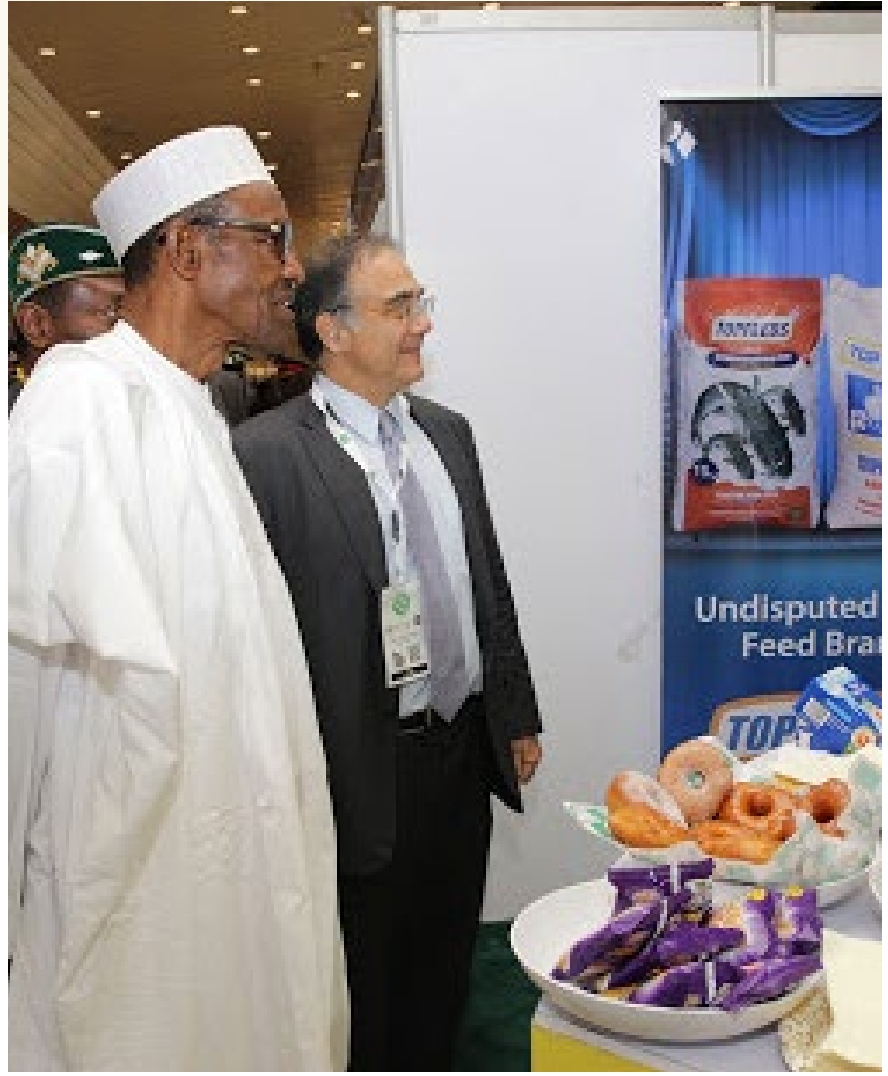

have had to explore coping strategies at a rapid rate albeit unpreparedly. Leading international organisations like the United Nations (UN) have provided leadership and direction through its agencies and allied organisations by sharing ideas, organising brainstorming meetings and webinars. At respective country levels, CSOs have been localising and adapting some of these ideas and initiatives with varied outcomes. Many of these CSOs have been 'learning and unlearning' almost simultaneously as they adjust to the complex realities forced upon them by the pandemic. The challenges thrown by COVID-19 can be seen from two main contexts. The first, described as constraints which speak to limitations, emergencies and losses in some cases imposed by the pandemic on CSOs' operations. The second are challenges, that is, unforeseen distress calls in the society that CSOs have had to be responding to directly and indirectly because of the pandemic.

In terms of constraints like funding and other operational limitations imposed by COVID-19, CSOs have not been left to fend for themselves by leading global institutions like the UN. In the Global Humanitarian Response Plan (2020: 3), the UN Secretary-General recognises that, "the world faces a global health crisis unlike any in the 75-year history of the United Nations - one that is spreading human suffering, crippling the global economy and upending people's lives." However, this should not translate into a suspension or diversion of attention and resources away from pre-COVID-19 activities because to do that will mean a loss of the gains and progress that have been made from investments in humanitarian action and in the Sustainable Development Goals. So, the need to devise strategies of sustainability during COVID-19 becomes imperative.

One of the ways of ingenuously coming up with strategies for sustainability is the Global Humanitarian Response Plan (GHRP). It identifies the most affected and vulnerable population groups in priority countries in a way that encompasses countries with pre-COVID-19 humanitarian response plan, refugee response plan or multi-country/ sub-regional response plan and those that have applied for international assistance such as Iran. The plan advocates that such plans should be reviewed towards creating room for emerging humanitarian needs triggered by the pandemic. Also, the possibility of creating a humanitarian response plan/Flash Appeal should be considered if they are unable to cope with the emergency.

Towards these, there are three areas of priorities. These are to contain the spread of the pandemic, attendant morbidity and mortality; reduce the deterioration of human assets and rights, social cohesion and livelihoods and the third is to protect, assist and speak up for the refugees, internally displaced people, migrants and host communities particularly vulnerable to the pandemic. These areas were made more specific by the SecretaryGeneral as critical areas for action thus: "First, tackling the health emergency. Second, we must focus on the social impact and the economic response and recovery. Third, and finally, we have a responsibility to recover better (GHRP 2020:8)." All of these are carried out to complement on-going efforts in respective member countries in strict adherence with humanitarian principles and a principle of adapting existing initiatives to alleviate the harsh realities of COVID-19 rather than creating new ones just because of the pandemic.

In carrying out their responsibilities amidst COVID-19, many CSOs have had to be creatively prudent as they adapt(ed) to the realities of COVID-19. One of the strategies they have come up with is relying on technology for their operations informed by the fact that many of them now have to work remotely in observance of the physical distancing protocols. For some, they have had to initiate new collaborations and to revive old networks as a way of optimising their use of resources. The use of social media and other forms of technology by CSOs has increased because it enables them to stay afloat while cushioning the effect of COVID-19 on their activities. 


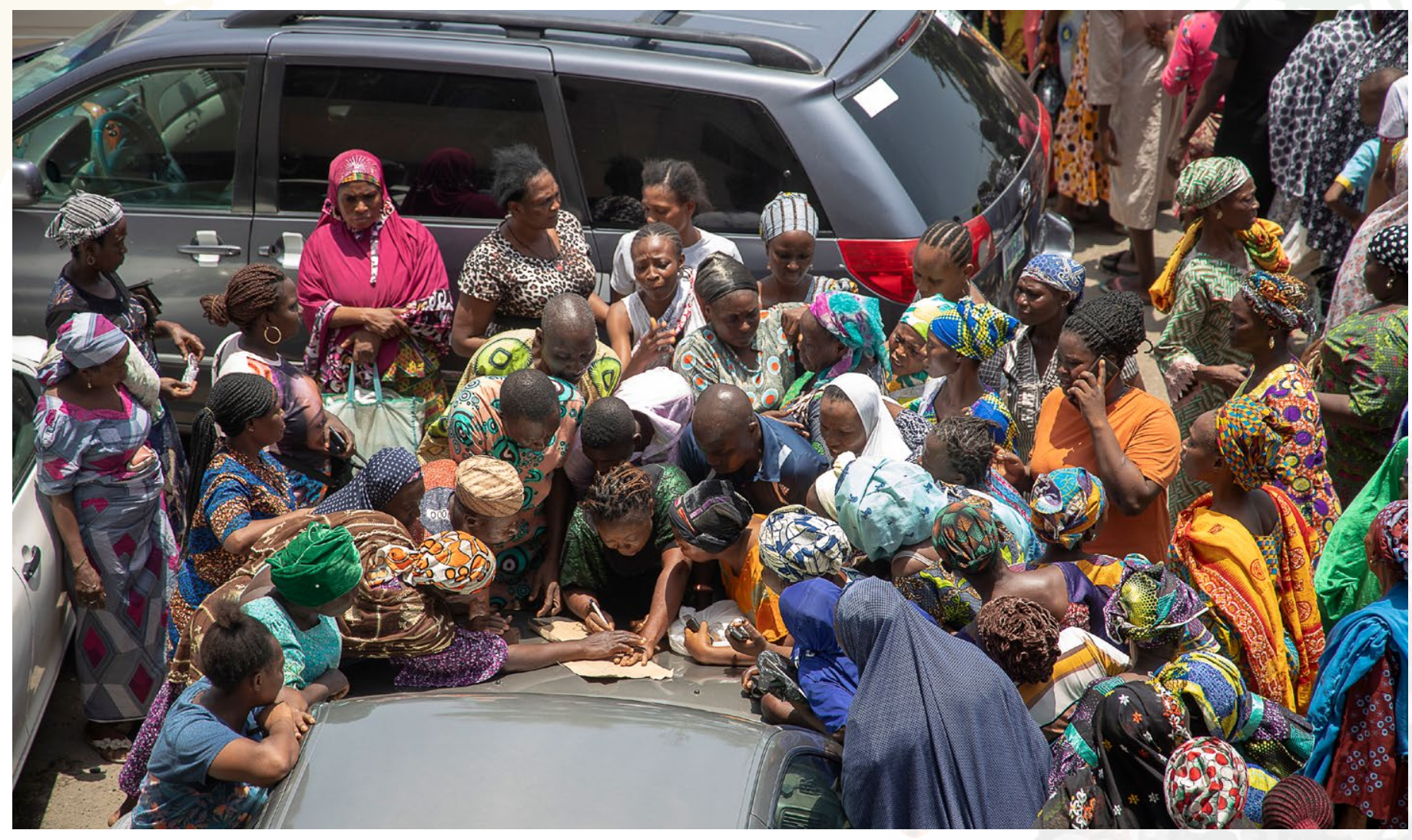

\subsection{Research Design}

Intended to explore, explain and describe how COVID-19 has affected the operations of CSOs in Nigeria, the study's design is sequential explanatory mixed methods (Northey et al., 2009). The study is exploratory to the extent that it raises questions aimed at generating responses on how the pandemic affected the operations of the CSOs and descriptive by presenting the responses in charts which are used as basis of explaining the impact of the pandemic on their operations.

\subsection{Population and Sampling Frame}

The population of the study is located in the broad sphere of registered CSOs in Nigeria from which the sample frame comprising eighty (80) organisations voluntarily participated. In addition, there were six CSO representatives comprising of founders and programme leaders that were purposively selected across the country's six geo-political zones. Of this, only four participated in the focus group discussions. These participants participated in the first phase of the research (quantitative) and were deliberately selected in order to elicit their perspectives on the realities across the country's six geo-political zones and to reflect the diversity of the spheres of operations of CSOs in the country.

\subsection{Data Collection Instruments}

The instruments used in this study were a questionnaire administered electronically through SurveyMonkey to eighty participating CSOs who earlier gave their consent to be part of the study. There was a session of an online focus group discussion with four out of the six invited participants conducted via Zoom. Also, indepth interviews were held with team leads of CSOs working on democracy, technology, eco-tourism and the environment, peace and security related issues. The interviews and focus group discussions were conducted electronically via Zoom. The discussions were recorded with the consent of all participants.

\subsection{Data Analysis}

The generated quantitative data were analysed into frequencies and percentages and presented using charts. The qualitative data were generated and transcribed according to themes developed from the aims of the study and used in corroborating, validating and querying the quantitative data where applicable. The qualitative data from the webinar were transcribed and used to corroborate/validate and to deepen the quantitative data. 


\subsection{Overview of CSOs Surveyed}

The CSOs in this study cut across the "operations" and "nonoperations" CSOs (Nesbit, 2003). The operational CSOs exist in two categories of member-serving organisations that provide services to CSOs of the organisation only and those described as public service organisations that provide services to beneficiaries, that is, members of the public whose affiliation with the member-serving organisation is not a condition for being supported (Nesbit, 2003). Found in a separate category are the nonoperational organisations which engage in activities such as research, advocacy, lobbying and fundraising.

As presented in figure 1, a total of 80 CSOs were sampled. Out of these, $1.2 \%$ were umbrella bodies or coalitions, another $1.2 \%$ constituted the "others" 3 , 3.5\% were social enterprise organisations just like faith-based organisations that were $3.5 \%$. NGOs constituted $70.9 \%$ while communitybased organisations represented $19.8 \%$. The dominance of the civil society landscape by NGOs is obvious going by the most significant percentile, that is, $70.9 \%$ while the coalitions also described as umbrella bodies formed $1.2 \%$. However, irrespective of their statistical significance or/and insignificance, all of them were affected by the pandemic as will be seen in subsequent analysis.

3 "Others" as used in this study comprise organisations not directly reflected in the questionnaire used but whose missions and operations cut across those listed

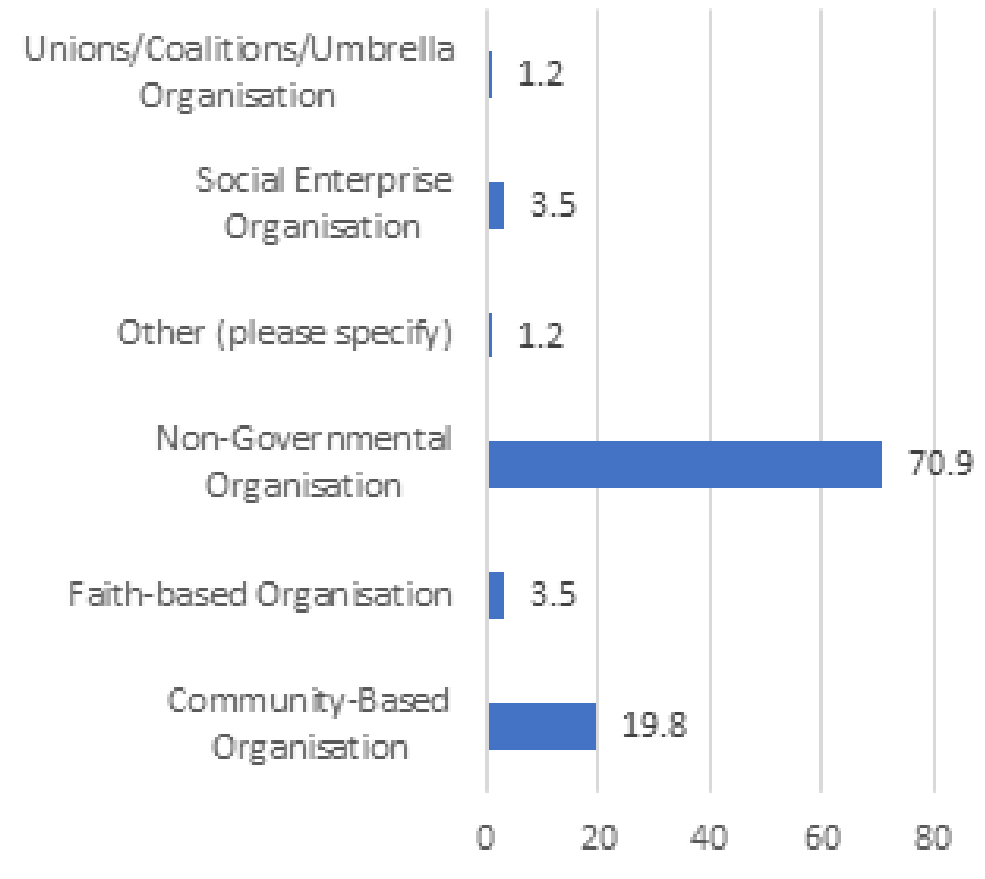

Figure 1: Types of organisations

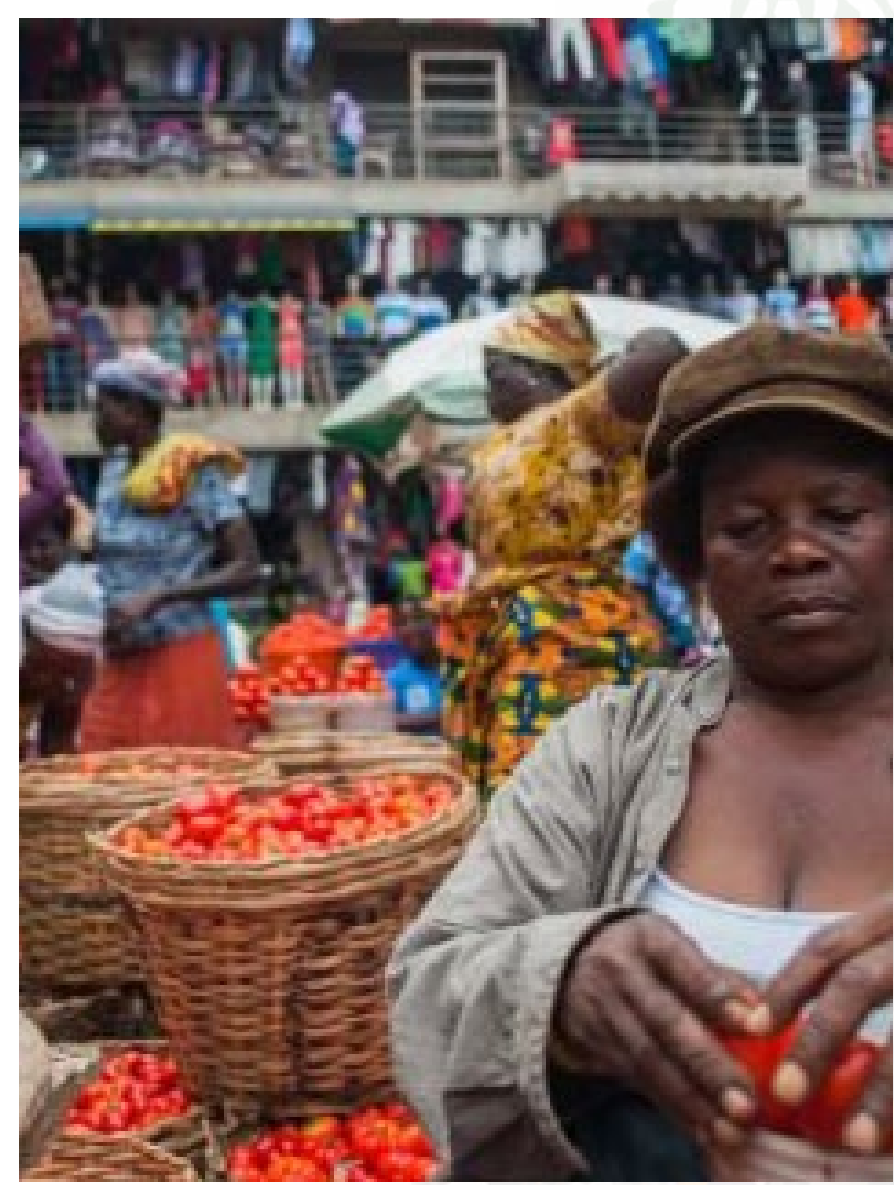

The findings reveal the diversity in the CSOs and the broad array of services and gaps they have been filling before and since the outbreak of COVID-19 in bridging the gap between the state and citizens. This is a pointer into how wide the constraint imposed on CSOs by COVID-19 would affect the populace across classes and even faiths.

\subsubsection{Years of Existence of Organisation}

In validating the literature that sequences emergence and trajectories of CSOs in Nigeria into three generations, the years of existence of the 80 CSOs in this study offers a reliable basis for understanding the impact of COVID-19 on CSOs. According to figure 2 below, $4.7 \%$ have existed for approximately twenty-one years (21 years) as at the time of conducting the study. Thirty of the eighty participating CSOs, representing $26.7 \%$ have existed for a period ranging from eleven to twenty years, $36 \%$ have been in operation for a period spanning six to ten years and thirty-five of the CSOs representing $32.6 \%$ less than six years old in operation. 


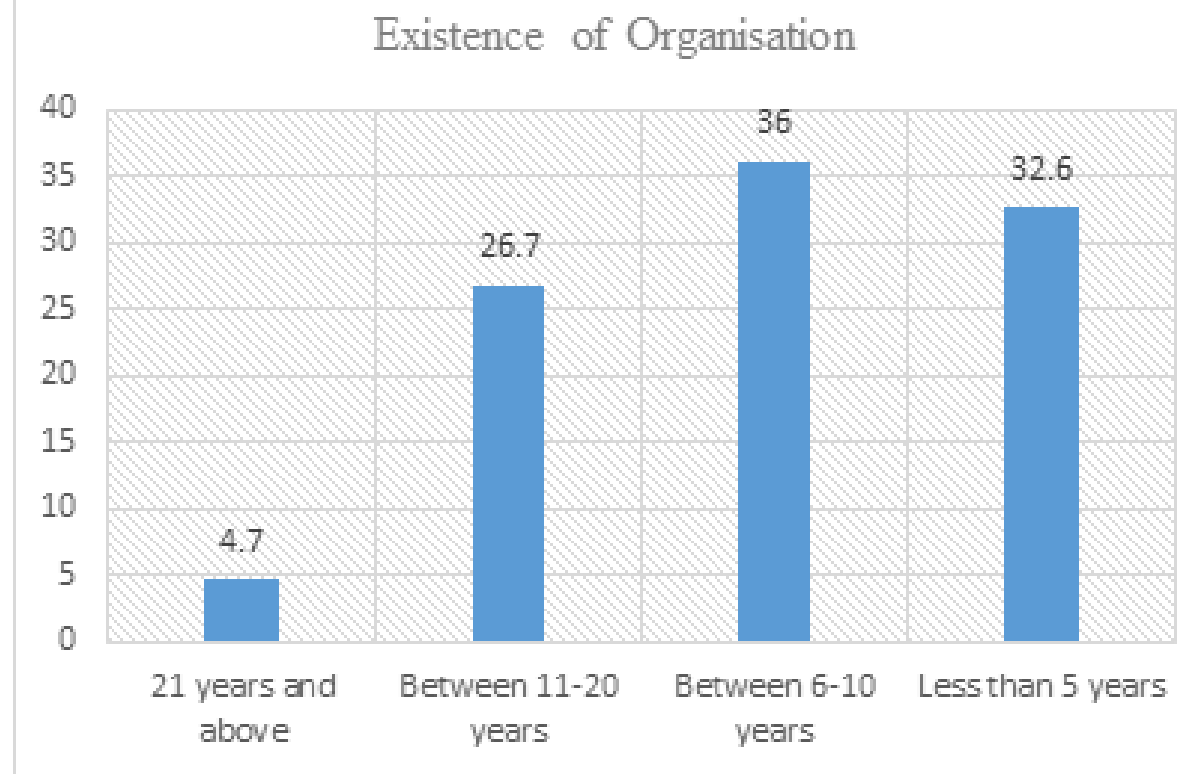

Figure 2: Years of existence

Figure 2 above shows that the length of the existence of these CSOs does not guarantee immunity from COVID-19 and that the pandemic has not been a respecter of age in the way it afflicts institutions.

\subsubsection{Geographic Location of Organisations}

Much as one may not fully subscribe to the argument of Diamond (1999) quoted in Moss (2007: 95) that "geography is destiny", geography indeed matters for analysing how COVID-19 has constrained institutions like CSOs. As presented in figure 3, forty-two percent (42\%) of the sampled CSOs are located in the state capitals, twenty-two percent (22\%) are in the urban areas, twentyone percent $(21 \%)$ in the sub-urban areas and fifteen percent (15\%) are in the rural areas.

The results in figure 3 provide an empirical basis for examining how COVID-19 impacted CSOs in the urban and rural communities where most of the country's

\section{Geographic area location}

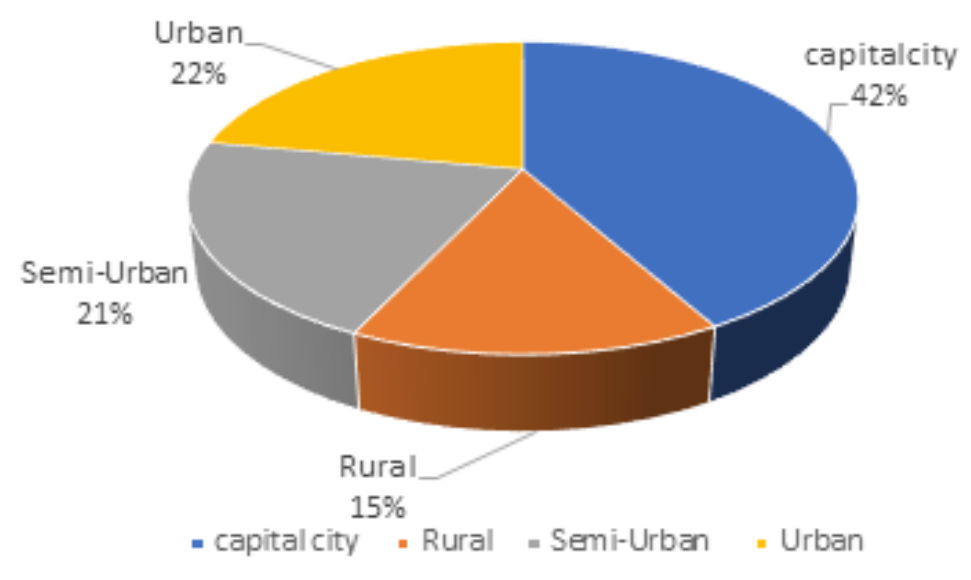

Figure 3: Geographic location of CSOs
200 million people reside and where the absence of government is acutely felt. Figure 3 reveals the spread, presence, potential and actual impact of the CSOs in the rural areas and urban areas in terms of presence and being readily available especially in providing service for the masses. The services of the public service CSOs are needed more in the rural and sub-urban areas and that is where they were less present before the outbreak of COVID-19; a situation made worse since the outbreak of the pandemic.

\subsubsection{Levell of Operation}

A major factor that helps in identifying CSOs is their geographical focus. Out of the eighty organisations, precisely $11.6 \%$ were regional in their focus, $1.2 \%$ operate at the regional level focused on policy and a similar $1.2 \%$ had a combined focus that was both international and national (see figure 4). The CSOs with interests cutting across community, regional and national were $1.2 \%$. Next to them are those whose areas stretched through community, district, national and regional that made up $2.3 \%$. There were those working in communities, districts and regions that made up $1.2 \%$ of all the CSOs that took part in this study. Those limited to just community and national physical spaces constituted 3.5\%. There were $27.9 \%$ with strictly national focus, $9.3 \%$ with a district centred focus, those working in districts and communities were $7 \%$ and those working strictly in communities were $32.6 \%$. The preceding shows the geographical spread of the CSOs in Nigeria and a basis for appreciating how far-reaching the effects of COVID-19 could have been on the communities who constitute the recipients and beneficiaries of these CSOs' programmes and initiatives across the country. 


\section{Level of Organisation's Operation}

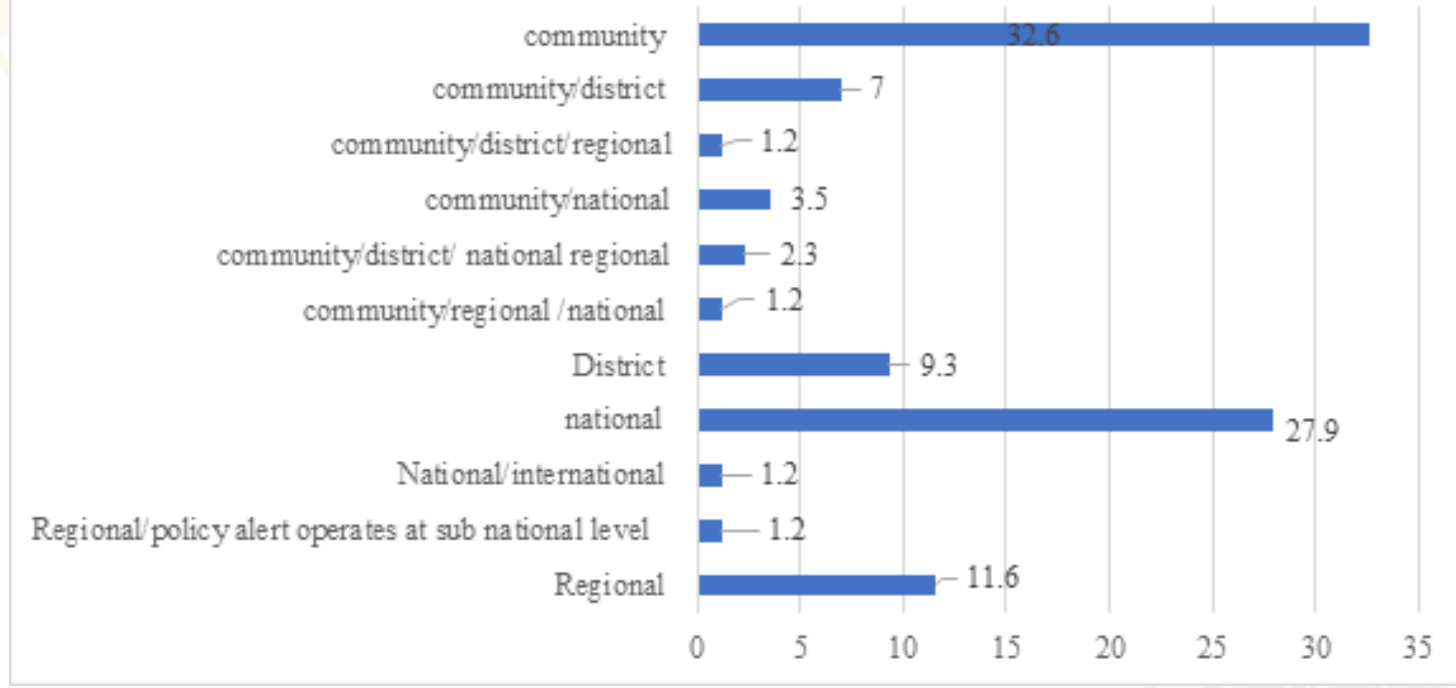

Figure 4: Level of CSOs' Operation

\subsubsection{Thematic Areas}

Although, many of the CSOs perform tasks that overlap and cut across different spheres, this does not take away the fact that they can be delineated according to their areas of thematic focus. The need to pay attention to areas of thematic focus is further underscored in anticipation of the support that might be required for cushioning and recovering from the effects of COVID-19.

\section{Main Thematic Areas}

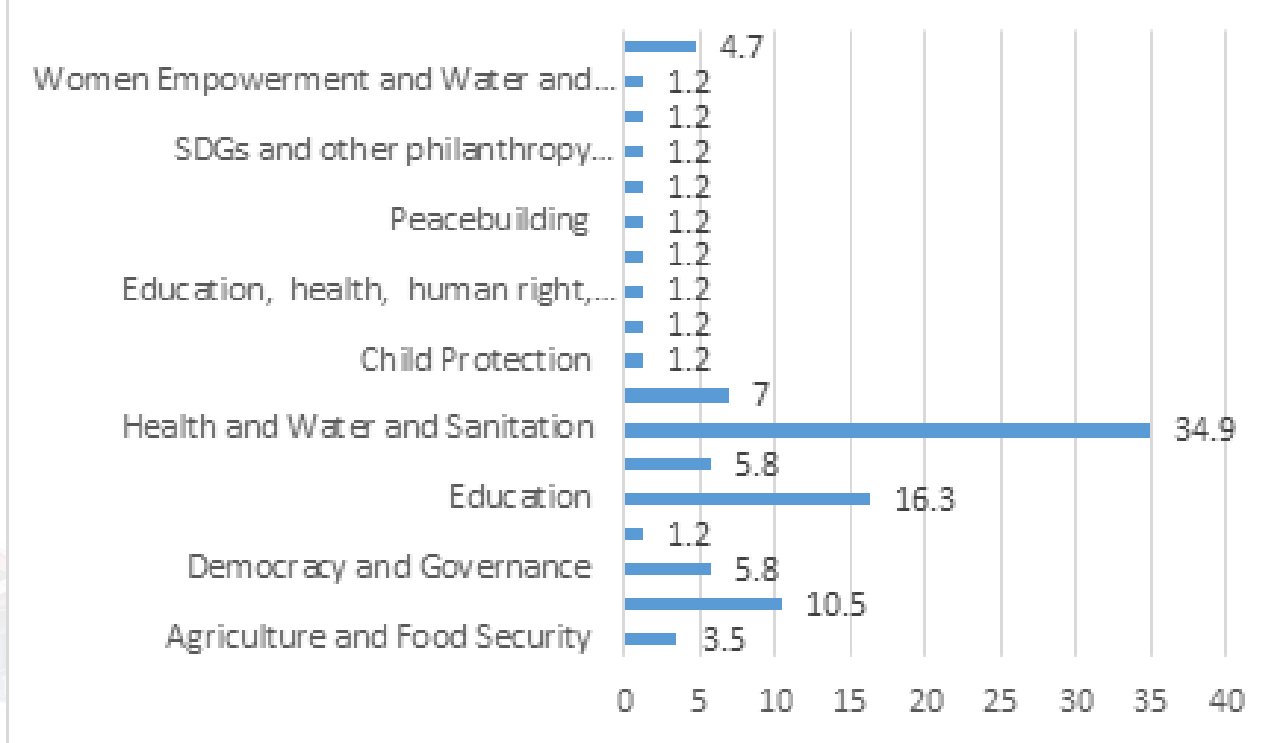

Figure 5: Thematic focus of CSOs

As presented in Figure 5, the majority of CSOs had thematic interests in health, water and sanitation $34.9 \%, 16.3 \%$ were focussed on education, $10.5 \%$ are focused on community development. There were $7 \%$ working on human rights, $5.8 \%$ were working on democracy and governance, $5.8 \%$ were working on wildlife and the environment, $4.7 \%$ focus on youths and $3.5 \%$ were devoted to agriculture and food security. In lower frequency, $1.2 \%$ of the CSOs worked respectively on women's empowerment and water sanitation, sustainable development goals (SDGs) and philanthropy, on peacebuilding, education, health, human and women's rights, child protection and the physically challenged. From the responses above, it is discernible that most of the CSOs in Nigeria are more of generalists than specialists in their activities. This chimes with the never-ending generalists-specialists debate in the CSO literature (AbouAssi et al., 2018). 


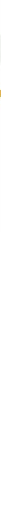

4.2. Impact of COVID-19 on Funding, Domestic Resources Mobilisation and Sustainability

A factor that is critical to the survival of institutions and initiatives like CSOs in both peace and pandemic periods is funding. Therefore, with the outbreak of the COVID-19 and its attendant impact on humans and institutions, it becomes expedient to examine how it has affected CSOs' funding, their sustainability and domestic resource mobilisation given that most CSOs in Nigeria survive on donor funding. Figure 6 presents the responses to the question on whether these CSOs have been told that there could be a drop in the volume of support from external sources because of the pandemic.

Have any of your funders informed you that COVID-19 may impact their ability to continue supporting your organisation

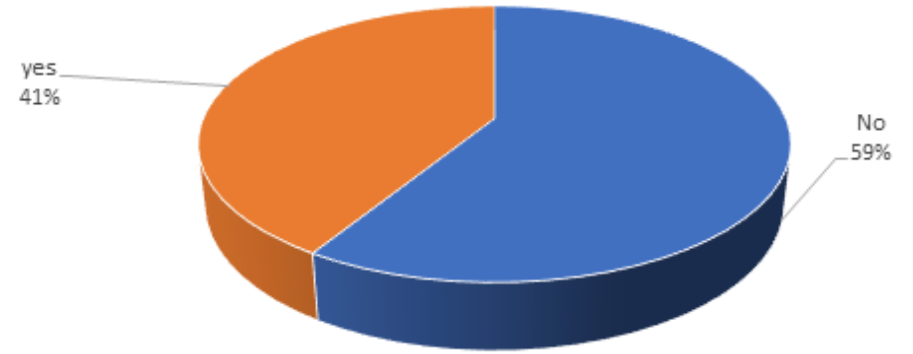

- No - yes

Figure 6: Donors informing CSOs about the impact of COVID-19 on funding

While the difference between those who have received indications that there might be a decline in funding from donors might be insignificant, the implications for the communities and individuals who are catered for by the CSOs will indeed be consequential. This is because, if taken as a reflection, it implies that more than $50 \%$ of CSO in Nigeria could be at-risk of dwindling resources as a result of the COVID-19 pandemic; a development that comes with dire implications given the level of socioeconomic, political and health fragility in the country.

Interactions during interviews and the FGD revealed that the sudden drop-in support constrained the delivery of services and operations of CSOs irrespective of domains of expertise as expressed by participants working on the environment, democracy, poverty alleviation and peace processes. Similar views were expressed during in-depth interview sessions.

For instance, while sharing her experience, the executive director of a CSO working on issues relating to development and democracy revealed that the paucity of funds has forced a downward review of over $75 \%$ in their overhead spending including consultancies. A similar experience was shared by a leading geographic information systems (GIS) expert and the Project Manager of a leading conservation foundation based in Lagos, "the pandemic compelled us to reshuffle work attendance of tour guides owing to the decline in the level of patronage."

\subsubsection{Impact of COVID-19 on the Operations and Programmes of CSOs}

The outbreak of the COVID-19 pandemic had several consequences on the operations, strategies and programmes of CSOs in the country. It is practical to investigate how the COVID-19 pandemic impacted on the operations and programmes of CSOs. Figure 7 below shows responses to the question on whether CSOs had to close their office during the COVID-19 partial or total lockdown.

4 Interview, conducted on August 17, 2020 
Did you ever have to close your office during the COVID-19 partial or total lockdown?

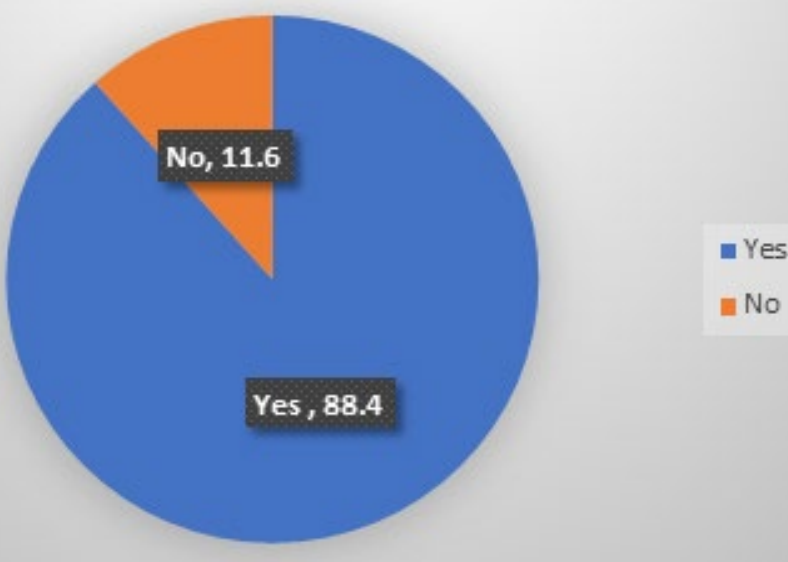

Figure 7: Closure of office due to COVID-19

As revealed in the figure 7 above, majority of the CSOs had to close their office during the COVID-19 lockdown. Out of the eighty CSOs that participated in the study, 88.4 $\%$ had to lockdown their offices thereby shutting down most of their operations and programmes. However, $11.6 \%$ of the CSOs indicated that they did not have to

close their offices during the pandemic national lockdown in the country.

Beyond the statistics, practitioners interviewed saw the impact of the lockdown as destabilising especially for initiatives like peace processes in communities that are transiting from conflict to peace or locked in intermittent conflict. This is because time and speed are crucial in sustaining the gains of such processes which are often incremental.

Also, a tech-expert who organises free summer bootcamps for pre-teens regretted that the 2020 edition could not be held on the usual scale because of the need to adhere strictly to COVID-19 regulations and protocols. In the words of a seasoned GIS expert, "as part of our reopening strategy after lockdown, we have introduced an online process of booking and reduced the duration of tours in addition to strict COVID-19 protocols for staffers and tourists." ${ }^{15}$ Therefore, the shutdown and inability to hold physical on-site deliberations meant reversal of some gains made prior to the outbreak of the pandemic.

5 Interview with an expert on Geographic Information System (GIS) expert held on August 26 2020

\title{
Short-term impact of COVID-19 on CSOs' operations (1 - 3 months)
}

\author{
How has the COVID-19 pandemic affected the operations \\ and programmes of your organisation in the short- term \\ (i.e.1-3months)?
}

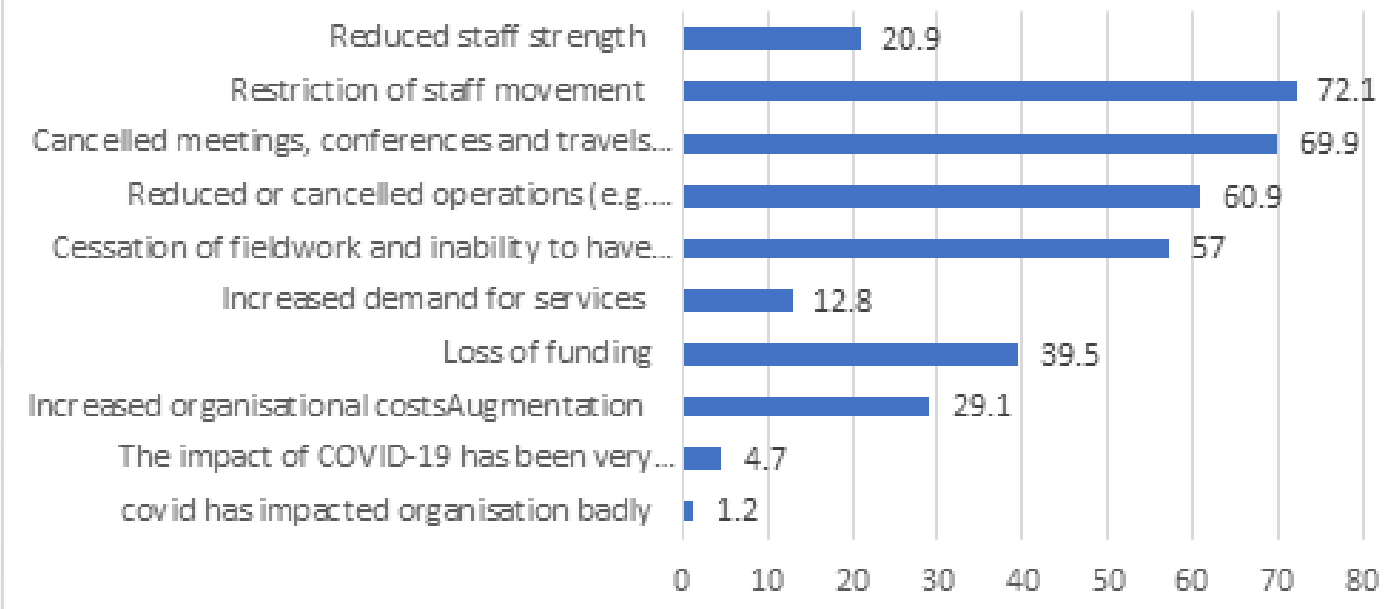

Figure 8: Short-term impact of COVID-19 on CSOs

To further understand the impact of COVID-19 on the operations and programmes of the CSOs in the short term i.e. within $1-3$ months, $20.9 \%$ of the CSOs indicated that they were compelled to reduce their staff strength, $72.1 \%$ had the restrictions imposed on their staff, $69.9 \%$ reduced and cancelled their operations in terms of training, workshops and campaign, while $57 \%$ suspended fieldwork and outreaches to communities. Also, 39.5\% suffered loss of funding, 29.1\% reported that there had been an increase in organisational cost. However, on a more encouraging note, $12.8 \%$ of the CSOs agreed that they have observed an increase in the demand for their services. 


\title{
Long-term impact of COVID-19 on CSOs' operations in the next 6-12months
}

\author{
How will the COVID-19 pandemic affect the operations of your organisation
} in the next $6-12$ months?

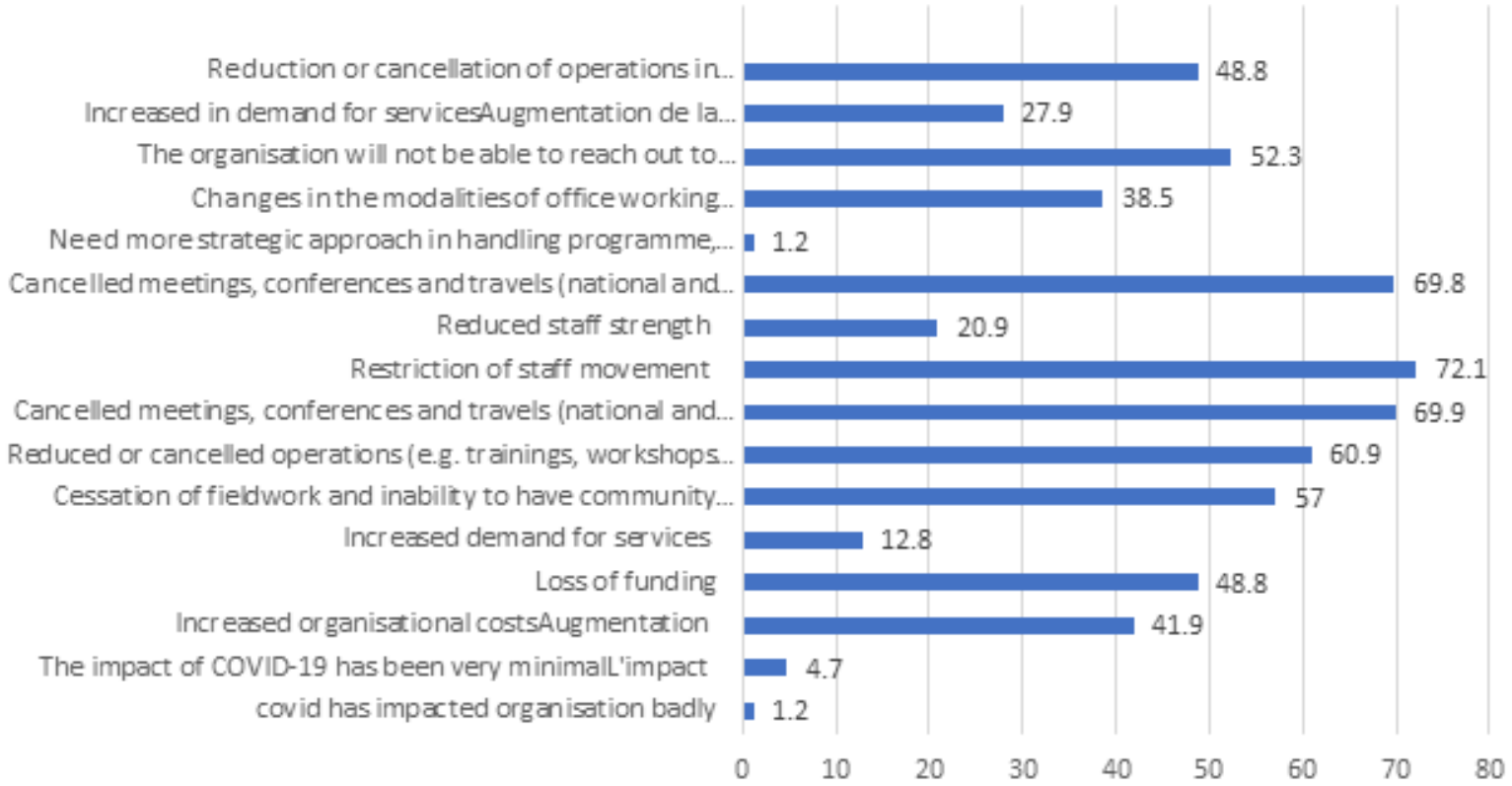

Figure 9: Long-term impact of COVID-19 on CSOs' operation

Figure 9 presents the results on how the COVID-19 will affect the operations of CSOs within 6-12 months. There were $48.8 \%$ that foresaw predictable reductions or cancellations of some of their programmes, $52.3 \%$ anticipated inability to reach out to their beneficiaries, $27.9 \%$ expected an increase in the demand for their services, $38.5 \%$ anticipated likely modification of their working space, $48.8 \%$ saw the possibility of experiencing a loss of funding which is significantly different from those who would experience loss of funds in the short term (39.5\% see figure 8$)$.

However, the pandemic had no impact on $1.2 \%$ of the respondents. On a lesser degree, $4.7 \%$ revealed that the impact of the COVID-19 outbreak on their CSOs would be minimal. Specifically, $29.1 \%$ claimed there would be increase in organisational cost, $20.9 \%$ indicate that they would be compelled to reduce staff strength, $72 \%$ would have their outreaches curtailed owing to movement restrictions. Precisely, $12.8 \%$ of the CSOs anticipated a boom resulting from increase in demand for their services as a result of the pandemic. In all, there seems to be little or insignificant difference between the long term and short-term impact of the COVID-19 pandemic on the operations of the CSOs in the country.
Knowing fully that providing or rendering essential services to beneficiaries is the hallmark of many CSOs, of the 80 CSOs that participated in the study, $48.8 \%$ of them revealed that their service-rendering capacity has been severely weakened due to the COVID-19 outbreak while $15.1 \%$ were greatly affected and could hardly provide their usual services to their beneficiaries. In contrast, the capacity of $29.1 \%$ was moderately reduced, while $3.5 \%$ continued to carry out their activities as they did preCOVID-19, while $1.2 \%$ were not affected at all.

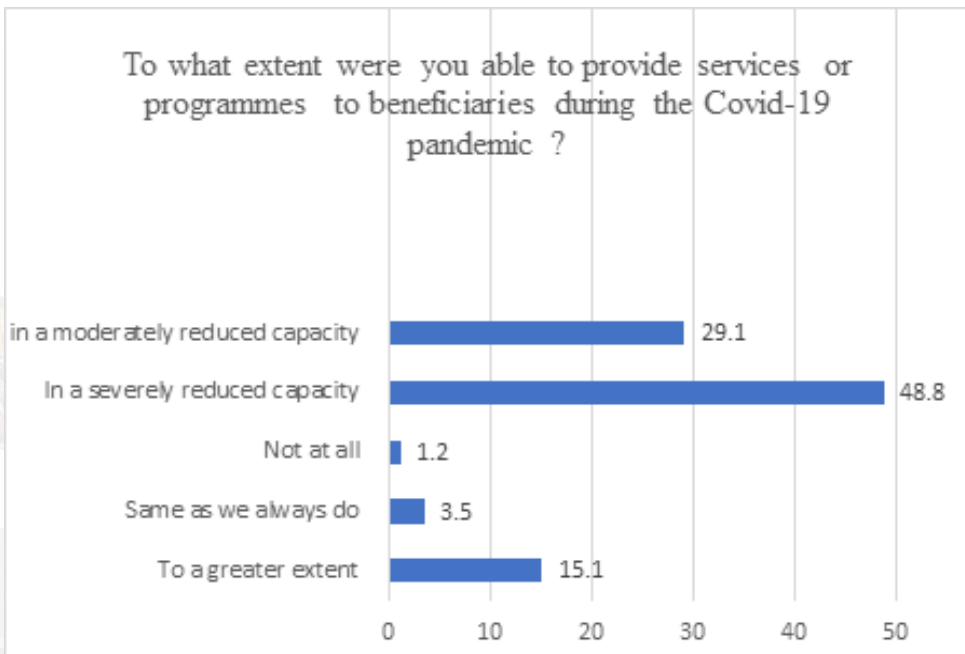

Figure 10: Extent of CSOs' ability to provide services to beneficiaries during the COVID-19 pandemic. 


\subsubsection{Impact of the COVID-19 on Funding, Resources Mobilisation and Sustainability}

Either in pandemic or normal times, the activities of CSOs are dependent on the availability of resources including funding. Next to funding, the presence of a pool of wellmotivated and well-trained staff is equally central to the sustainability needed by organisations to continue their operations and activities unperturbed and without assistance or additional funding from donor. Figure 11 below shows responses on whether CSOs have had to dismiss any employees due to the impact of COVID-19 on their financial solvency.

Of the 80 CSOs who participated in the survey, $65.1 \%$ reported that they did not dismiss any of their employees due to the impact of the COVID-19 on their financial resources. However, $33.7 \%$ have had to dismiss some employees due to the financial strain imposed by COVID-19 on their organisations. (See Figure 11).

Out of the 80 CSOs who took part in the survey, $46.5 \%$ reported that they experienced financial constraints brought about by funding restrictions and constraints. Precisely, 38.4\% encountered funding reductions from major donors. However, $15.1 \%$ opined that the COVID-19 pandemic provided the opportunities for the mobilisation of domestic resources within their locality, while $1.2 \%$ were affected by reduction in individual funding. (See Figure 12).

On whether the COVID-19 will affect their organisational funding in the next 3-6 months, $54.7 \%$ of the CSOs agreed that the COVID-19 pandemic will affect their organisational funding in the next 3-6 months, $29.1 \%$ also strongly agreed and aligned with the previous assertion, while an insignificant $4.6 \%$ either disagreed or strongly disagreed that COVID-19 would affect their funding.
Have you had to dismiss any employees until now due to the impact of the covid-19 on yor finacial position?

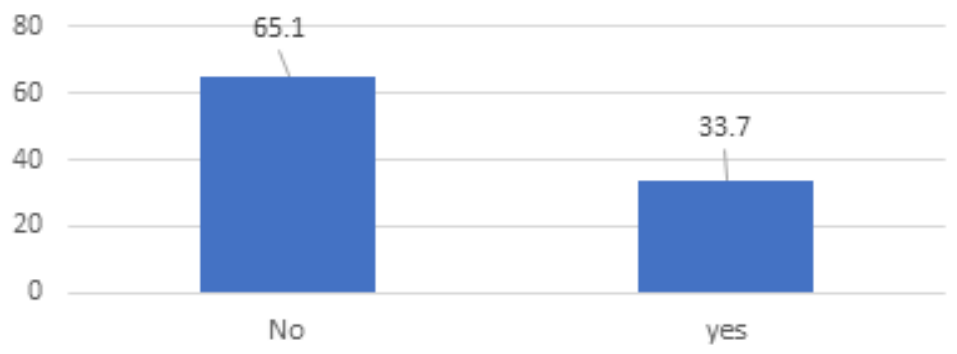

Figure 11: Dismissal of staff by CSOs due to COVID-19

However, $11.6 \%$ of the respondents remained indifferent as they neither agreed nor disagreed (See Figure 13 on page 23).

On the survivability of the CSOs in the next 6-12 months without any additional funding, $11.6 \%$ of the CSOs believe they would not survive. Reflecting a slight hope, $27.9 \%$ feared that they are unlikely to survive without additional funding. While being cautiously optimistic, $37.2 \%$ are of the view that they would survive but will be compelled to make significant cuts in the number of staff, major programmes and activities. Only $22.1 \%$ of the CSOs indicated that they can survive without any additional funding, while a few CSOs representing 1.2\% opined that they would not be able to survive in major areas of their activities although they are trying to restructure to remain active. (See Figure 14 on page 23).

CSOs on whether they possess any reserves to mitigate the impact of COVID-19 on their funding for the next 6-12 months. A significant number representing $79 \%$ of the CSOs revealed that they do not have any financial reserves to mitigate the impact of the COVID-19 on their organisational funding, while $21 \%$ have financial reserves to continue their operations for the next of the 6-12 months. (See Figure 15 on page 23).

In what ways has the covid-19 pandemic affected your organisational funding?

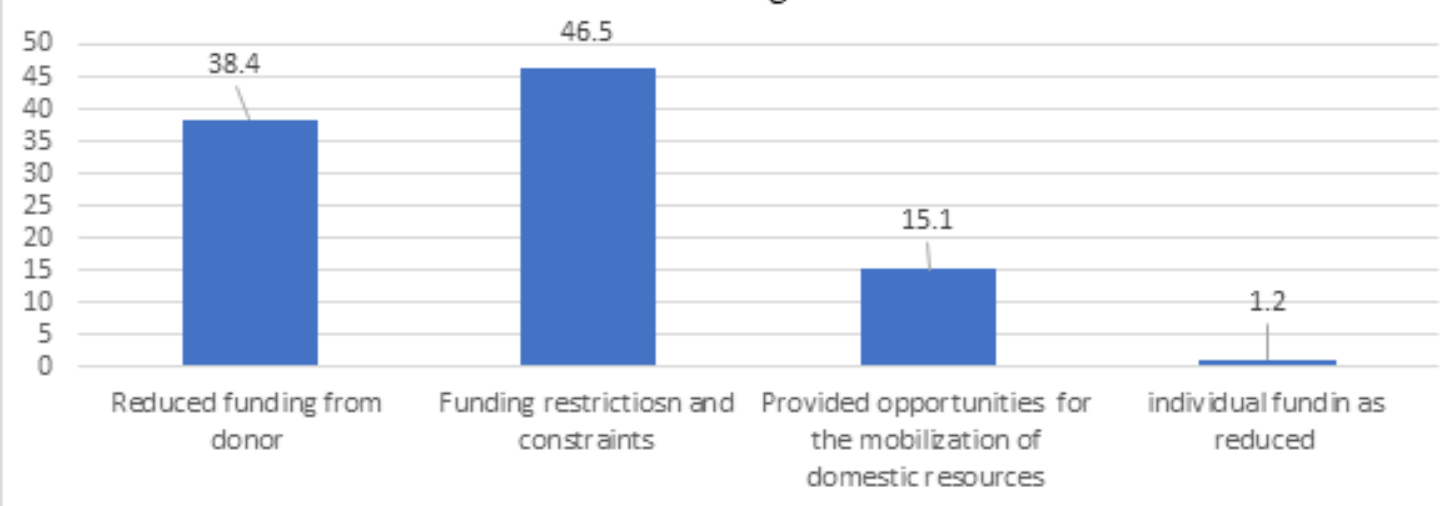

Figure 12: Impact of COVID-19 on organisational funding 
Do you you believe that the COVID-19 pandemic will affect your organisational funding in the next 3-6months?

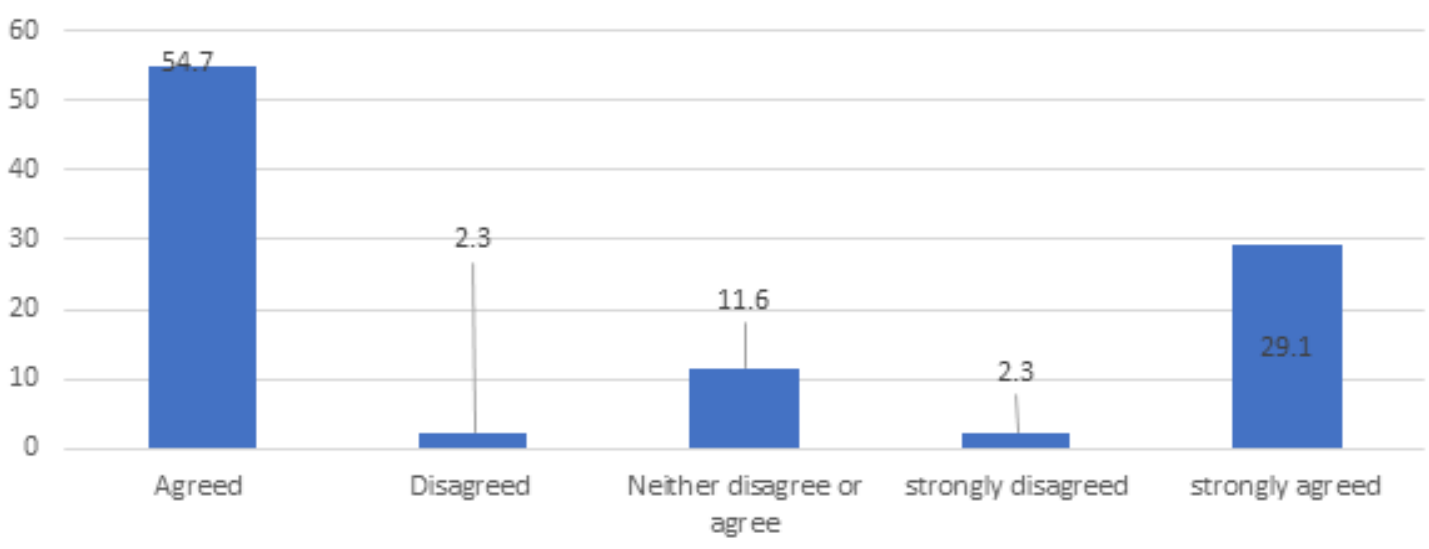

Figure 13: COVID-19 and organisational funding in the next 3-6 months

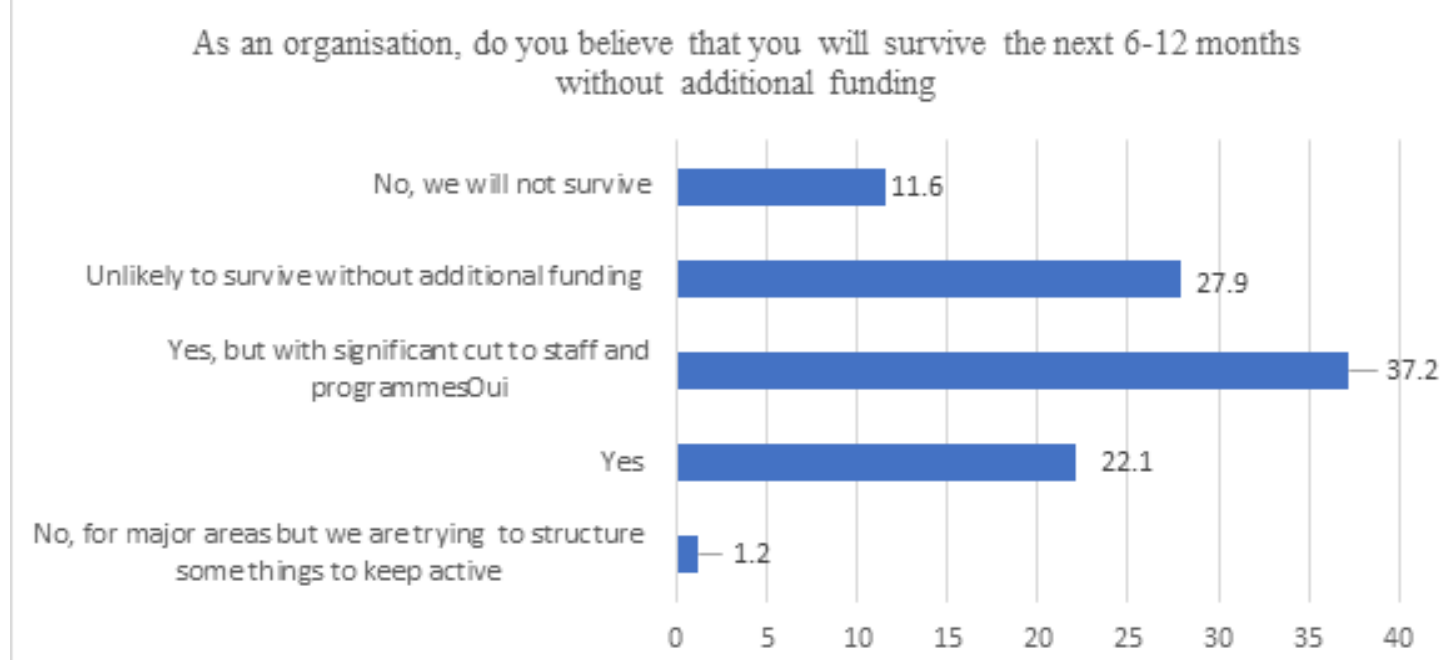

Figure 14: Survival of CSOs in the next 6-12 months

Does your organisation have any reserves to mitigate the impact of COVID-19 on your funding for the next $6-12$ months?

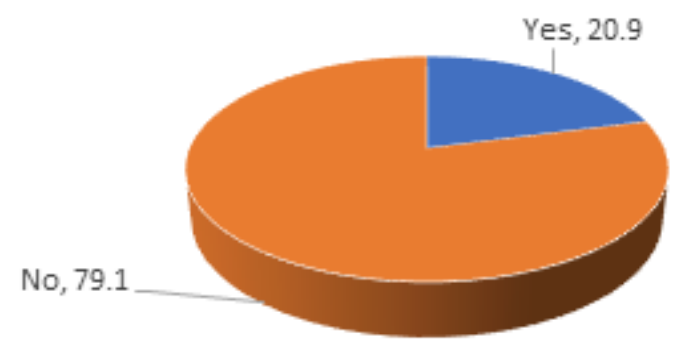

Figure 15: Availability of organisational reserves

On whether they have been able to raise any domestic resources during the COVID-19 pandemic, $58.1 \%$ CSOs reported that they had not been able to raise any domestic resources during the pandemic to complement external donor funding. Conversely a significant $41.9 \%$ of them had raised domestic resources to complement what they had received from the external donors during the pandemic. (See Figure 16).
Have you raised any domestic resources during the COVID-19 pandemic to complement external donor funding?

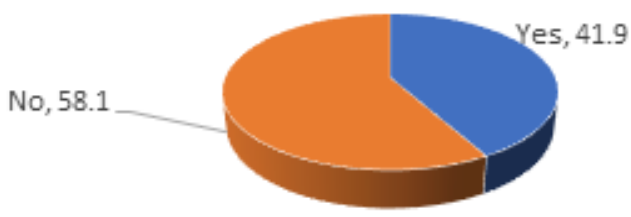

Figure 16: Mobilisation of domestic resources by CSOs during the COVID-19 pandemic 
Please indicate the sources of the domestic resources

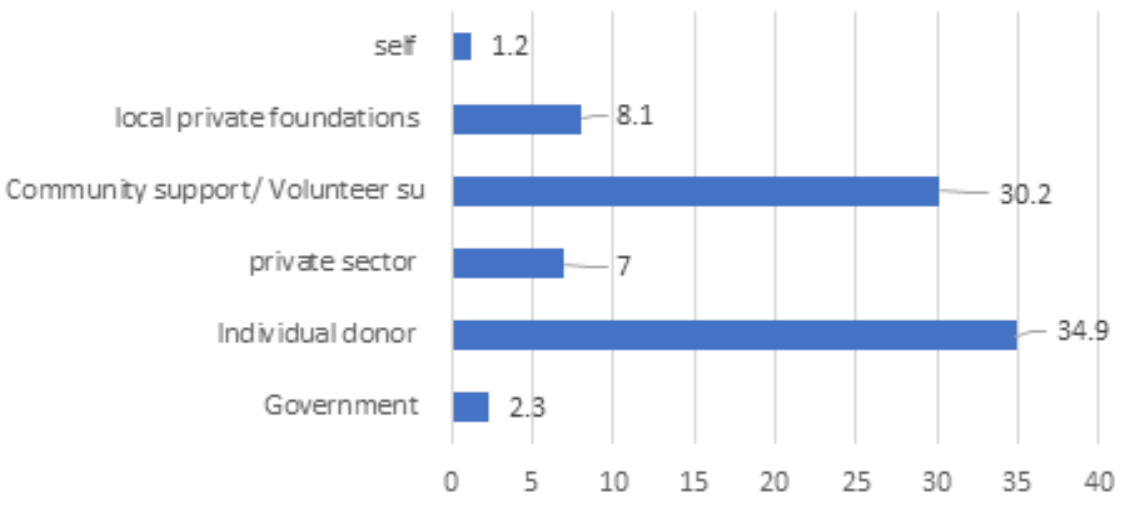

Figure 17: Sources of domestic resources for CSOs during the pandemic

On the sources of the domestic resources received during the pandemic, 30\% of the CSOs received domestic resources through community and volunteer support, 35\% received through individual donors, $8.1 \%$ through private foundations, $7 \%$ through private sector donations, while $2.3 \%$ received from government as shown in figure 17 above.

The COVID-19 pandemic provides opportunities for CSOs to mobilise domestic resources to support their activities ?

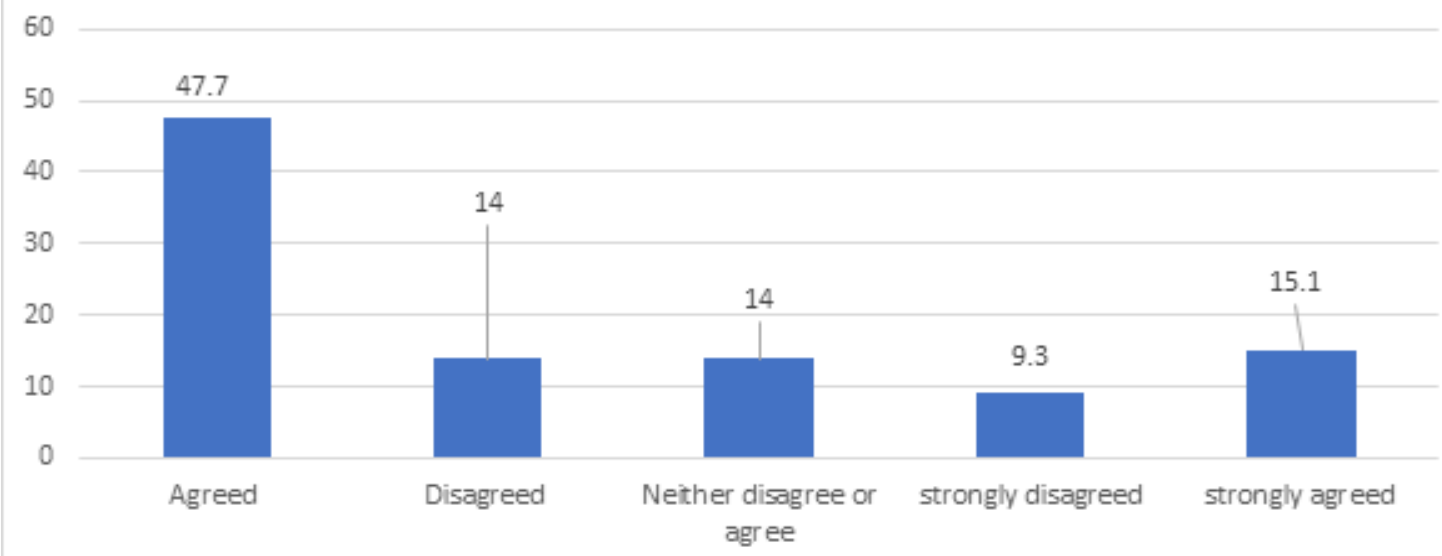

Figure 18: COVID-19 and opportunities for mobilising domestic resources

In figure 18 above, the CSOs shared their experiences on how the COVID-19 pandemic provides opportunities for them to mobilise domestic resources to support their activities. Out of the 80 sampled CSOs, $47.7 \%$ agreed that the pandemic provides opportunities for them to mobilise domestic or local resources to support their activities. On the other hand, $15.1 \%$ strongly agreed, while $14 \%$ disagreed and another $9.3 \%$ strongly disagreed. In contrast with these trends, $14 \%$ neither agreed nor disagreed.

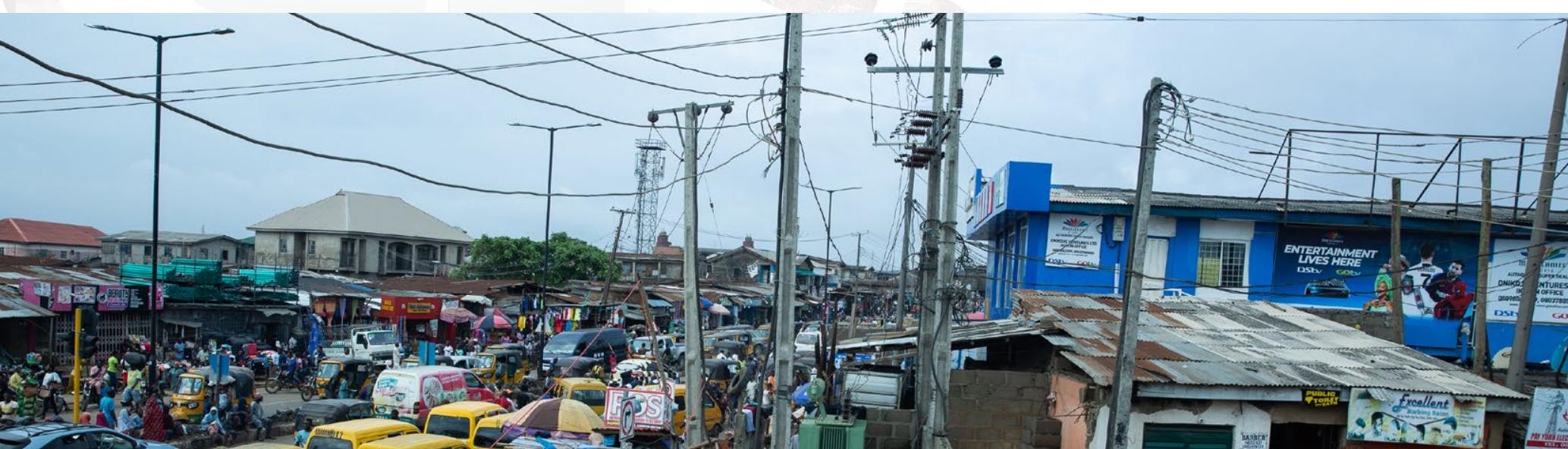




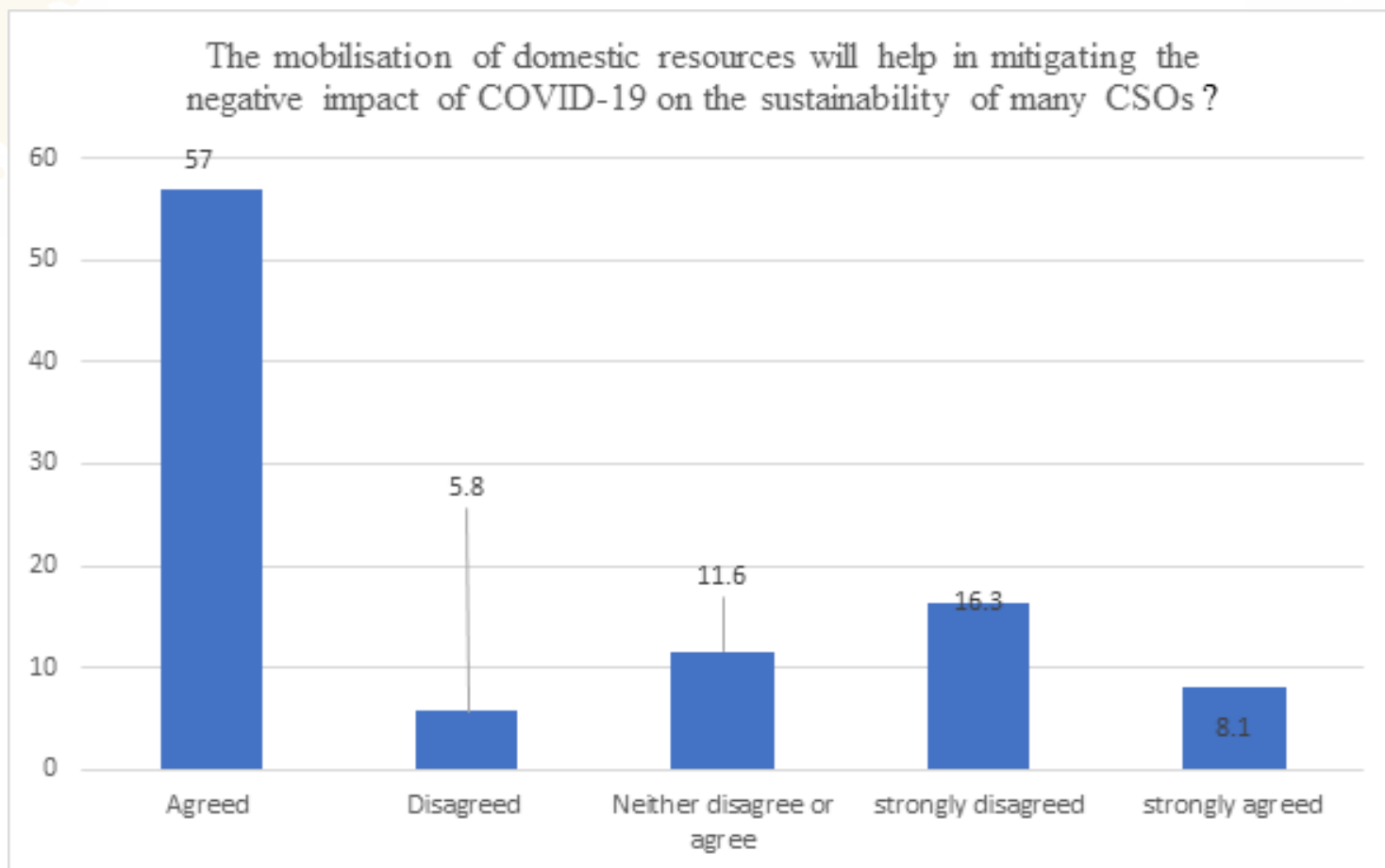

Figure 19: Domestic resources' potential to mitigate against the impact of COVID-19

Of the 80 CSOs that partook in the survey, $57.0 \%$ agreed that the mobilisation of domestic resources will help in mitigating the negative impact of COVID-19 on the sustainability of many CSOs, $8.1 \%$ also strongly believed that it will help. On the contrary, $5.8 \%$ of CSOs disagreed and another $16.3 \%$ strongly disagreed. It should also be noted that $11.6 \%$ of these organisations neither disagreed nor agreed.

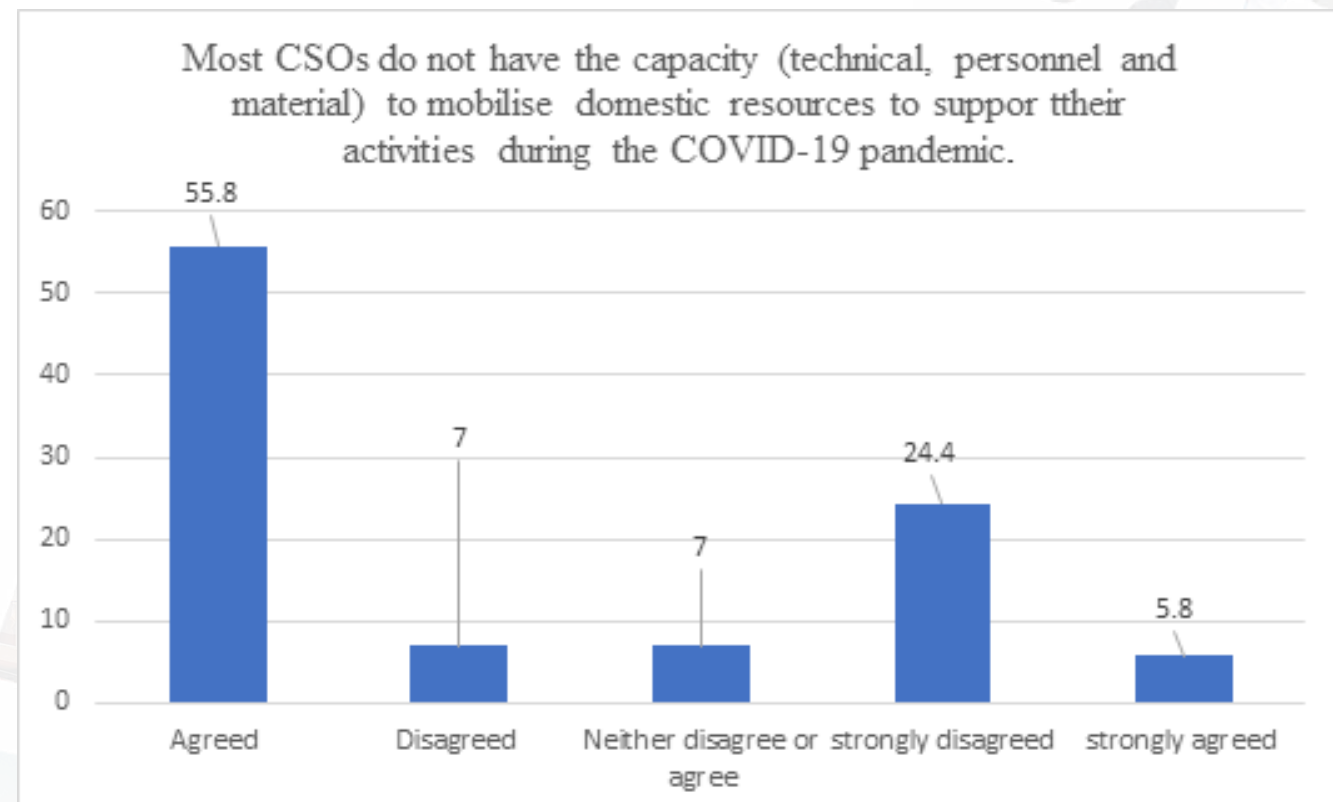

Figure 20: Most CSOs do not have the capacity (technical, personnel and material) to mobilise domestic resources to support their activities during the COVID-19 pandemic

Figure 20 shows that $55.8 \%$ of CSOs agreed that they do not have the capacity to mobilise domestic resources. However, a section of the sampled CSOs (24.4\%) rejected the notion and insisted that they have the technical, material and personnel capacity to mobilise domestic support for their activities during the pandemic. Obviously, most of the CSOs did not have the capacity to mobilise local resources because even before COVID-19, they depended largely on foreign sources of support for their programmes; a situation that has worsened as a result of the pandemic. 


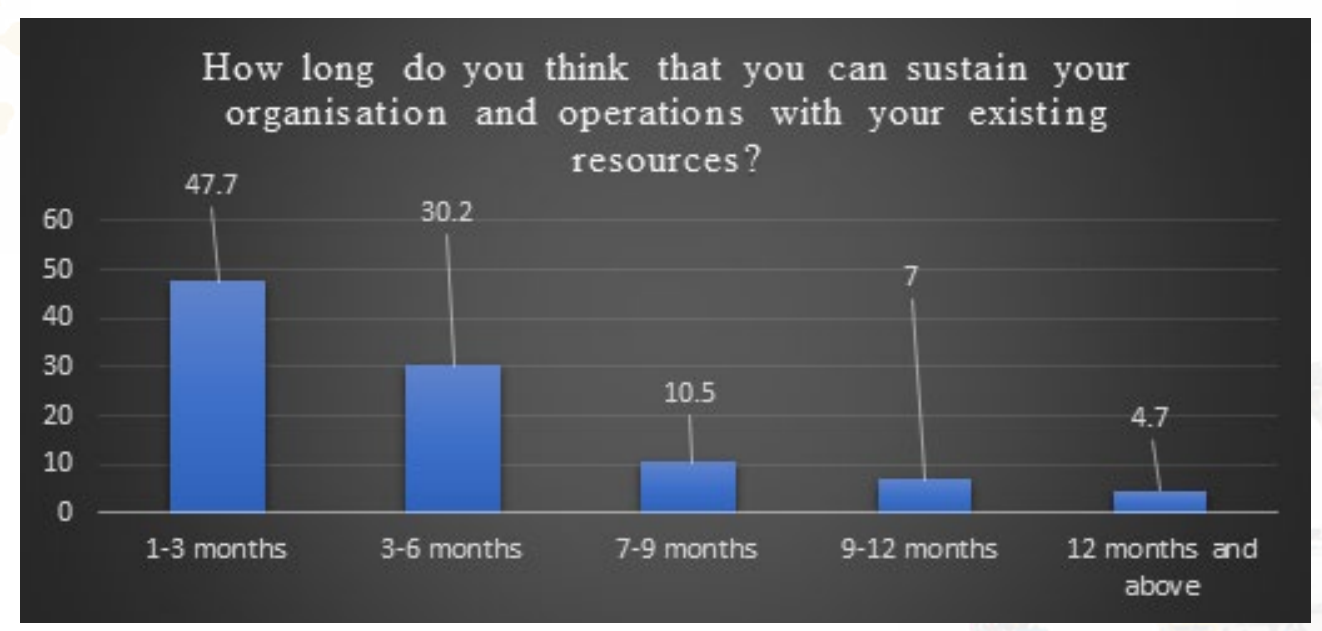

Figure 21: Ability for CSOs to sustain their activities with existing resources

On the sufficiency of their current resources as a means of sustenance of their organisations and operations, as shown in figure $21,47.7 \%$ of the sampled CSOs averred that they can only operate with the current resources at their disposal within 1-3 months before they shut down. About $30.2 \%$ claimed that they can only survive for just 3-6 months, $10.5 \%$ can cope for $7-9$ months, while $7 \%$ of them can sustain their activities with their current resources for 9-12 months. Only $4.7 \%$ of the CSOs believed the current resources at their disposal can sustain them for more than one year (Figure 21). The decreasing trend shows that a low number of the CSOs can sustain themselves in the long run with their existing resources. This is likely to be the case for CSOs across the country and could, in part, be attributed to the high donor dependency of CSOs in the country. (See Figure 21).

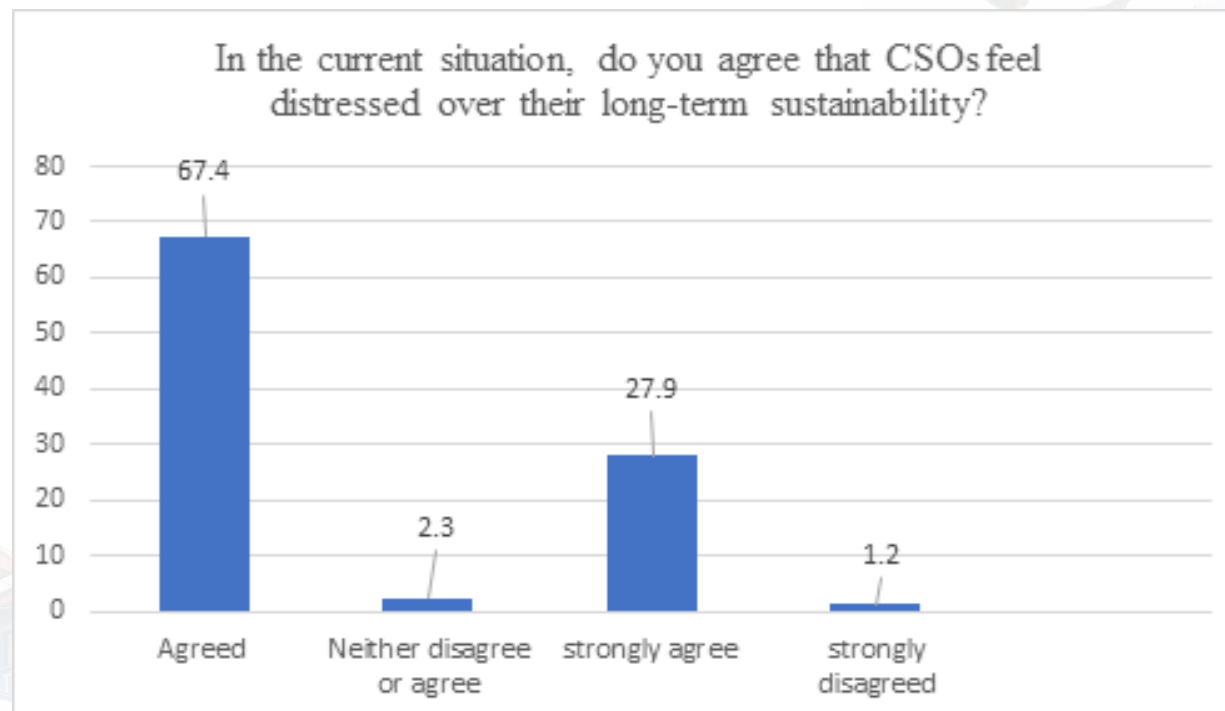

Figure 22: CSOs' perception of feeling distressed about their sustainability

The Figure 22 above shows the responses of the CSOs on whether they feel distressed over their long-term sustainability in the current situation. From the data presented above, almost all the CSOs believed they are distressed as about $95.3 \%$ of the sampled CSOs either agreed or strongly agreed, while an insignificant $1.2 \%$ strongly and $2.3 \%$ were indifferent. It should be noted that none of the respondents disagreed.
On the extent of effect of the COVID-19 on the overall sustainability of the civil society sector in the country, figure 23 shows that $47.7 \%$ agreed that it will affect the sector to a very high extent. On the other hand, 37.2\% believed it will affect the sector to a high extent, 1.2\% believed it will affect to a very low extent, while $10.5 \%$ of the CSOs were not quite sure of the extent to which COVID-19 will affect the civil society sector in Nigeria. (See

Figure 23 on page 27). 


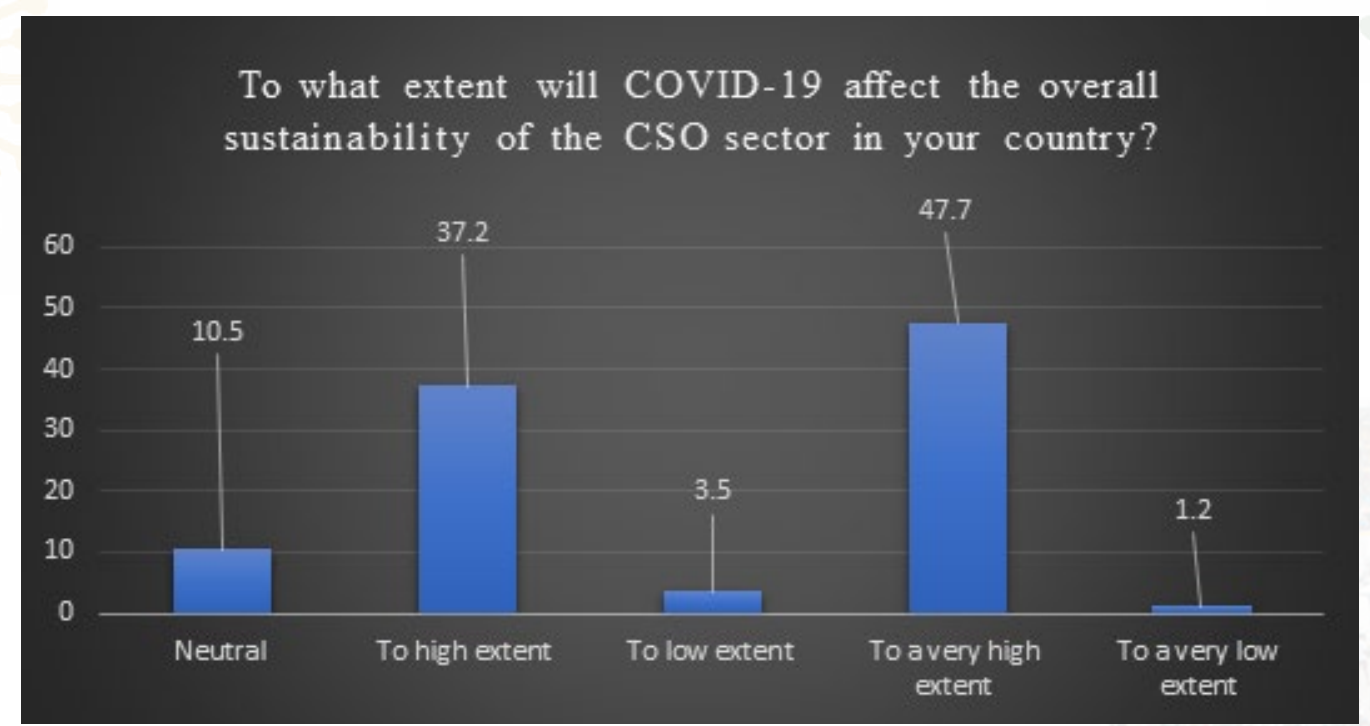

Figure 23: To what extent will COVID-19 affect the overall sustainability of the CSO sector in your country?

\subsubsection{Impact of the COVID-19 on CSOs' Role and Relationship with Stakeholders}

As an emergency, COVID-19 has strained governmental and non-governmental institutions' capacities. However, more direly affected are CSOs and their relationships as well as their capacities to sustain the delivery of services and support to beneficiaries. In the chart below, respondents shared their views on whether their projects and initiatives that catered for beneficiaries could be sustained after COVID-19.

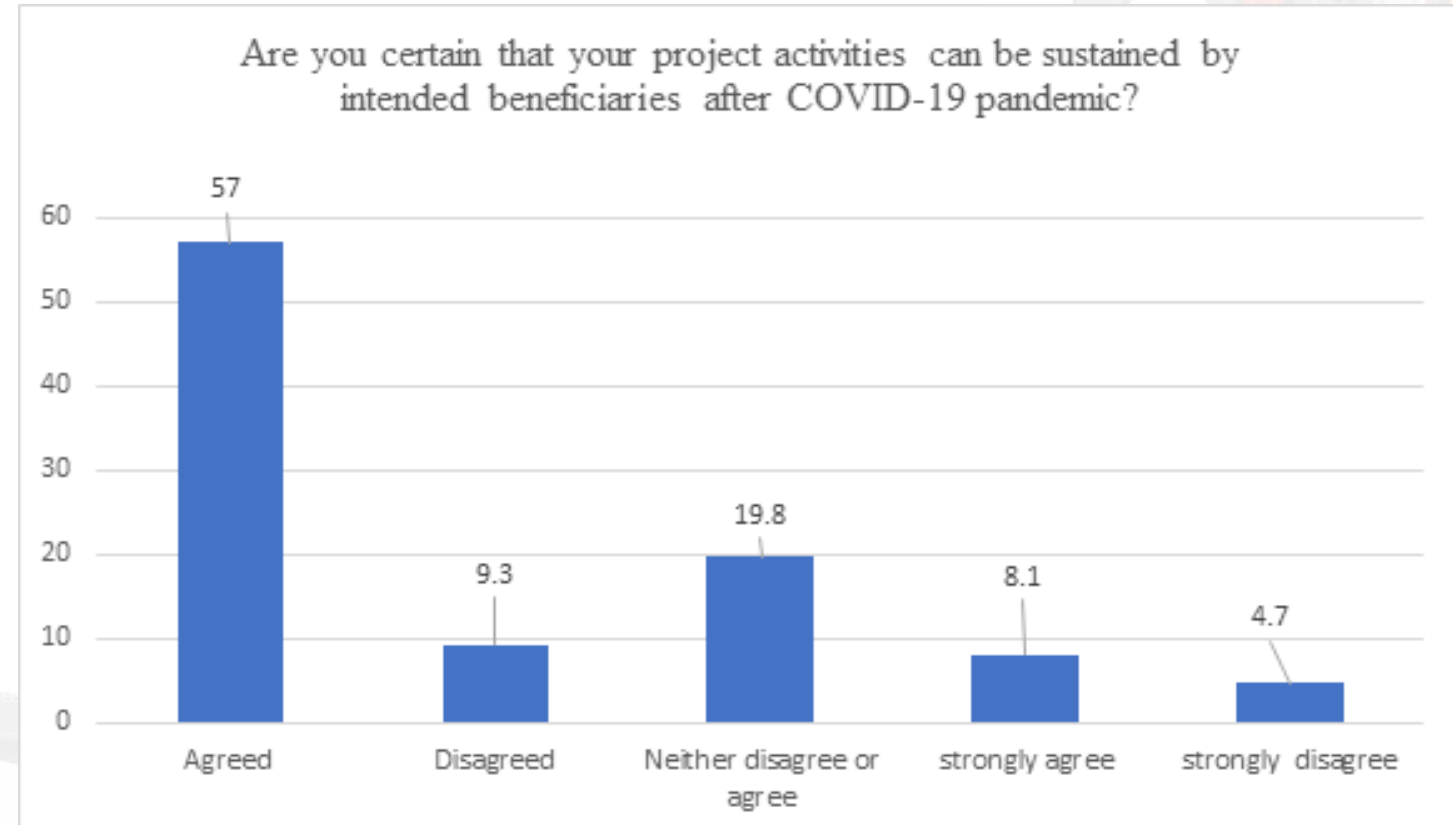

Figure 24: Are you certain that your project activities can be sustained by intended beneficiaries after COVID-19 pandemic?

From Figure 24 above, out of the 80 CSOs that participated in the survey, $57 \%$ of them agreed that their activities will be sustained in apparent confidence despite COVID-19. For $8.1 \%$ of the CSOs that participated, they strongly agreed that their operations will not be undermined by the harsh conditions imposed by COVID-19. Significantly and in contrast, 9.3\% disagreed and expressed pessimism that their activities might be curtailed owing to the impact of the pandemic. On the other hand, $4.7 \%$ of the respondents voiced strong disagreement that they will be able to go on after COVID-19, given the extent of its impact.

In all, it could be deduced that $65 \%$ of the CSOs were looking forward to sustaining their activities after COVID-19, while $14 \%$ were not excited at the realities that await them after COVID-19. However, precisely $19.8 \%$ were unsure about whether or not the pandemic will frustrate their operations. 


\subsubsection{Organisations" Active Cooperation with other CSOs and Beneficiaries to Mitigate}

\section{the Effects of the COVID-19 Pandemic}

One of what could be described as a coping strategy adopted by CSOs during the pandemic is exploring and maximising the potentials of pooling resources together in order to sustain themselves.

Is your organisation actively involved in working with other

CSOs and beneficiaries to mitigate the effects of the COVID-19 pandemic

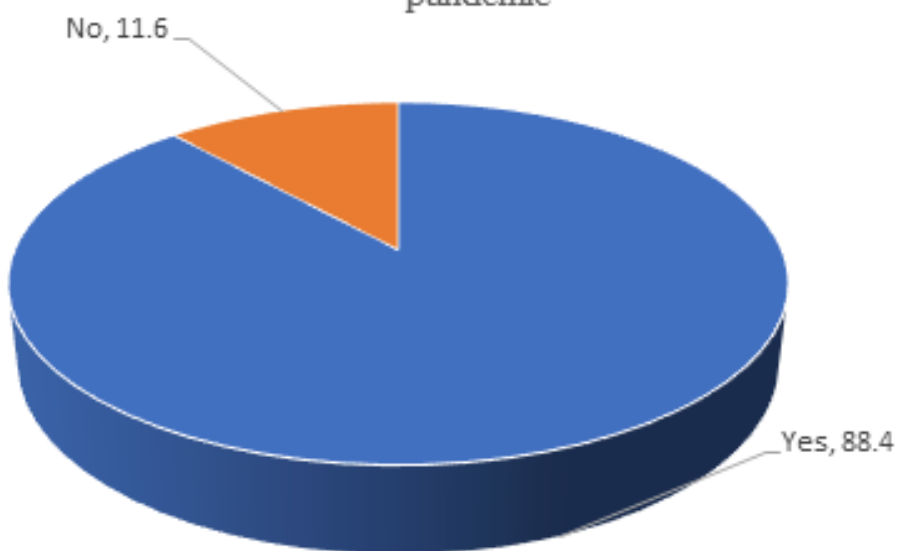

Figure 25: Is your organisation actively involved in working with other CSOs and beneficiaries to mitigate the effects of the COVID-19 pandemic

From the Figure 25 above, $88 \%$ of those who participated in the study revealed that they are actively working with other CSOs and beneficiaries to cushion the effects of the pandemic. On the contrary, $12 \%$ have had a different experience. They have not been able to collaborate with other CSOs and beneficiaries to mitigate the effects of the pandemic.

\subsubsection{Specific Initiatives Implemented to Support Beneficiaries and Communities During COVID-19}

Few weeks into the total lockdown in Nigeria, the federal and state governments across the country came up with the idea of providing palliatives especially for the most vulnerable and those whose sources of livelihood were suspended because of the total lockdown of the country's economy. In complementing the interventions by government and reaching out to sections of the community whose needs are beyond feeding, CSOs offered services within their capacities.

What specific activities/initiatives have you undertaken as an organisation to support beneficiaries and communities during the

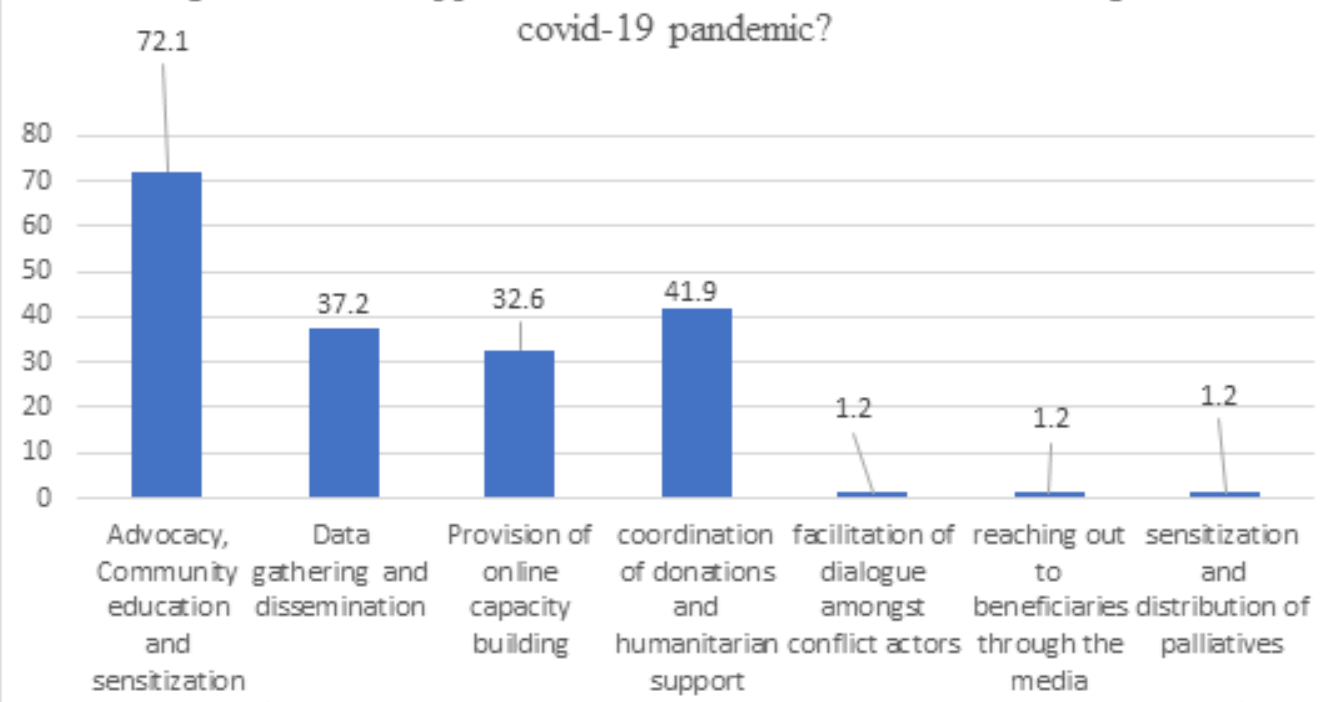

Figure 26: Specific initiatives implemented as an organisation to support beneficiaries and communities during the covid-19 pandemic

Figure 26 above reveals that among the efforts to provide relief to vulnerable groups, $72 \%$ of the CSOs that participated in the study embarked on advocacy, community education and sensitisation. Precisely $37.2 \%$ were also engaged in data gathering and dissemination of information. A section of CSOs (32.6\%) were also engaged in the provision of online capacity building. On the other hand, $41.9 \%$ were also involved in the coordination of donations and humanitarian support. A small section of CSOs (1.2\%) facilitated dialogue amongst conflict actors, gave out palliatives and sensitised communities. 


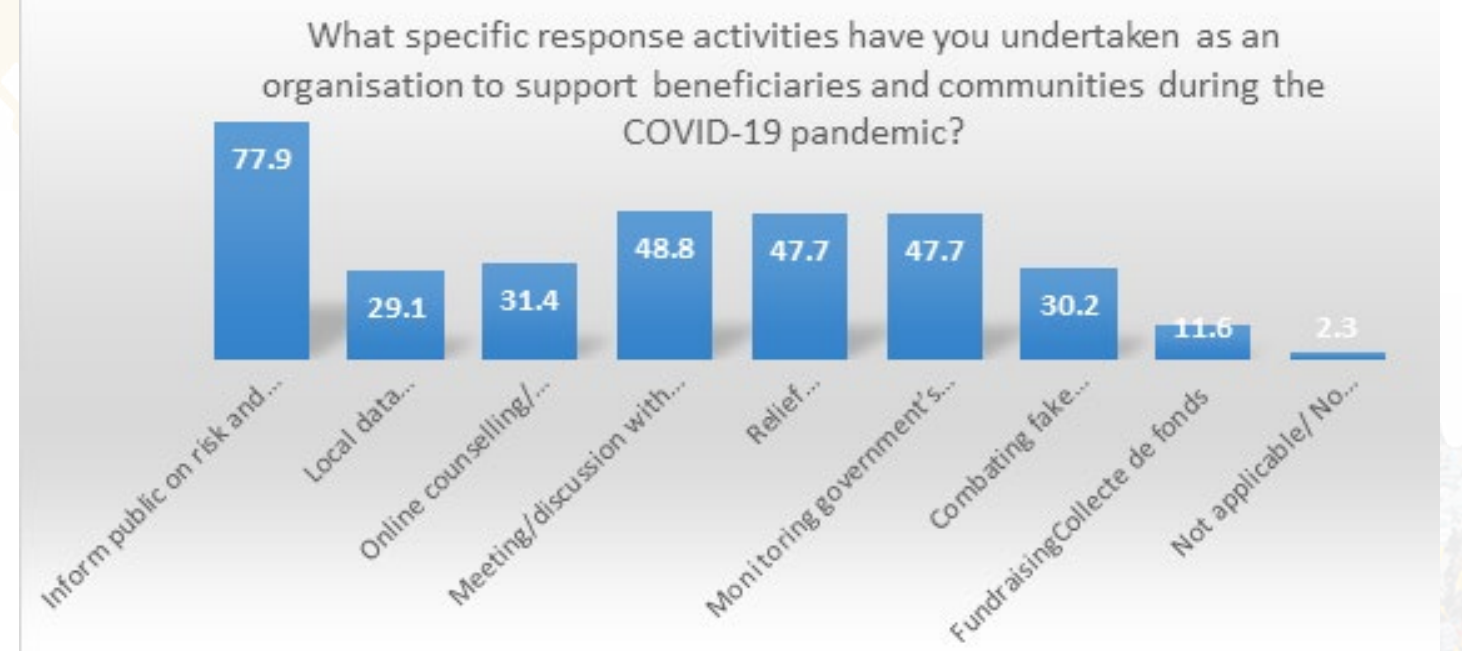

Figure 27: What specific response activities have you undertaken as an organisation to support beneficiaries and communities during the COVID-19 pandemic?

In addition to the activities that CSOs sustained (see figure 26) during the COVID-19 period, there were other activities (as contained in figure 27) that were not deterred by COVID-19. In this vein, $77.9 \%$ of CSOs sustained the dissemination of information on public risk and steps needed to prevent them from harming members of the public. Data generation received unhindered attention from $29.1 \%$ of the CSOs, $31.4 \%$ sustained their online counselling, 48.8\% kept facilitating and hosting meeting virtual meetings with other CSOs, $47.7 \%$ were involved in the distribution of relief materials while another $47.7 \%$ were monitoring the distribution of relief materials by governments at all tiers. $30.2 \%$ of the CSOs worked to combat fake news that was being propagated at the peak of the pandemic in Nigeria. Some $11.6 \%$ of the CSOs were engaged in activities geared towards raising funds while a minimal $2.3 \%$ were not busy during the pandemic. (See

\section{Figure 27).}

In all, these charts have shown the specific activities that were carried out to cushion the effects of COVID-19 on communities and individual beneficiaries by CSOs across rural, sub-urban and urban locations in Nigeria. All of the preceding alludes to the fact that despite the pandemic, CSOs in Nigeria were able to sustain their mandates and activities albeit with strains on their finances and logistics. The sustenance of their respective mandates was in varying degrees based on how quick respective organisations were able to adapt to the situations imposed by COVID-19, and thrive based on the available resources at their disposal during the period.

\subsubsection{Change in Donor Funding Priorities after the COVID-19 Pandemic}

Amongst the realities that characterise emergencies, are fear and anxiety which manifest and affect all and sundry differently. So, as Nigerian-based institutions whose sustenance depends largely on foreign donors from the global north, there are valid grounds to entertain fears of a drop in the volume of support they were expecting given the global nature of the pandemic.

As shown in Figure 28, respondents expressed with apprehensions that donors will change their priorities after COVID-19 pandemic. However, some were confident that there will not be a decline in their support from donors. Amongst those optimistic were $1.2 \%$ who strongly disagreed and $7.0 \%$ who merely disagreed but not in strong terms that they will experience a decline in the quantum of support available to them from external sources. However, $11.6 \%$ and $50.0 \%$ strongly agreed and agreed respectively that their sources of financial energy might be interrupted as a result of the pandemic. Appearing neutral were $27.9 \%$ who expressed indifference by neither agreeing nor disagreeing that they could experience fall in their funding from external sources. (See Figure 28 on page 30 ).

Putting together those who expressed fear reveals that $61.6 \%$ are gripped by the fear of experiencing a decline in their support from external sources. This underscores the need for exploring and expanding local sources of financial support accessible to CSOs in Nigeria in order to ameliorate the harsh impacts of COVID-19. 
Do you think your funders/donors will change their priorities after the COVID-19 pandemic

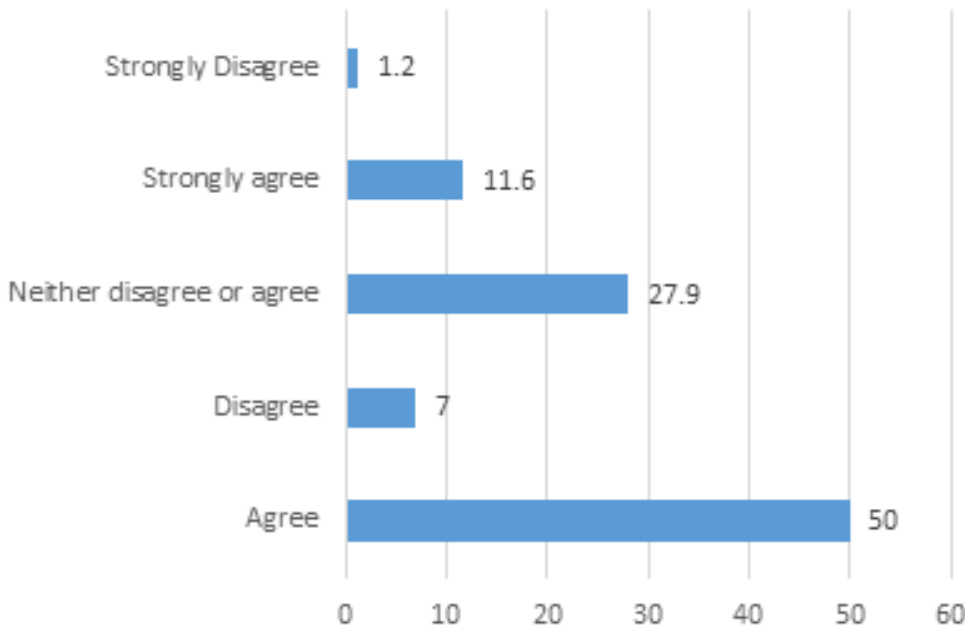

Figure 28: Do you think your funders/donors will change their priorities after the COVID-19 pandemic

\subsubsection{Issues Discussed with Donors by CSOs in the Light of COVID-19}

Participants were asked if they have held discussions with their donors about options and means of mitigating the harsh realities of paucity of funds brought about by COVID-19. Responses to the question are contained in figure 29. From figure 29, a small proportion of CSOs (1.2\%) revealed that they had never depended on external donors. Another $1.2 \%$ had no external support as at the time of the study even though they used to. Also, 1.2\% discussed switching to alternative programmes or/and modifying ongoing projects. However, $46.5 \%$ had not

In Mitigating the effects of COVID-19, which of the following issues have you discussed with your donors

We don't have donors yet 1.2

Currently we don't have an existing... $\| 1.2$

Also the alternative programme to... 1.2

also discussed modifying project... $\mid 1.2$

No, we have not discussed...

Details regarding the use of donor...

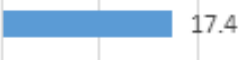

Cancellation of project... 19.8

Extension of project completion...

$\begin{array}{llllll}0 & 10 & 20 & 30 & 40 & 50\end{array}$

Figure 29: In Mitigating the effects of COVID-19, which of the following issues have you discussed with your donors? held any discussion with their donors as at the time of the study. Discussions have also been held around how to use donor funding by $17.4 \%$, cancellation of projects was contemplated by $19.8 \%$ while $30.2 \%$ explored the extension of projects.

The preceding implies hope and readiness to confront the emergencies arising from COVID-19 on the parts of both recipients of donors' funds and the donors themselves through collaboration. The plausibility of this can also be measured by the flexibility of donors which is explored in the next section. (See Figure 29).

\subsubsection{Ranking the Flexibility of Donors to CSOs in Nigeria during COVID-19}

A valid and reliable means of measuring and predicting the chances of CSOs in Nigeria to survive after COVID-19, is how well their funders from the global North are amenable to adjusting to the needs of these CSOs. However, this is going to vary according to the experience of individual CSOs and their funders. Therefore, a ranking as done below becomes instructive and reliable in being aware of the kind of realities that might confront these non-state actors based on how well their donors are willing or likely to be flexible.

As shown in figure $30,1.2 \%$ of $\mathrm{CSO}$ revealed that their donors were extremely flexible during the COVID-19 pandemic. For $33.7 \%$, their external funders were neither flexible nor rigid which contrasts with the feedback from $11.6 \%$ whose funders were not flexible at all and $14 \%$ whose foreign donors were not flexible. However, 32.6\% had assurances from their donors who were very flexible and perhaps the most assuring. (See Figure 30 on page 31 ).

\subsubsection{Top Needs of CSOs from Donors and Stakeholders to Mitigate the Impact of COVID-19}

Towards ensuring that CSOs in Nigeria are prepared for life after COVID-19, the need for prioritisation cannot be over-emphasised because of its usefulness in helping to know how to rank activities amidst shrinking resources. The responses are presented below. 
How would you rank the flexibility of your donors with regards

to the needs of your organisation during the COVID-19 pandemic

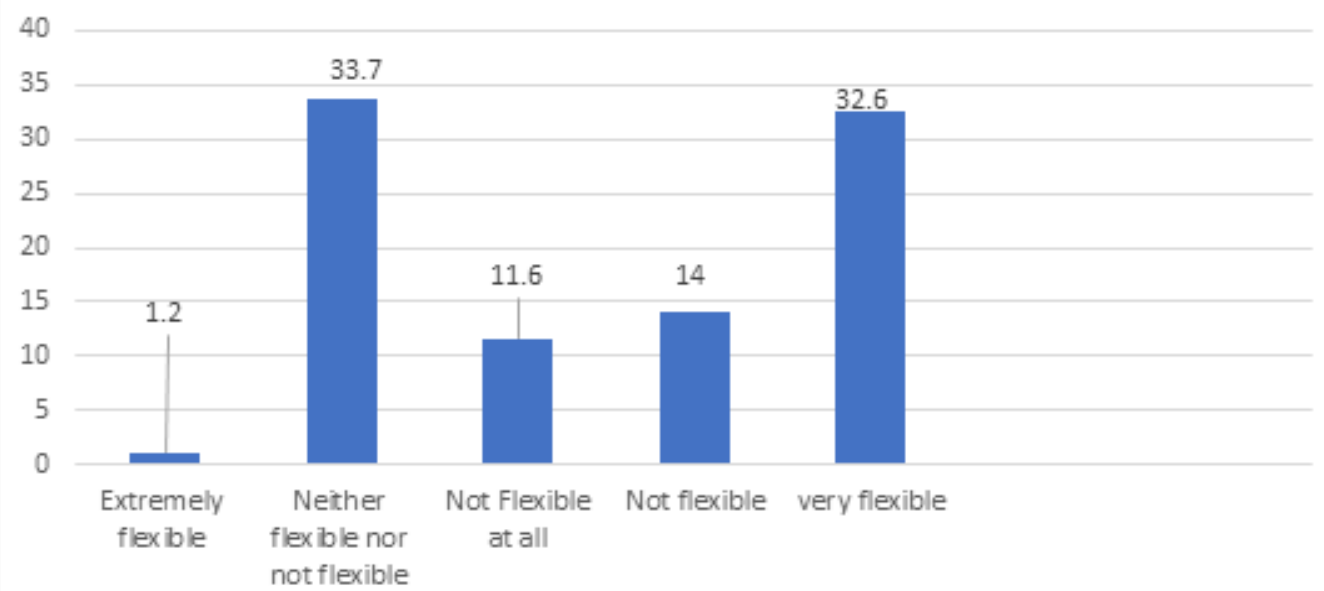

Figure 30: How would you rank the flexibility of your donors with regards to the needs of your organisation during the COVID-19 pandemic?

In the Figure 31 below, for $37.2 \%$ of the sampled CSOs, human resource management comes as the topmost priority. For $15.1 \%$, providing advice that will serve as guidance to their board of directors formed the prime priority. The wellness and self-care of members of the institution was their main concern of $32.6 \%$ of the CSOs. Using technology to facilitate a movement of their activities to cyber-space mattered most for $68.6 \%$ of the participating CSOs. The need for financial scenario planning in anticipation of the shocks arising from the COVID-19 was crucial for $46.5 \%$ of the CSOs. Acquiring relevant skills that will equip them to be able to face the challenges posed by COVID-19 through coaching sessions centred around how to lead in ambiguous times. In the considered opinion of $24.4 \%$ of the participants, sharing real time data was of utmost importance while re-evaluating fundraising strategies was rated as the most important by $60.5 \%$.

The responses above offer a birds-eye view of the diverse expectations and priorities of the civil society in Nigeria as triggered by COVID-19. It also presents an insight into the peculiarities of each organisation and the specific areas where they will need support towards recovery in the post-COVID-19 era.

What do you think are your top needs requiring assistance from donors and stakeholders to mitigate the impact of COVID-19 on your organisation?

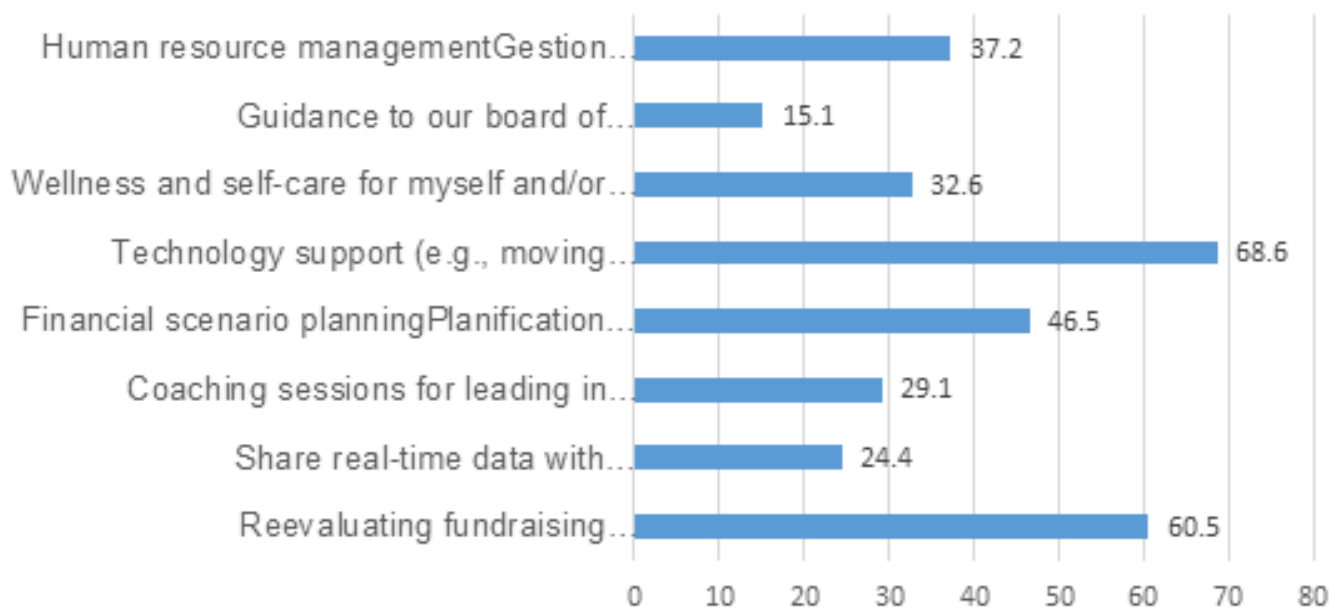

Figure 31: What do you think are your top needs requiring assistance from donors and stakeholders to mitigate the impact of COVID-19 on your organisation? 


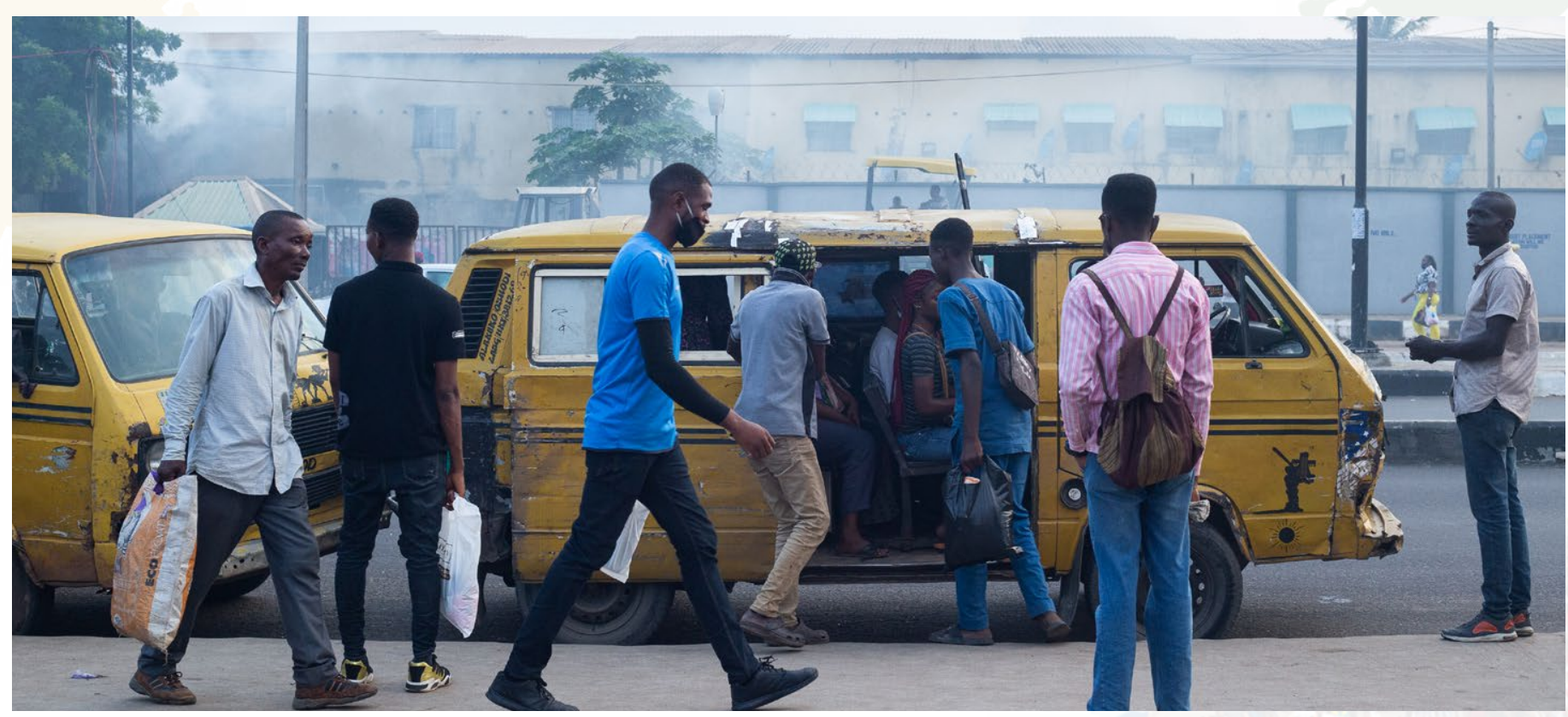

4.3. CSOs' Strategies for Coping Amidst COVID-19

Interactions with representatives of CSOs in the course of this study revealed the impact of the pandemic on their operations, delivery of services to their intended beneficiaries and finances. During interviews and focus group discussions, CSO representatives revealed how they had to adjust their operations towards cushioning and containing the consequences of their reduced support from external sources while mobilising internal or domestic resources towards ensuring their sustainability post COVID-19. A consensus among interviewees in relation to COVID-19 was the shock, protraction and immediate adjustments they had to make to their finances and operations, personnel and administration and preparation for return to normalcy after the pandemic.

The constraints imposed by the pandemic differed based on the degree of dependence of their operations on technology before the outbreak of the pandemic. For those whose activities entailed physical outreach events, the prohibition of physical gatherings across the country meant a temporary suspension of their activities. A shared perspective expressed during the focus group discussion by CSOs working in the areas of environmental justice and security, health, peace education and peacebuilding was that, they had to suspend their activities in order not to contravene regulations that outlawed physically gatherings. This meant a temporary suspension of these crucial services and support to communities. However, for those whose operations were already driven by technology and whose services could be delivered digitally, the restrictions and prohibitions that came with the pandemic were less constraining as they could continue their outreach activities albeit minimally during the pandemic. In the words of one of such actors empowering children and women with technology: "our summer bootcamp was cancelled but our internal operations were not affected because we had always depended on technology."

Also, due to some challenges that come with the use of technological tools such as irregular power supply, lack of digital tools like smart phones and tablets as well as cost of data, there was little these CSOs could do in using technology to sustain their activities during the pandemic.

For CSOs whose activities required hiring consultants for field activities and those with ad-hoc staffers, they had to suspend such employments because it was impracticable to conduct field-based activities. This was peculiar to CSOs working in the areas of peacebuilding and peace education. In the same vein, CSOs with contract staffers had to suspend the contracts while some had to cut down on wages paid as a result of suspension of activities. As a result, the impact of the pandemic on their operations was felt adversely by their intended beneficiaries especially in communities where they carried out their activities. Comparatively, the impact of COVID-19 on CSOs' operations and activities was more on outreach activities than the internal operations of the CSOs because after a while, many of them adjusted to working remotely.

The impact of COVID-19 on funding, domestic resources mobilisation and sustainability was also explored. Analysis of interview data revealed that the level of external dependence for resources vary. For some CSOs, they depend on external donors only for projects while their over-head costs are catered for through internally 


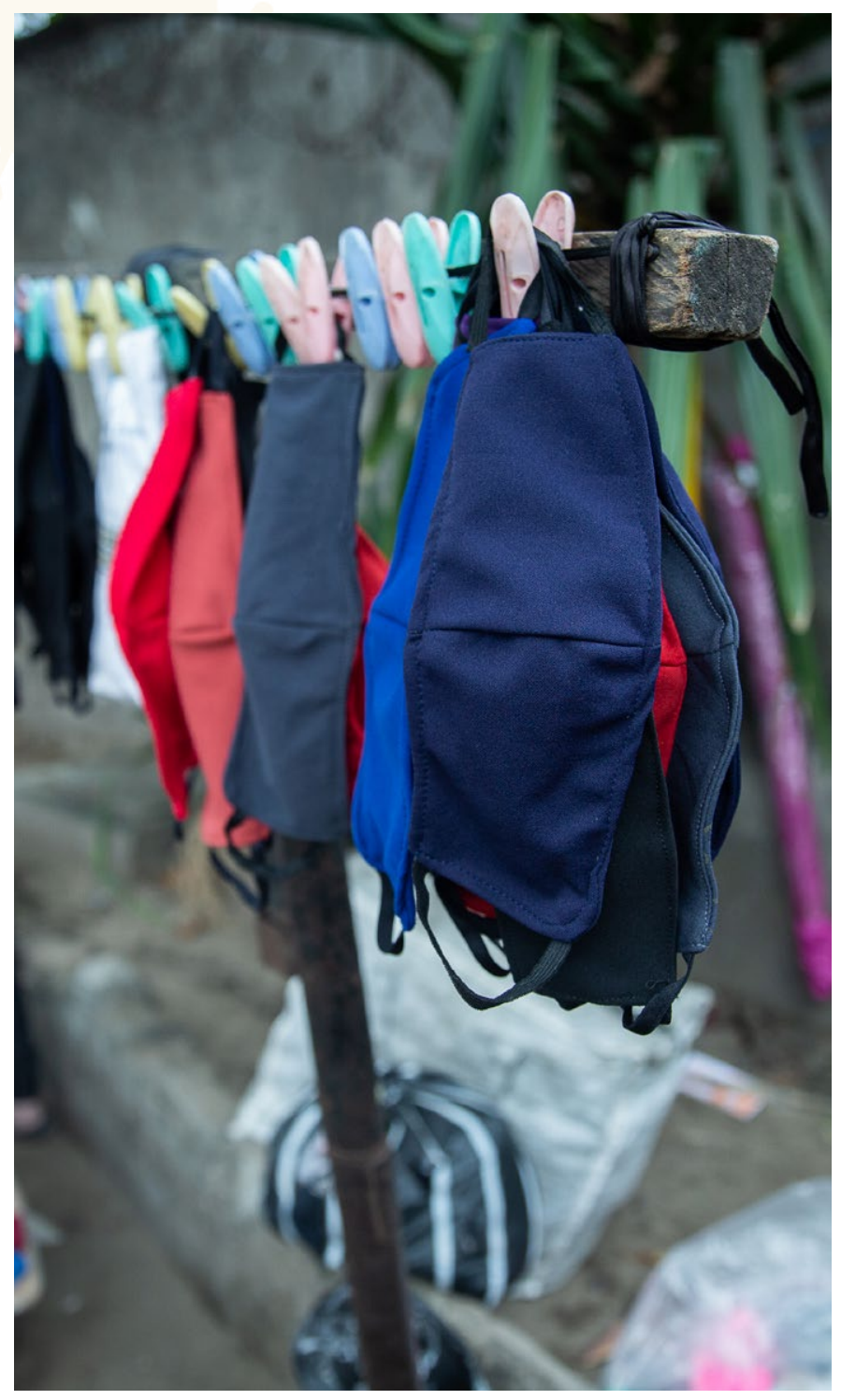

generated funds. For those in this category, they did not have to let go their core-members, hence, a retention of their operational costs. In another category are those whose over-head costs and outreach activities depended solely on external funding. Those in this category had to suspend all their outreach activities while looking inward for the generation of resources in the face of dwindling external resources which hitherto sustained many of them. In raising funds, some of these CSOs have turned to using crowdfunding initiatives which are yielding impressive results based on their respective track record of accountability and transparency in utilising funds generated through this means.

A major lesson that has been learnt as a result of the pandemic is that a place of work is no longer physically determined as many have learnt how to work away from their known physical office addresses. According to a respondent, "working remotely was a sudden and hurried adjustment because no organisation envisaged having to readjust how and where they work even a month before the restrictions." Furthermore, new ways of mobilising resources internally or domestically, organising and hosting events through the creative use of technology, volunteering, networking and collaborating with other organisations through sharing strategic resources as well as building alliances have been learnt during the pandemic as surmised during the focus group discussion. Other areas of need for intended beneficiaries were also revealed as expressed by the head of an organisation that empowers women and children through technology: " in order to sustain our activities post-COVID-19, the children have to be provided with internet-enabled tablets while hoping that they and their parents will use it strictly for the purpose for which it is meant".

In projecting recovery post-COVID-19, the respondents envisaged a gradual return to normalcy in about six to nine months. For these $\mathrm{CSO}$, there were plans to reach out to the children and women who are their intended beneficiaries to jointly review their experiences during the pandemic and to factor that into their future programmes and outreach plans. This is because most of their beneficiaries are low income earners and children attending public schools that had no functional access to on-line schooling. For those working in rural communities, they are just taking stock and waiting for the return of normalcy before resuming their activities.

All the respondents were unanimous in enlisting the support of WACSI towards recovery, repositioning and revamping their activities through facilitation of linkages to sources of support and resources like emergency fund injection into their activities. As stakeholders in the country's polity, some 407 CSOs, through a communique, expressed their readiness and expectations from the government as they enthused that:

"Civil society organisations across Nigeria will continue to be active partners in progress, by supporting government's efforts at all levels in responding to the COVID-19 pandemic. It is hoped that the Nigerian government will continue to develop and execute coherent strategies in collaboration with local and international stakeholders." 


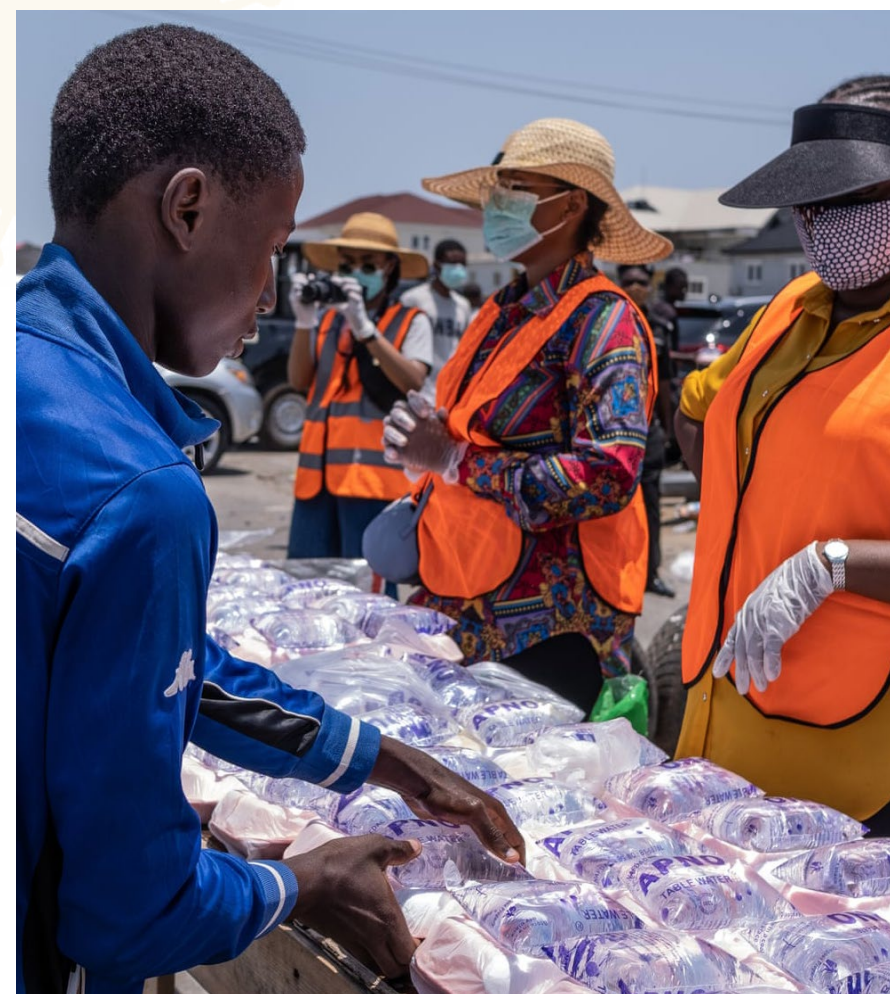

Doubtlessly, the outbreak of COVID-19 has come with far-reaching implications for both state and non-state actors including CSOs. As a major source of support and livelihood for many Nigerians, any disruption in the activities of civil society comes with direct and indirect implications for the polity and individuals given the role and extent of the impact of their activities. In this study, there has been a documentation of the impact of COVID-19 on the operations of CSOs in Nigeria based on a sample of 80 organisations working on a broad range of issues that range from promotion of the rule of law and democracy, accountability and transparency, poverty alleviation, women's rights advancement and promotion, health promotion and awareness, peace and non-violent transformation of conflict amongst others.

The needs of CSOs including funding, logistics and technological inadequacies have worsened because of the pandemic just as their capacity to work under harsh conditions like the ones imposed by the sudden and disruptive impact of the pandemic. Also revealed in this study is the resilience of CSOs. This is evident in their demonstrated capacity to leverage on their areas of comparative advantage in providing mutual support within their sphere of influence. This went a long way in sustaining their activities. Specifically, their capacities to improvise, cope amidst crises and plan for post-pandemic organisational recovery and sustainability of service delivery were revealed. However, the disproportionate level of technological advancement, availability of financial reserves and dependence on foreign sources of funding became major determinants of the level of individual resilience of these organisations.

More than anything, the pandemic has revealed the frailty of the financial sustainability of many CSOs in the country and the compelling need for them to look inward towards reducing their dependency on foreign sources of support. Therefore, in the face of shrinking international support, it has become expedient to broaden the support base available and accessible to CSOs in the country to involve every Nigerian. As public health has forced itself on the top of the agenda, it provides an opportunity for exploring novel and more impactful collaboration among the CSOs and between them and the government towards securitising public health.

The pandemic has also revealed the benefits that can accrue to the government from CSOs' influence and global connections. Some of these advantages are trust and credibility, reach, capacity to mobilise external support and public confidence. For instance, in the area of trust and credibility, the social capital built over the years by many $\mathrm{CSO}$ same handy for deployment in complementing the messaging of the government towards creating awareness on COVID-19. The messaging of the government became increasingly credible as more actors and organisations from the civil society sector added their voices. The reach and presence of these organisations in the rural communities especially served as a compass for the government in reaching many of the rural dwellers just as it revealed the limitations in the conception and delivery of the palliatives by the government. The social capital of the CSOs in Nigeria was another means of support for state institutions like the police during the pandemic as special and dedicated trainings and manuals were provided by some CSOs towards upscaling and adapting the skills and conduct of the police to be pandemic-sensitive in the discharge of their responsibilities.

The study has also revealed that organisations like WACSI have a major leading role to play in facilitating recovery and sustainability for the CSOs not only in Nigeria, but also in the West African region as expatiated in the next section. In the next section, recommendations emanating from the data are addressed to the government, donors and beneficiaries. 


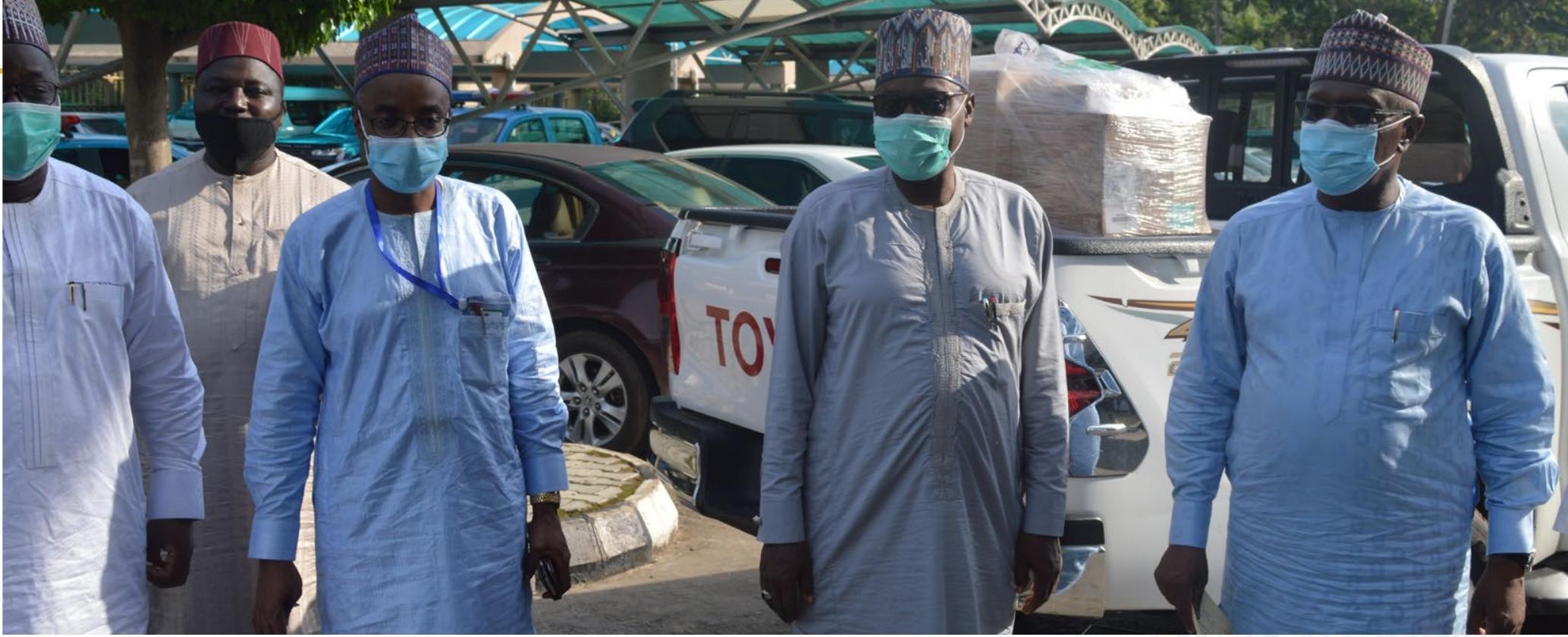

Providing the support needed by civil society actors in Nigeria in mitigating the impact of COVID-19 should not be restricted only to regional and international CSOs. The Nigerian government at all levels, policy makers, academia, media and citizens also need to support CSOs' initiatives at this period. This can be done in part by ensuring favourable policies that can facilitate meaningful engagements with CSOs to curb the spread of the pandemic, to repose social trust and capital in their work, and also make financial and non-financial contributions to support their endeavours.

\subsection{Government}

The state, being a beneficiary of the complementary services by CSOs, must in the prevailing circumstances, appreciate the need to come to the aid of CSOs in the country. A case in point was the specialised training provided for the police through a local CSO that sourced for funds for the training from its foreign partner. In addition to such initiatives, there are many Nigerians benefiting from the diverse range of support provided by CSOs who might be denied such services if CSOs cease to exist as a result of COVID-19.

\subsection{WACSI, Civil Society and} Development Partners

\subsubsection{Resource Mobilisation, Capacity Building and Leadership}

By revealing the areas of needs of CSOs in the country, this report comes handy in planning how best to intervene in mobilising resources for the CSOs and to build their capacities and boost their chances of being sustainable. In this regard, pilot states and CSOs can be selected across the geo-political zones of the country and thematic areas to initiate programmes geared towards enhancing CSOs' capacities to mobilise resources locally to complement external resources that have access to. Indeed, such an initiative would go a long way promoting self-reliance and upscaling capacities.

Given the size and spread of CSOs in Nigeria and the deficit in technological infrastructure, WACSI can provide support in the areas of improving their use of technology, capacity to generate funds without compromising their values, creating a community of mutually helpful CSOs working together to alleviate the impacts of the pandemic on vulnerable communities in Nigeria.

Doing the above requires a clear-headed leadership which WACSI is most suited for as it has shown over the years. Indeed, CSOs have specific areas in which they need to self-reform. In this regard, WACSI also has a leadership role to play. This study revealed the need for greater internal accountability within CSOs in Nigeria, need to adapt to contemporary technology in delivering their services, sharing resources with other organisations and how to be more innovative in driving their programmes and to be resilient during emergencies such as COVID-19.

\subsubsection{Strategic Engagement}

As non-state actors whose main agenda is not to subvert the state but to make it more accountable, it is imperative for civil society actors to have a means of engaging the state at the strategic level. The findings contained in this report offer useful thematic areas which can be the focus of strategic engagement with the state. 


\subsubsection{More Research and Collaborations with} Academic Institutions

There should be a deliberate effort in first evaluating the capacities of these CSOs in relation to their capacities to be less-donor dependent, the resources they have to share or their areas of strength and the resources they need to have to survive and function post-COVID-19. Such a goal can be pursued in collaboration with academics. Amongst other advantages, such collaborations will provide an evidence-based status of the needs of CSOs of their needs and areas where they need to be strengthened. The identified needs can be the basis of subsequent programmatic interventions and support in two folds. First supporting them to do better in their areas of strength and providing avenues for them to enhance their capacities in areas where they have deficiencies.

\section{Implications of the Research Findings for Policy and Practice}

At the heart of this research is the need to ensure that it brings about improvement in policy making and practice by CSOs by using the pandemic as a learning experience. In Nigeria, the attempt to stealthily pass the controversial Health Bill highlights some of the state-centric efforts to shrink the space in which CSOs operate. This highlights the need for CSOs to sustain beaming searchlights on existing obnoxious laws that ought to be reviewed for democracy to serve the people's interests and for their freedoms of association to be guaranteed by the state.

The pandemic revealed the extent of knowledge, data and capacity deficit in critical sectors. For instance, the lack of data on house-hold poverty, house-hold nutritional needs, mental health and public health awareness meant that the distribution of palliatives and provision of other essential service were done without empirical data. The spike in gender-based violence, human rights abuses by the police and other security agencies, the proliferation of fake news constitute some valuable topical issues that require more research collaborations and initiatives to understand why such social ills flourished during the COVID-19 pandemic (and possibly other pandemics).
The lack of appropriate skills in information and communication technology and the existence of laws that ought to have been reviewed constrained the activities of CSOs, media, academics and even the government in forming the appropriate synergy and collaboration to cushion the effects of COVID-19 and mobilise adequate resources to minimise the impact of these effects. Arising from preceding, the need to devote more resources and to explore collaborations for the generation of meta data, knowledge and experience sharing on fore-listed issues and similar ones cannot be over-emphasised.

The study has also shown the dangers of the generalist nature of many CSOs which made the maximisation of scarce resources during the emergency challenging. Therefore, more needs to be done in upscaling the capacity of the CSOs towards becoming specialised or less generalist towards optimal utilisation of resources. This further highlights the need for CSOs to be focused, carve a niche for themselves and develop their competencies within their defined niches.

Indeed, the complementary roles played by CSOs during the pandemic which was aided by their vast networks, track-record and presence in hard to reach areas, can be explored for extending research and advocacy especially by the academic and CSO communities across the country. This can go a long way in generating evidencebased findings which can in turn be used for teaching and strategic engagement by CSOs.

Given the disruption that many communities, institutions, relationships and individuals have suffered as a result of the pandemic, responding to these must be deliberate and informed. This is why the research community comprising think-tanks and tertiary institutions, governments and CSOs need to be in closer collaborations.

A COVID-19 impact assessment towards ascertaining the scale of its impact is important. This should inform a corresponding change in the programming and delivery methods used by CSOs. Achieving this can benefit from the research competencies of the academia which can also lend validity to their outcomes as tools of engagement and advocacy with policy makers.

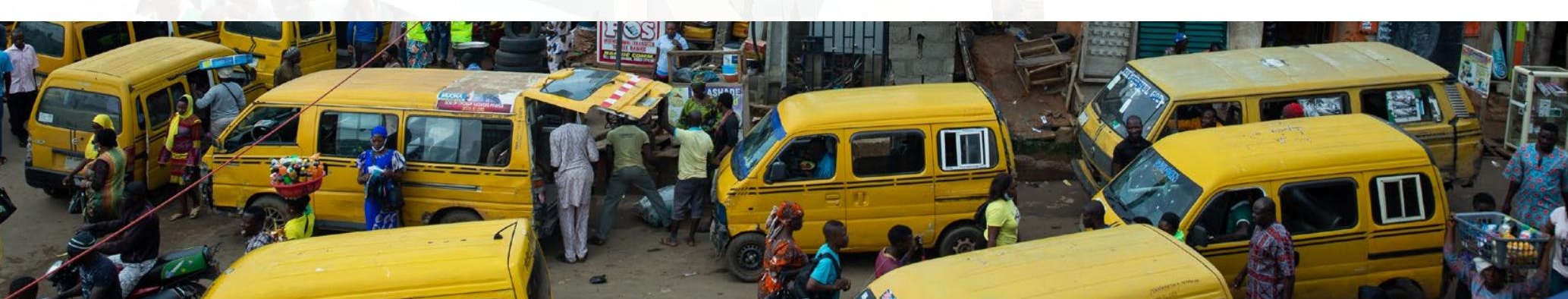




\section{REFERENCES}

Adebowale, Nike. (2020). CSOs kick against Infectious Disease Bill, demand review, publichearing, Premium Times, May 6, 2020, https://www.premiumtimesng.com/ news/more-news/391589-csos-kick-against-infectiousdisease-bill-demand-review-public-hearing.html (accessed August 12, 2020)

AbouAssi, K., Makhlouf, N., \& Tran, L. (2018). 'Association between Organizational Capacity and Scope among Lebanese Nonprofits.' Public Performance \& Management Review, 42(2): 461-482.

Animasawun, G. (2020). Making Defence Budgets Count: The Imperative for an Intellectual Collective on Transparency and Accountability in Nigeria. Democracy \& Development Journal of West African Affairs. 5:1, 18-31. http://democracyanddevelopmentjournal.org/download/ (Accessed on August 1, 2020)

Bank of Industry (BoI). (2018). Economic Development through the Nigerian Informal Sector: A BOI perspective. https://www.boi.ng/wp-content/uploads/2018/05/BOIWorking-Paper-Series-No2 (Accessed on August 10, 2020)

Civil Society Groups Launch Legal Helplines (08145000093 \& 07039855775) to combat COVID-19-linked Human Rights Abuses in Nigeria https://spacesforchange. org/civil-society-groups-launch-legal-helplines08145000093-07039855775-to-combat-covid-19-linkedhuman-rights-abuses-in-nigeria/

CNBC Africa COVID-19: Nigeria extends lockdown by two weeks in Lagos, Abuja \& Ogun States, CNBC Africa, April 13, 2020, https://www.cnbcafrica.com/ coronavirus/2020/04/13/covid-19-nigeria-extendslockdown-by-two-weeks-in-lagos-abuja-ogun-states/ (accessed August 8, 2020)

COVID 19 Government Palliatives https://statehouse. gov.ng/covid19/government-palliatives/ Egbunike, N., \& Olorunnisola, A. (2015). Social media and the\# Occupy Nigeria Protests: Igniting or damping a Harmattan Storm? Journal of African Media Studies, 7(2), 141- 164
Fukuyama B. (2020) The Pandemic and Political Order: It Takes a State. Foreign Affairs. https://www.foreignaffairs. com/articles/world/2020-06-09/pandemic-and-politicalorder. July/August 2020. (Accessed on July 12, 2020).

Global Humanitarian Response Plan. (GHRP). 2020 https:// reliefweb.int/sites/reliefweb.int/files/resources/GHRPCOVID19 Annexes July update.pdf

Haruna, A. (2020) Coronavirus: Senator accuses federal aid committee of fraud, calls for disbandment, Premium Times, April 16, 2020 https://www.premiumtimesng. com/regional/nnorth-east/388332-coronavirus-senatoraccuses-federal-aid-committee-of-fraud-calls-fordisbandment.html (accessed August 12, 2020)

Ibezim-Ohaeri, V. (2017). 'Confronting Closing Civic Spaces in Nigeria' Reclaiming Civic Space SUR 26 -14: 26, $129-140$

Implementation Guidelines for Phase 1 of Gradual Easing of Lockdown (May 4-17, 2020) https://statehouse.gov.ng/ covid19/2020/05/01/implementationguidelinesphase1/ Update: $F G$ extends gradual easing of lockdown by 2 weeks, Nairametrics, https://nairametrics.com/2020/05/18/justin-fg-extends-gradual-easing-of-lockdown-by-2-weeks/

Kew, D. (2004). 'The third generation of Nigerian civil society: The rise of Non-Governmental-Organization in the 1990s' in Agbaje, A.A.B; Diamond, L; and Onwudiwe, E. (eds..). Nigeria's struggle for democracy and good governance. Ibadan: University Press. 101 - 136

Kukah, H. (1999). Democracy and Civil Society in Nigeria. Ibadan: Spectrum Books Mohammed, A; Yakubu, U.I and Babatunde, H M. (2018). 'The 2018 CSO Sustainability Index for Nigeria 2018' in Civil Society Organization Sustainability Index for Sub-Saharan Africa 10th Edition, November 2019. United States Agency for International Development, Bureau for Democracy, Conflict, Humanitarian Assistance Center of Excellence on Democracy \& Human Rights and Governance. 169-177 
Musila, G. (2020). The Spread of Anti-NGO Measures in Africa. https://freedomhouse.org/report/specialreport/2019/spread-anti-ngo-measures-africafreedoms-under-threat (Accessed August 15, 2020).

National Human Rights Commission Press Release on Covid-19 Enforcement: So Far Report on Incidents of Violation of Human Rights, NHRC, April 15, 2020 https://www.nigeriarights.gov.ng/nhrc-media/pressrelease/100-national-human-rights-commission-pressrelease-on-covid-19-enforcement-so-far-report-onincidents-of-violation-of-human-rights.html (accessed August 12, 2020)

Nigeria Centre for Disease Control Global Covid-19 Update https://covid19.ncdc.gov.ng/globals/ (Accessed on September 12, 2020)

Nigerian Network of CSOs, AML/CFT Advisory for Nonprofits on the Covid- 19 Pandemic, https://nnngo. org/aml-cft-advisory-for-nonprofits-on-the-covid-19pandemic/ (accessed August 12, 2020).

Obadare, E. (2016). Humour, Silence, and Civil Society in Nigeria. New York, University of Rochester Press

Obadare, E and Adebanwi, W. (2013). 'Introduction: Democracy and Prebendalism: Emphases, Provocations and Elongations' in Wale Adebanwi and Ebenezer Obadare (eds.,) Democracy and Prebendalism in Nigeria Critical Interpretations. New York: Palgrave Macmillan. 1-24

Obadare, E. ( 2004), "In Search of a Public Sphere: The Fundamentalist Challenge to Civil Society in Nigeria" Patterns of Prejudice Vol. 38, No. 2, pp. 177-198

Okonta, I. (2008). When Citizens Revolt: Nigerian Elites, Big Oil and the Ogoni Struggle for Self-Determination. New Jersey: Africa World Press (AWP)

Presidential Task Force on COVID https://statehouse.gov. ng/covid19/objectives/Presidential Task Force's Guidance on the Implementation of the Federal Government's Lockdown Policy (Lagos, Ogun and FCT), April 1, 2020, https://statehouse.gov.ng/wp-content/uploads/2020/04/ PTF-COVID-19-Guidance-on-implementation-oflockdown-policy-FINAL.docx-2.pdf (accessed August 6, 2020)
Public Health Advisory to Nigerians on Novel Corona Virus, NCDC, 31 January 2020 https:// ncdc.gov.ng/news/219/31st-january-2020\%7Cpublic-health-advisory-to-nigerians-on-novelcoronavirus-\%28\%232\%29 (accessed August 6, 2020)

Smith, D. J. (2010). Corruption, CSOs, and development in Nigeria. Third World Quarterly,

$31(2), 243-258$

SPACES FOR CHANGE, Legal Analysis of the Proposed Control of Infectious Diseases Bill, Policy Briefing Paper 013, MAY 5, 2020 https://closingspaces.org/restrictiveproposal-legal-analysis-of-the-proposed-control-ofinfectious-diseases-act-cida-2020/; Bill Analysis, https:// placng.org/i/wp-content/uploads/2020/05/Bill-Analysison-Control-of-Infectious-Diseases-Bill-2020.pdf

Spaces for Change, Closing Spaces for Civic Engagement and Civil Society in Nigeria, https://spacesforchange. org/part-a-closing-spaces-for-civic-engagement-andcivil-society-in-nigeria/, June 1, 2017 (accessed August 12, 2020) Closing Spaces https://closingspaces.org/ incidents/?tab=categories (accessed August 12, 2020)

Spaces for Change, Beyond FATF: Trends, risks and restrictive regulation of nonprofit organisations in Nigeria, May 31, 2017 https://spacesforchange.org/beyond-fatftrends-risks-and-restrictive-regulation-of-non-profitorganisations-in-nigeria/ (accessed August 12, 2020)

UN Women (2020) The Shadow Pandemic: Violence against women during COVID-19. https://www.unwomen. org/en/news/in-focus/in-focus-gender-equality-incovid-19-response/violence-against-women-duringcovid-19

Updated Implementation Guidelines for Extension of Lockdown: http://statehouse.gov.ng/covid19/wpcontent/ uploads/2020/07/UPDATED-IMPLEMENTATIONGUIDELINES-FOR-EXTENSION-OF-LOCKDOWN June-30to-July-27-2020.pdf

World Health Organization. WHO Director-General's Opening Remarks at the Media Briefing on COVID-19 March 2020; World Health Organization: Geneva, Switzerland, 2020 


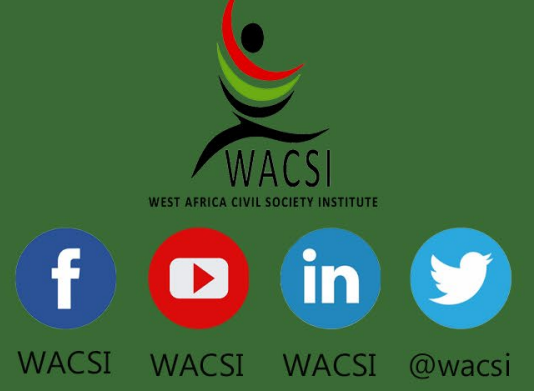

